\author{
UNIVERSIDADE DE SÃO PAULO \\ FACULDADE DE MEDICINA DE RIBEIRÃO PRETO
}

STELLA ANDRADE RODRIGUES CAMPOS

Morfometria do nervo safeno no envelhecimento:

estudo experimental em ratos

RIBEIRÃO PRETO 
STELLA ANDRADE RODRIGUES CAMPOS

\section{Morfometria do nervo safeno no envelhecimento: estudo experimental em ratos}

Tese apresentada à Faculdade de Medicina de Ribeirão Preto da Universidade de São Paulo- Departamento de Neurociências e Ciências do Comportamento para a obtenção do título de Doutora em Neurologia.

Área de concentração: Neurologia

Opção: Neurociências

Orientadora: Prof ${ }^{\mathrm{a}}$. Dra. Valéria Paula Sassoli Fazan

RIBEIRÃO PRETO 
Autorizo a reprodução e divulgação total ou parcial deste trabalho, por qualquer meio convencional ou eletrônico, para fins de estudo e pesquisa, desde que citada a fonte.

Campos, Stella Andrade Rodrigues

Morfometria do nervo safeno no envelhecimento: estudo experimental em ratos/Stella Andrade Rodrigues Campos; orientadora, Valéria Paula Sassoli Fazan.-2017

$$
122 \text { f.:il. + 2CDs }
$$

Tese de doutorado- Programa de Pós-graduação em Neurologia,

Faculdade de Medicina de Ribeirão Preto-USP, Ribeirão Preto, 2017

CDs: Tese de Doutorado

Versão original

1. Nervo Safeno. 2. Envelhecimento. 3. Nervos Periféricos. 4. Ratos. I.Fazan,Valéria Paula Sassoli,orient. II. Título. 
Folha de Aprovação

Nome: CAMPOS, Stella Andrade Rodrigues

Título: Morfometria do nervo safeno no envelhecimento: estudo experimental em ratos

Tese de doutorado apresentada á Faculdade de Medicina de Ribeirão Preto-USP

Aprovado em:

Banca examinadora:

Prof $^{\circ}$. Dr. Norberto Cysne Coimbra

Instituição: Faculdade de Medicina de Ribeirão Preto-USP

Julgamento:

Prof $^{\circ}$. Dr. Luís Fernando Tirapelli

Instituição: Faculdade de Medicina de Ribeirão Preto-USP

Julgamento:

Prof $^{\mathrm{a}}$. Dra. Delane Viana Gondim

Instituição: Universidade Federal do Ceará

Julgamento:

Prof $^{\circ}$. Dr. Rogério Wagner da Silva

Instituição: Universidade Católica de Brasília

Julgamento: 


\section{Dedico este trabalho}

Aos meus pais Omar e Sheila,

se há algo que faz diferença na formação da personalidade e na vida de uma pessoa é o amor que ela recebe. Vocês me educaram com amor, se dedicaram à minha educação como ser humano e não pouparam esforços para que todos meus sonhos se tornassem realidade. Inclusive a de me tornar doutora. E hoje chegou o grande momento, e quero agradecer todo o incentivo, os cuidados com o Felipe e Mateus, as rezas para que tudo desse certo, o apoio financeiro e emocional. Com certeza o exemplo que tive de vocês me incentivou para a conclusão deste trabalho. 


\section{Dedico este trabalho em especial}

Aos meus filhos queridos Felipe e Mateus! Que toda a dedicação que precisei para a realização deste trabalho, na qual foi presenciada e sentida por vocês sirva de inspiração e incentivo em suas vidas profissionais. Ser mãe é uma missão maravilhosa, com muitos desafios, mas que nos faz crescer muito. Desculpem-me pelas ausências, mas sei que ficaram bem. Todo o esforço valeu e valerá a pena! Toda a doçura de seus sorrisos me deram força para continuar. Foram 4 anos viajando de Uberaba a Ribeirão Preto, 4 anos de estudo e dedicação e que agora chegam ao fim. Todo o esforço é para vocês! 


\section{Agradecimento especial}

À professora Dra. Valéria Paula Sassoli Fazan, minha orientadora, expresso minha eterna gratidão, pela amizade, paciência, disponibilidade e incentivo. As críticas construtivas, as reflexões, ensinamentos e discussões foram importantes para a continuidade do estudo. $\mathrm{O}$ seu

profundo conhecimento, os dias, meses e anos em que convivemos me rendeu muito aprendizado e levarei comigo para toda minha vida, particular e acadêmica. O meu muito obrigada! 


\section{Agradecimentos}

- Ao Antônio Renato Meirelles, técnico do laboratório, agradeço os ensinamentos, orientações e amizade.

- À ex-secretária do departamento de neurociências e ciências do comportamento Silvana Lo Turco, pelas orientações.

- À secretária do departamento de neurociências e ciências do comportamento Ivana Cintra Faria, pelas orientações.

- À técnica Maria Teresa Picinato Maglia, pelo trabalho primoroso realizado nos cortes histológicos.

- $A \mathbf{C N P q}$, pela bolsa de pesquisa concedida.

- Ao $\operatorname{Prof}^{\circ}$ Dernival Bertoncello, por permitir, durante 2 anos, a conciliação das aulas como professora substituta no curso de Fisioterapia da UFTM com a realização do doutorado.

- Às amigas do laboratório, Ana leda Simões, Carolina Giorgetto, Letícia Neri, Luciana Sanada, pelas ajudas, conversas, trocas de informações e experiências.

- Aos técnicos do laboratório Jorge Forjaz e Sandra Martins, pela amizade, pelo café nas pausas para o descanso, pelas conversas e boas risadas.

- Aos Professores que me acolheram em suas disciplinas para que pudesse obter os créditos necessários para defesa do Doutorado.

- À Cristiane Faria pela ajuda na formatação do trabalho.

- Ao meu marido Rubio, por sempre estar ao meu lado, incentivando e apoiando meus projetos profissionais!

- À minha irmã Esther, pela amizade e torcida para que tudo desse certo. Obrigada!

- À minha irmã Stael , cunhado Túlio e sobrinha Maria Clara, vocês me acolheram de forma carinhosa e generosa. Meu muito obrigada de coração!!

- Aos meus avós, Cairo e Carmem, que já se foram......mas torceram por esta conquista.

- A todos aqueles que não foram citados nominalmente, mas que contribuíram nesta minha trajetória. 


\section{RESUMO}

CAMPOS, S.A.R. Morfometria do nervo safeno no envelhecimento: estudo experimental em ratos. 2017. 122 f. Tese (Doutorado) - Faculdade de Medicina de Ribeirão Preto, Universidade de São Paulo, Ribeirão Preto, 2017.

A função dos nervos periféricos é afetada pelo desenvolvimento e pelo envelhecimento. Entretanto, o conhecimento a respeito das diferenças entre os nervos de animais adultos e velhos tem sido embasado em comparações de apenas dois grupos experimentais e tem sido apontada a necessidade de múltiplos grupos experimentais nos estudos de desenvolvimento e envelhecimento. Apesar de algumas descrições de alterações morfológicas nos nervos periféricos de ratos velhos, a maioria dos estudos investigou nervos motores ou mistos, enquanto informações em nervos sensitivos são escassas. O nervo safeno é utilizado em estudos experimentais que investigam lesão e regeneração do sistema nervoso periférico. Apesar da utilização, informação a respeito dos aspectos morfológicos e morfométricos do nervo safeno de animais velhos não é comum na literatura. Os objetivos do presente estudo foram investigar os aspectos morfológicos e morfométricos do nervo safeno em ratos velhos. Para tanto, ratas da linhagem Wistar com $180(\mathrm{~N}=6), 360(\mathrm{~N}=6)$ e $720(\mathrm{~N}=6)$ dias de idade foram utilizadas. A morfometria em nível de microscopia de luz foi realizada com o auxílio de um programa de análise de imagens computacional. A análise estatística foi realizada de forma a comparar dados obtidos entre segmentos do mesmo lado, entre níveis iguais e lados diferentes e entre os nervos. Diferenças foram consideradas significativas quando $\mathrm{p}<0,05$. Alguns parâmetros, apresentaram diferenças significativas, como, densidade de fibras, área dos axônios diâmetro fascicular e razão G. Alterações morfológicas decorrentes do envelhecimento foram observadas, principalmente, relacionadas à bainha de mielina e vasos endoneurais. Concluindo, a morfologia do nervo safeno é afetada pelo envelhecimento, o que pode refletir morfometricamente nas diferenças observadas nos histogramas de distribuição de fibras e razão $G$.

Palavras chaves: nervo safeno, morfologia, morfometria, envelhecimento. 


\begin{abstract}
CAMPOS, S.A.R. Saphenous nerve morphometry in aging: experimental study in rats.

2017. 122 f. Tese (Doutorado) - Faculdade de Medicina de Ribeirão Preto, Universidade de São Paulo, Ribeirão Preto, 2017.

Peripheral nerve function is significantly affected by maturation and aging. However, knowledge regarding differences between the nerves of adult and aged animals has been based on comparisons of only two experimental groups, and it has been pointed out the need for multiple time points in maturation and ageing studies. Despite some descriptions of peripheral nerve morphologic alterations in aged rats, most of the studies used motor or sensory-motor nerves, while information on sensory nerves is scanty. The saphenous nerve in rats is widely used in experimental studies investigating injury and regeneration of the peripheral nervous system. Despite this wide utilization, information on morphological and morphometric aspects of aged rats saphenous nerve is not common in the literature. The aims of the present study were to investigate morphological and morphometric aspects of the saphenous nerve in aged rats. Female Wistar rats aged $180(\mathrm{~N}=6), 360(\mathrm{~N}=6)$ and $720(\mathrm{~N}=$ 6) days were used. Light microscopy morphometry was carried out with the aid of a computer software. Statistical analysis was performed to compare data between segments of the same hand, and between the same levels and from different sides nerves. Differences were considered significant when $\mathrm{p}<0,05$. Some parameters presented significant differences, such as fiber density, axillary area, fascicular diameter and G ratio.

Morphological alterations due to ageing were observed, mainly related to the myelin sheath and endoneural vessels. In conclusion, the saphenous nerve morphology is affected by ageing, which might be morphometrically reflected on the differences observed on the myelinated fiber and $\mathrm{G}$ ratio distributions.
\end{abstract}

Keywords: saphenous nerve, morphology, morphometry, aging 


\section{SUMÁRIO}

1 INTRODUÇÃO 15

1.1 Fundamentação 16

1.2 Nervo Safeno em Humanos 17

1.3 Nervo Safeno em Ratos 20

1.4 Morfometria de Nervos Periféricos 23

1.5 Desenvolvimento e Maturação dos Nervos Periféricos 25

2 OBJETIVOS 28

2.1 Objetivos Gerais 29

2.2 Objetivos Específicos 29

3 MATERIAIS E MÉTODOS 30

3.1 Animais 31

3.2 Grupos experimentais 31

3.3 Procedimentos Cirúrgicos 31

3.4 Procedimentos Histológicos 32

3.5 Análise Morfológica e Morfométrica 36

3.6 Análise Estática 38

3.6.1 Comparações Morfométricas intra-grupos 39

3.6.2 Comparações Morfométricas entre-grupos 39

4 RESULTADOS 40

4.1 Dados Ponderais 41

4.2 Análise morfológica geral 41

4.2.1 Comparação entre os diferentes grupos 45

4.3 Análise morfométrica $\quad 47$

4.3.1 Morfometria dos fascículos $\quad 47$

4.3.1.1 Animais do Grupo I-180 dias $\quad 47$

4.3.1.2 Animais do Grupo II-360 dias 49

4.3.1.3 Animais do Grupo III-720 dias $\quad 51$

4.3.1.4 Comparação entre os diferentes grupos 53

4.3.2 Morfometria das fibras mielínicas $\quad 57$

4.3.2.1 Animais do Grupo I-180 dias 57

4.3.2.2 Animais do Grupo II-360 dias 59

4.3.2.3 Animais do Grupo III-720 dias 61 
4.4 Histogramas de Distribuição de Frequência do Diâmetro Mínimo das Fibras Mielínicas e seus Respectivos Axônios e da Razão G

4.4.2 Animais do Grupo I-180 dias

4.4.3 Animais do Grupo II-360 dias

4.4.4 Animais do Grupo III-720 dias

4.4.5 Comparação entre os diferentes grupos

5.1 Modelo Animal

5.2 Dados morfológicos

5.3 Dados fasciculares

5.4 Fibras mielínicas e seus respectivos axônios 


\section{LISTAS DE FIGURAS}

Figura 1: Anatomia do nervo safeno em humanos 18

Figura 2: Anatomia do nervo safeno em ratos 21

Figura 3: Bomba de perfusão e posicionamento do animal para fixação 32

Figura 4: Dissecação dos nervos safenos nos animais 33

Figura 5: Nervos safenos dissecados 34

Figura 6: Nervos safenos incluídos em resina epóxi 35

Figura 7: Montagem sequencial de campos microscópicos 37

Figura 8: Binarização dos Campos Microscópicos 37

Figura 9: Secção transversal semifina do nervo safeno de ratas Wistar de 180 dias 42

Figura 10: Secção transversal semifina do nervo safeno de rata Wistar de 360 dias

Figura 11: Secção transversal semifina do nervo safeno de rata Wistar de 720 dias 44

Figura 12: Espaço endoneural do fascículo do nervo safeno de rata Wistar de 360 dias

Figura 13: Lesão das fibras do nervo safeno 46

Figura 14: Lesão dos vasos do nervo safeno $\quad 47$

Figura 15: Gráficos da área fascicular total $\quad 54$

Figura 16: Gráficos do diâmetro mínimo fascicular $\quad 55$

Figura 17: Gráficos do número total das fibras mielínicas 56

Figura 18: Gráficos da densidade das fibras mielínicas $\quad 57$

Figura 19: Gráficos da área média das fibras mielínicas 64

Figura 20: Gráficos do diâmetro mínimo médio das fibras mielínicas 65

Figura 21: Gráficos da área média da bainha de mielina das fibras mielínicas $\quad 66$

Figura 22: Gráficos da área média dos axônios mielinizados $\quad 67$

Figura 23: Gráficos do diâmetro mínimo médio dos axônios das fibras mielínicas $\quad 68$

Figura 24: Gráficos da Razão G média das fibras mielínicas $\quad 69$

Figura 25: Histogramas de distribuição de frequência da razão $G$ das fibras mielínicas dos nervos safenos de animais Wistar do Grupo I (180 dias)

Figura 26: Histogramas de distribuição de frequência do diâmetro mínimo das fibras mielínicas dos nervos safenos de animais Wistar do Grupo II (360 dias) 
Figura 27: Histogramas de distribuição de frequência do diâmetro mínimo dos axônios mielinizados dos nervos safenos de animais Wistar do Grupo III (360 dias)

Figura 28: Histogramas de distribuição de frequência da razão $G$ das fibras mielínicas dos nervos safenos de animais Wistar do Grupo II (360 dias)

Figura 29: Histogramas de distribuição de frequência do diâmetro mínimo das fibras mielínicas dos nervos safenos de animais Wistar do Grupo III (720 dias)

Figura 30: Histogramas de distribuição de frequência do diâmetro mínimo dos axônios mielinizados dos nervos safenos de animais Wistar do Grupo III (720 dias)

Figura 31: Histogramas de distribuição de frequência da razão $G$ das fibras mielínicas dos nervos safenos de animais Wistar do Grupo III (720 dias)

Figura 32: Histogramas de distribuição de frequência do diâmetro mínimo das fibras mielínicas dos nervos safenos

Figura 33: Histogramas de distribuição de frequência do diâmetro mínimo dos axônios mielinizados dos nervos safenos

Figura 34: Histogramas de distribuição de frequência da razão $G$ das fibras mielínicas dos nervos safenos

Figura 35: Histogramas de distribuição de frequência do diâmetro mínimo dos axônios mielinizados dos nervos safenos

Figura 36: Histogramas de distribuição de frequência da razão $G$ das fibras mielínicas dos nervos safenos 


\section{LISTA DE TABELAS}

Tabela 1: Parâmetros morfométricos fasciculares dos nervos safenos dos animais do Grupo I (180 dias)

Tabela 2: Parâmetros morfométricos fasciculares dos nervos safenos dos animais do Grupo II (360 dias)

Tabela 3: Parâmetros morfométricos fasciculares dos nervos safenos dos animais do Grupo III (720 dias)

Tabela 4: Parâmetros morfométricos das fibras mielínicas e dos axônios dos nervos safenos dos animais do Grupo I (180 dias)

Tabela 5: Parâmetros morfométricos das fibras mielínicas e dos axônios dos nervos safenos dos animais do grupo II (360 dias)

Tabela 6: Parâmetros morfométricos das fibras mielínicas e dos axônios dos nervos safenos dos animais do grupo III (720 dias)

Tabela 7: Resumo dos principais achados no sistema nervoso periférico, decorrentes do envelhecimento 


\section{LISTA DE ABREVIATURAS}

\begin{tabular}{ll}
${ }^{\circ} \mathrm{C}$ & Celcius \\
DPM & Desvio padrão da média \\
EPM & Erro padrão da média \\
et al & e colaboradores \\
Fibras $/ \mathrm{mm}^{2}$ & Fibras por milímetro quadrado \\
$\mathrm{g}$ & grama/gramas \\
$\mathrm{M}$ & Molar \\
$\mathrm{mm}$ & Milímetro quadrado \\
$\mathrm{mg} / \mathrm{Kg}$ & Micro grama por quilo \\
$\mathrm{N}$ & Número de animais analisados \\
$\mathrm{N}$ & Nervo \\
$\mathrm{Núcleos} / \mathrm{mm}^{2}$ & Núcleos por milímetro quadrado \\
$\mathrm{NVC}$ & Velocidade de condução nervosa \\
$\mathrm{O}_{\mathrm{s}} \mathrm{O}_{4}$ & Tetróxido de Ósmio \\
$\mathrm{p}$ & Probabilidade \\
$\mathrm{PBS}$ & solução salina tamponada \\
$\mathrm{pH}$ & Potencial hidrogeniônico \\
$\mathrm{Razão} \mathrm{G}$ & razão obtida entre o diâmetro do axônio e o diâmetro da fibra \\
$\mu \mathrm{m}$ & Micrômetro \\
$\mu \mathrm{R}^{2}$ & micrômetro quadrado \\
$\mathrm{RCG}$ & Porcentagem \\
$\mathrm{USP}$ & Red, Green, Blue \\
\hline
\end{tabular}


INTRODUÇÃO 


\section{INTRODUÇÃO}

\subsection{Fundamentação}

O envelhecimento é considerado um processo dinâmico e progressivo, o que gera modificações morfológicas, funcionais, bioquímicas e psicológicas (TEIXEIRA,et al.,2010). Modificações que ocorrem em células, tecidos e órgãos, principalmente, no sistema nervoso central e periférico. Os efeitos do envelhecimento sobre os nervos periféricos localizados nos membros inferiores repercutem sobre a marcha e a postura, fazendo com que o conhecimento sobre esses efeitos seja de suma importância (VANDERVOORT, 2002).

Nos últimos anos, observa-se um aumento da utilização de animais de experimentação para estudos crônicos (de sobrevivência) aos efeitos da exposição a baixos níveis de substâncias tóxicas, na tentativa de se reproduzir doenças metabólicas humanas de desenvolvimento lento, ou para se estudar os efeitos do envelhecimento sobre o sistema nervoso central e periférico (VAN STEENIS;KROES, 1971). Esses últimos requerem um entendimento detalhado dos nervos de animais controles de mesma idade, sexo e peso corporal, para que se possam separar as alterações adquiridas com o avançar da idade daquelas induzidas pelas lesões neuropatológicas. Ratos são frequentemente escolhidos para estudos experimentais de neuropatias tóxicas e metabólicas, envolvendo estudos combinados de eletrofisiologia, morfologia e bioquímica. No entanto, como enfatizado por Jefferys et al. (1978), a interpretação de pequenas mudanças na velocidade de condução está cercada de uma grande dificuldade, pois além da ampla variabilidade interanimais, os nervos de ratos não oferecem uma situação experimental estacionária devido às mudanças decorrentes do crescimento, que continuam durante uma parte substancial da vida pós-natal e que afeta tanto o diâmetro da fibra quanto a velocidade de condução.

Estudos que utilizam modelos animais de diferentes idades para analisar a influência do envelhecimento no processo de regeneração do sistema nervoso concordam quanto á relação de idade dos animais com as modificações orgânicas observadas no envelhecimento. Desta maneira, pode-se classificar os animais em faixas etárias com o avançar da idade, portanto, ratos com idade média de 3 meses são considerados adultos jovens, enquanto que, ratos com 24 meses são considerados senis.

(KANDA e HASHIZUME, 1998; COQ E XERRY,2000; HESS et al, 2006). 
Vários estudos têm demonstrado que a idade mais jovem está associada a um prognóstico mais favorável após o dano em nervos periféricos (VERDÚ et al, 2000; HESS et al, 2006). Essas observações clínicas dependentes da idade são corrobadas por trabalhos em modelos animais que mostram que os animais mais velhos apresentam capacidade de regeneração diminuída após esmagamentos, transecção ou dano do sistema nervoso periférico (BOWE et al, 1987; POLA et al, 2004).

Investigações prévias neste laboratório (JERONIMO et al., 2005), comparando o nervo sural de ratos Wistar fêmeas em grupos de 30, 90 e 180 dias de idade, mostraram que este apresenta um crescimento simétrico e contínuo do fascículo e das fibras mielínicas, mais acentuado no período entre 30 e 90 dias, o que pode afetar diretamente a velocidade de condução das fibras mielínicas. Além disso, o mesmo estudo mostrou que a distribuição dos diâmetros das fibras mielínicas se altera com a idade, passando de unimodal para bimodal.

Em um outro estudo, JERONIMO et al., 2008, comparou o nervo sural de ratos Wistar fêmeas em diferentes idades de envelhecimento, 360, 640, 720 dias, e mostrou que a distribuição dos diâmetros das fibras mielínicas não se alterou com a idade, permanecendo bimodal.

Esses dados, se não conhecidos adequadamente, poderá trazer erros importantes de interpretação em estudos experimentais.

\subsection{Nervo Safeno Humano}

No homem o nervo femoral é o maior ramo do plexo lombar. Origina-se da face posterior dos nervos lombares 2, 3 e 4, se forma na substância do músculo psoas maior e emerge da borda lateral deste músculo, um pouco abaixo da crista ilíaca. Em seguida, desce em um sulco entre os músculos ilíaco e psoas maior e penetra na coxa, atrás do ligamento inguinal, em situação lateral aos vasos femorais. O nervo femoral permanece por fora da bainha femoral, pois sua origem no plexo lombar está atrás da fáscia que recobre os músculos ilíaco e psoas maior. Na coxa, o nervo femoral situa-se no trígono femoral, ao nível do meio do ligamento inguinal, lateralmente à artéria femoral e, quase em seguida, divide-se em vários ramos. A divisão posterior do nervo femoral dá origem a ramos musculares e o nervo safeno.

O nervo safeno é considerado como a terminação do nervo femoral, sendo o maior ramo cutâneo desse. Descende com os vasos femorais através do trígono femoral e canal subsartorial, lateralmente à bainha femoral, que contém os vasos femorais. No canal 
subsartorial ele cruza a artéria femoral do lado lateral para o medial. Logo, em seguida, acompanha o ramo safeno da artéria descendente do joelho, tornando-se, superficial, cutâneo, entre os músculos sartório e grácil, no nível do joelho. Perfura a fáscia profunda na face medial do joelho, desce para frente e para baixo na perna, acompanhando a veia safena magna, e inerva a pele do lado medial da perna e do dorso do pé, além de suprir a fáscia das faces anterior e medial do joelho, perna e pé. O nervo safeno fornece um ramo para a articulação do joelho e contribui para os plexos subsartorial e patelar. O plexo subsartorial consiste de comunicações, profundas ao sartório, entre ramos do nervo cutâneo medial da coxa e os nervos safeno e obturatório. O plexo patelar, na frente do joelho, é formado por comunicações entre ramos dos nervos cutâneos intermédio, medial e lateral da coxa e o nervo safeno. Essa descrição anatômica do nervo safeno de humanos foi fundamentada pelas descrições de MOORE, 1994, GARDNER, e cols., 1978 e WARWICK \& WILLIAMS, 1979.

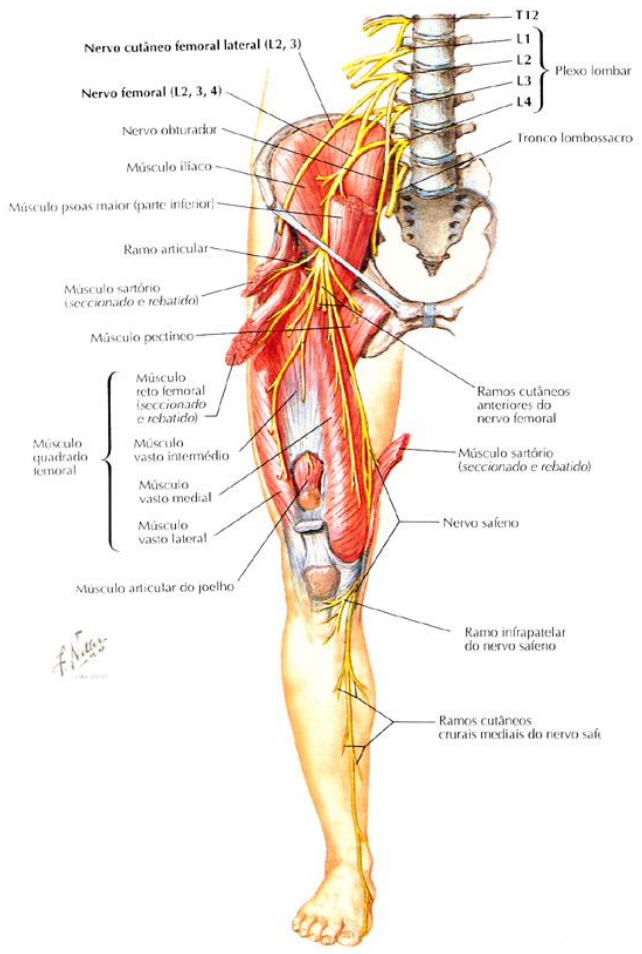

Figura 1: Esquema representativo do nervo safeno humano: origem, ramificação e distribuição cutânea. (Modificado de Netter,1996).

O nervo safeno pode estar comprometido nas síndromes do compartimento, que levam à compressão do nervo, embora isso seja raro. Normalmente, essas síndromes são de difícil diagnóstico, ocasionando demora e erros diagnósticos, que podem durar anos (NIRPAZ e cols, 2006). Pacientes adultos podem se apresentar com dor unilateral na face medial 
do joelho e perna; algumas vezes a dor se irradia para a coxa. Em indivíduos mais jovens, crianças e adolescentes, dor abdominal atípica, na fossa ilíaca, região sacral, pélvica e coxa, associada a fraqueza podem complicar o diagnóstico (NIR- PAZ e cols, 2006) e erros diagnósticos podem levar a cirurgias desnecessárias. Compressão do nervo safeno parece ser responsável por menos de $1 \%$ das causas de dores nos membros inferiores em adultos, sendo mais comum a localização dessa compressão no canal subsartorial (de Hunter) e a etiologia iatrogênica (pós-cirurgia) ou secundária à lesão por prática de esporte físico (NIR-PAZ e cols, 2006). Atenção importante deve ser dada ao fato de que, em pacientes jovens, a dor envolve outras regiões, tais como a pelve e o baixo abdômen.

O nervo safeno também está particularmente susceptível nas cirurgias das veias varicosas. A remoção da veia safena para sua utilização em enxertos arteriais também expõe esse nervo aos mesmos riscos. A lesão desse nervo geralmente causa perda da sensibilidade no seu território de distribuição mas, em alguns casos, dor neuropática severa pode ocorrer (PYNE e cols., 2003). A lesão do nervo safeno pós-fasciotomia para descompressão da síndrome do compartimento posterior foi descrita pela primeira vez por Pyne et al (2003) e os autores chamam a atenção para a importância do conhecimento da anatomia do nervo safeno, bem como para a localização correta da incisão cirúrgica para evitar a lesão do mesmo. Lesão do nervo safeno após injeção da articulação do joelho, no lado medial, foi descrita pela primeira vez por lizuka e colaboradores (2005), em um paciente obeso. Os autores ressaltam que os especialistas devem estar atentos a esse tipo de complicação, quando escolherem o procedimento medial, especialmente quando os pontos de referência anatômicos para os procedimentos estiverem mal delineados, como no caso de pacientes obesos.

O comprometimento do nervo safeno na Hanseníase foi descrito por Laxmisha e colaboradores (2004), sendo que o paciente apresentava abscessos em vários nervos sensitivos.

Por fim, o nervo safeno é importante nas cirurgias de reconstrução de pele, nas quais se necessita de uma área doadora. A região do joelho é uma boa área doadora, uma vez que apresenta mínima quantidade de tecido sub-cutâneo, além de ser esteticamente muito bem aceita, por ser uma área "escondida" (KARAMURSEL \& CELEBIOGLU, 2006). A região pode ser conhecida como "flap de safeno", de acordo com o ramo safeno da artéria genicular descendente. 


\subsection{Nervo Safeno no Rato}

No rato, o nervo safeno (também chamado de safeno longo) é ramo da divisão posterior do nervo femoral, como descrito em humanos. A divisão anterior do nervo femoral consiste de ramos musculares para os músculos ilíaco e pectíneo. A divisão posterior consiste de ramos musculares para as várias partes do músculo quadríceps femoral e o nervo safeno. $\mathrm{O}$ nervo safeno apresenta trajeto superficial em sentido inferior na superfície medial da coxa e da perna, acompanhado pela artéria safena e a veia safena magna. Ele emite ramos cutâneos que suprem a pele da superfície medial da perna, sendo que alguns desses ramos podem suprir o território do ramo cutâneo sural medial, do tibial. Ao alcançar a região do tornozelo, o nervo safeno se divide em vários ramos que suprem a face medial do calcanhar, o tarso e a pele da região medial do primeiro metatarso. Sua extensão no pé depende da distribuição do nervo fibular superficial nessa região (GREENE,1963).

O nervo safeno de ratos, provavelmente em decorrência de seu trajeto superficial, bem como pelo fato de não apresentar componente motor, tem sido utilizado experimentalmente para as observações de desnervação e regeneração (Shakhanbeh e Khleifat, 2003). Experimentos que utilizam a técnica de extravasamento de plasma são utilizados na demonstração da inervação do território cutâneo pelo nervo safeno, tanto em ratos normais (Brenan e cols., 1988) quanto em experimentos de lesão nervosa (Brenan et al., 1988; Allnatt e cols, 1990). Vários autores investigaram a distribuição central (no corno dorsal da medula espinal) dos prolongamentos dos neurônios sensitivos primários que formam o nervo safeno no rato, após vários mecanismos de lesão (Doubell e cols., 1998; LaMotte e cols., 2004a; Pomeranz e cols., 1984; Fitzgerald, 2004; Molander e cols., 1988). Interessante ressaltar que Doubell e cols. (1998) demonstraram que o nervo safeno e o nervo cutâneo dorsal da coxa são somatotopicamente organizados no corno dorsal da medula espinal, estando suas áreas contíguas em algumas regiões e sobrepostas em outras, com aquelas do nervo isquiático. Posteriormente, LaMotte e cols. (2004b) demonstraram que as projeções do nervo safenos se estendem da região superficial do corno dorsal, nos níveis de L1 caudal até L4, descrevendo sobreposição substancial dos territórios safenos e isquiático, do corno dorsal da medula. Esses achados justificam a investigação da reorganização das projeções centrais do nervo safeno quando se provoca uma lesão no nervo isquiático (Molander e cols., 1988; Fitzgerald, 2004; Pomeranz e cols., 1984). 
Mais recentemente, o nervo safeno tem se mostrado muito utilizado nas investigações de dor neuropática, hiperalgesia e seus tratamentos (Yasuda e cols., 2005). Recentemente, um modelo experimental de dor neuropática foi desenvolvido a partir da ligadura desse nervo em ratos (Walczak e cols., 2005).
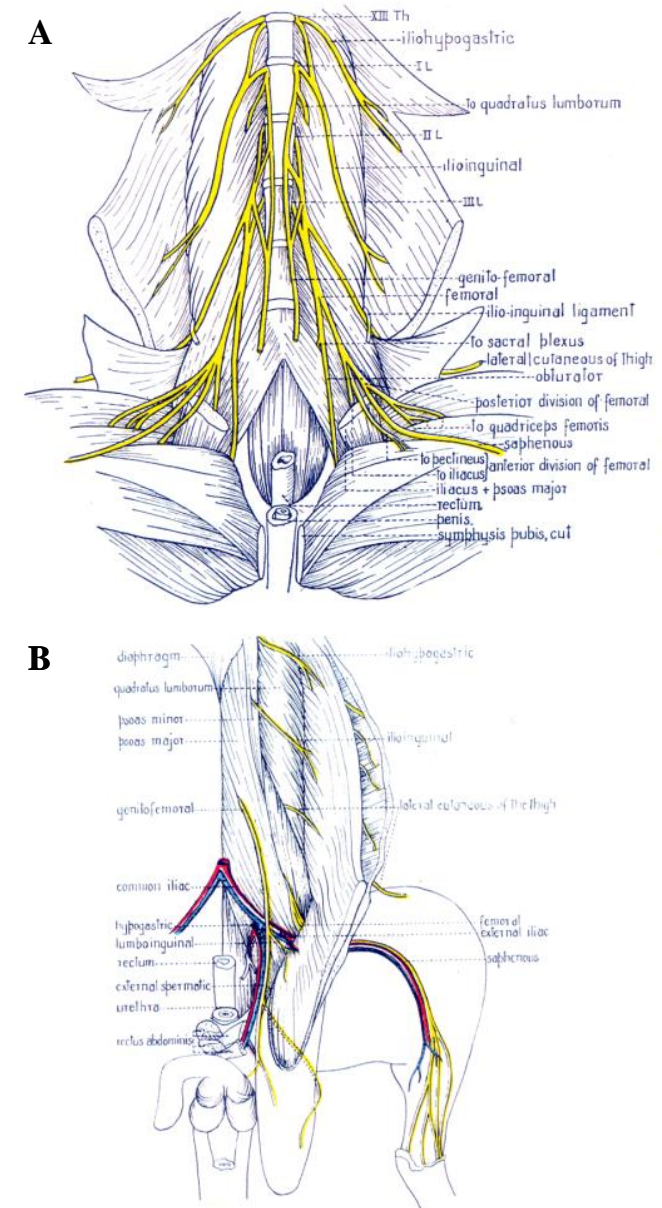

Figura 2: A: Divisões do nervo femoral do plexo lombar do rato, com origem do nervo safeno. B: Dissecação superficial dos ramos do plexo lombar do rato, com a distribuição periférica do nervo safeno, em conjunto com os vasos femorais. (Modificado de Greene, 1963).

Os autores ressaltam que esse modelo é de fácil execução, sendo menos traumático para os animais que os disponíveis na literatura. Isso em decorrência da localização superficial e anterior na coxa do animal. Em adição, o fato de que esse modelo utiliza um nervo exclusivamente sensitivo, torna possível o discernimento de qualquer efeito em fibras motoras. Além disso, esse modelo é ideal para se utilizar nas preparações "nervo-pele", para um melhor entendimento dos mecanismos periféricos da dor neuropática (Walczak e cols., 2005). 
Apesar da importância do nervo safeno do rato nessas investigações, ainda são raras as descrições morfológicas e morfométricas desse nervo na literatura. Os poucos dados disponíveis, aparecem em forma dos grupos controle de determinados experimentos e um estudo sistematizado da anatomia microscópica do envelhecimento desse nervo, em ratos, ainda não está descrito na literatura. 


\subsection{Morfometria de Nervos Periféricos}

De acordo com Behse em 1990 no final do século XIX ocorreram as primeiras investigações morfométricas das fibras mielínicas de nervos periféricos. Em 1875, Ranvier (apud BEHSE, 1990) descreveu que, quanto maior o calibre da fibra, mais longos são os internodos. Boycott (1904) determinou a relação entre o comprimento internodal e o diâmetro de fibras isoladas. Sherrington (1894) foi o primeiro a estudar os constituintes anatômicos dos nervos de músculos esqueléticos e dos nervos cutâneos. Donaldson e Hoke (1905), durante suas investigações sobre a área do axônio e da bainha de mielina, em secções transversais de nervos espinhais de vertebrados, encontraram uma relação do tipo 1:1 entre a bainha e o axônio.

Ficou estabelecido que, em estudos morfométricos de fibras mielínicas, os parâmetros anatômicos mais relevantes são o comprimento e o diâmetro do segmento internodal, o diâmetro axonal e a espessura da bainha de mielina (BEHSE, 1990).

Rexed (1944) estudou o desenvolvimento pós-natal e o tamanho das fibras em nervos periféricos humanos. Sunderland et al. (1949) investigaram o número e o calibre das fibras em nervos cutâneos humanos e Sunderland e Bradley (1949) determinaram o número de fascículos e a porcentagem da sua área de secção transversal em um tronco nervoso em alguns nervos humanos. Tiago et al em 2008, analisaram as fibras do nervo laríngeo, em um estudo sobre análise quantitativa das fibras mielínicas em humanos.

Jeronimo et al. (2005), ao analisar parâmetros normais da morfologia e da morfometria do nervo sural de ratas Wistar de 30, 90 e 180 dias de vida, descreveram a área fascicular, o número de fibras mielínicas e de núcleos de células de Schwann presentes no fascículo, a densidade das fibras mielínicas e dos núcleos das células de Schwann, a porcentagem da área ocupada pelas fibras mielínicas, área da fibra mielínica, do axônio e da bainha de mielina e a distribuição do diâmetro das fibras, axônios e da razão $G$ nos nervos surais, nos segmentos proximais e distais, dos lados direito e esquerdo.

Da mesma maneira, Jerônimo et al em 2008, ao analisar parâmetros normais da morfologia e da morfometria do nervo sural de ratas Wistar em diferentes fases do envelhecimento, 360, 640 e 720 dias de vida, descreveram a área fascicular, o número de fibras mielínicas e de núcleos de células de Schwann presentes no fascículo, a densidade das fibras mielínicas e dos núcleos das células de Schwann, a porcentagem da área ocupada pelas fibras mielínicas, área da fibra mielínica, do axônio e da bainha de mielina e a distribuição do 
diâmetro das fibras, axônios e da razão $G$ nos nervos surais, nos segmentos proximais e distais, dos lados direito e esquerdo.

Grande motivação para estudos morfométricos em nervos periféricos se instalou quando os neurofisiologistas tentaram correlacionar velocidade de condução nervosa e diâmetro da fibra (GASSER; ERLANGER, 1927; GASSER; GRUNDFEST, 1939). Investigações adicionais foram realizadas para se obter uma classificação referente ao diâmetro das fibras mielínicas aferentes e eferentes (ECLES; SHERRINGTON, 1930; LLOYD, 1943; LLOYD;CHANG, 1948).

O objetivo principal de estudos morfométricos de nervos normais é a obtenção de valores característicos e específicos que permitam a comparação com nervos anormais (MEZIN et al., 1994). A análise morfométrica de nervos tem sido extensivamente utilizada em pesquisas sobre reparo dos mesmos (ORGEL; TERZIS, 1977); (LUGNEGARD et al.,1984a); (OLIVEIRA et al., 2004), regeneração (GUTMANN; SANDERS, 1943); (SCHRODER, 1972); (LUTHMAN et al., 1988); (MENDONÇA et al., 2003); (RASO et al., 2005), implante e transplante (LUGNEGARD et al., 1984b); (SECKEL et al., 1986);MACKINNON et al., 1987); (DE SÁ et al., 2004), sendo que os métodos quantitativos constituem ferramentas importantes no estudo de neuropatias experimentais. Além disso, a morfometria tem sido amplamente utilizada nas investigações de modelos experimentais de doenças que acometem o sistema nervoso periférico, tais como o diabete (RODRIGUES FILHO; FAZAN, 2006); (FAZAN et al., 2006), a hipertensão (FAZAN et al., 1999); FAZAN et al., 2001), (FAZAN et al., 2005) e o envelhecimento (JERONIMO et al., 2005), (JERONIMO et al., 2008).

Além da ampla utilização da morfometria nos estudos de neuropatias, essa técnica tem se mostrado extremamente útil nas definições de parâmetros normais de nervos, tanto no homem (BERTHOLD, 1968); (FRAHER, 1978); (SWALLOW, 1966); O’SULIVAN SWALLOW, 1968) quanto em animais de laboratório (FRIEDE; SAMORAJSKI, 1967); (FAZAN et al., 1997); (FAZAN et al., 2002), sendo que os dados obtidos fornecem a base morfológica para os estudos dos danos causados pelas doenças que acometem o sistema nervoso periférico.

A utilização de técnicas morfométricas para diagnóstico de neuropatias periféricas é também extensamente utilizada na prática clínica, (ORGEL;TERZIS,1977) ; LUGNEGARD et al.,1984b), (TORCH et al., 1989a) de forma que essa técnica torna o diagnóstico o mais rápido e confiável possível. 
Neurologistas eventualmente utilizam a quantificação dos achados de biópsias como um método científico auxiliar para investigação de neuropatias (DYCK e LOFGREN, 1966; OCHOA e MAIR, 1969; OCHOA e MAIR, 1969; THOMAS, 1970).

Assim sendo, não é surpresa o grande número de métodos que têm sido empregados na morfometria de nervos, numa tentativa de se ganhar mais precisão na obtenção de dados quantitativos. Em estudos experimentais com ratos, o nervo safeno tem sido utilizado naqueles trabalhos que envolvem o conhecimento da descrição da morfometria e morfologia normal do nervo (CAMPOS, S.A.R.; SANADA, L. S.; SATO, K. L.; FAZAN, V. P. S., 2008), lesões nervosas (IIZUKA, M.; YAO, R.; WAINAPEL.,2005) estudos de dor neuropática experimental (WALCAZAK, J. S.; PICHETTE, V.; LEBLOND, F.; DESBIENS, K.; BEAULIEU, P.,2005); trabalho para estudos de fibras C (BRENAN, A.; JONES, L.; OWAIN, N. R.,1988) e, principalmente, estudos de lesão e regeneração nervosa (ALLNAT, J. P.; DICKSON, K. E.; LISNEY, S. J.,1990). Em humanos o nervo safeno foi utilizado para estudos de dor, (RODRIGUES, F.F, et al.,2009).

\subsection{Desenvolvimento e Maturação do Nervo Periférico}

O desenvolvimento dos nervos periféricos envolve um processo de interação simbiótica e dinâmica, entre axônios e células de Schwann (JESSEN \& MIRSKY, 1994). As células de Schwann e seus precursores têm um papel crucial na geração dos nervos periféricos (MIRSKY \& JESSEN, 2001). A interação começa com um sinal do axônio que age no recrutamento de populações celulares potencialmente mielinizantes, na sua diferenciação e proliferação e na iniciação da síntese e manutenção das moléculas específicas da mielina (GRAÇA, 1988).

A função dos nervos periféricos é significativamente afetada pela idade, sendo os déficits funcionais consequência de perda de fibras, anormalidades da bainha de mielina ou alterações do tecido conjuntivo e vascularização nervosa. A idade também influencia a capacidade dos nervos periféricos se regenerarem e reinervarem os órgãos-alvo, com diferentes padrões para fibras motoras, sensitivas a autonômicas (VERDU et al., 1996). Entretanto, em estudos de envelhecimento, diferenças entre os animais adultos e velhos são comumente baseados em apenas dois grupos experimentais (um grupo de adulto e outro de animais velhos), ao passo que toda a vida e a duração dos períodos de crescimento devem ser cuidadosamente levados em consideração para se comprovar especificamente que animais 
adultos e velhos estejam sendo comparados (CEBALLOS et al., 1999). Coleman et al. (1990) chamaram a atenção para a necessidade e a importância de múltiplos grupos experimentais nos estudos de maturação e envelhecimento. A realização de um estudo prévio em nosso laboratório, utilizou três grupos experimentais, 30, 90 e 180 dias de vida para descrever os parâmetros normais do nervo sural de ratas Wistar (JERONIMO et al., 2005). Outro estudo, no mesmo laboratório, comparou as alterações que ocorrem com o nervo sural em diferentes fases do envelhecimento (JERONIMO et al., 2008).

Estudos eletrofisiológicos encontraram redução na velocidade de condução nervosa em animais mais velhos comparados aos jovens (VERDÚ et al., 2000). Entretanto, existem algumas controvérsias em relação a essa redução. Alguns estudos mostram um declive linear na velocidade de condução nervosa com a idade (LAFRATA; CASTETRARI, 1966); (DORFMAN; BOSLEY, 1979), e outros mostraram uma diminuição não linear (TROJABORG, 1976); (TAYLOR, 1984); (SCHMELZER; LOW, 1987); (BOUCHE et al., 1993).

Quando o nervo periférico de ratos é estudado através de técnicas morfológicas e morfométricas, avaliando-se várias fases da vida, estudos demonstraram que alterações não lineares estão presentes em vários parâmetros (CEBALLOS et al., 1999), confirmando o que se observa nos estudos de velocidade de condução. Verdú et al. (2000) descrevem que existe uma aparente estabilização morfológica dos nervos periféricos de camundongos de 6 a 12 meses de idade, sendo que 12 meses representa o final do período de maturação das fibras mielínicas. Em ratos da linhagem Wistar, Sharma et al. (1980), mostraram que o diâmetro das fibras mielínicas apresenta um crescimento muito rápido até o $40^{\circ}$ dia de vida pós-natal e continuam a crescer com uma taxa menor, estabilizando no $6^{\circ}$ mês de vida.

Esses autores demonstraram, na análise da curva de crescimento dos animais, que há um rápido aumento do peso corporal desses animais até o $100^{\circ}$ dia de vida. Estes continuam crescendo, com velocidade menor, até por volta do $6^{\circ}$ mês de idade e, então, o peso corporal se estabiliza para idades maiores. Existe, portanto, clara evidência de crescimento contínuo nos nervos periféricos por um período de, pelo menos seis meses de idade.

Em roedores, nos primeiros dias de vida, as células de Schwann imaturas divergem em função: as mielinizantes envolvem os axônios de maior diâmetro e os mielinizam e as não mielinizantes acomodam-se superficialmente sobre os axônios de menor diâmetro formando uma membrana celular (MIRSKY et al., 2001). Esse processo é guiado por sinalização dos 
axônios, apesar da natureza dessa comunicação ainda permanecer alusiva (JESSEN \& MIRSKY,1994).

Interessante mencionar que são raros os estudos que descrevem a morfometria normal dos nervos periféricos de ratos com idades acima de um ano, uma vez que essa idade não é comumente utilizada em experimentos. Entretanto, uma vez que experimentos de regeneração necessitam do estudo por longo tempo de sobrevivência, o conhecimento dos valores normais se faz necessário, principalmente daquelas variáveis que sabidamente se alteram com a idade. 


\section{OBJETIVOS}




\section{OBJETIVOS}

\subsection{Objetivos Gerais}

O objetivo do presente trabalho foi realizar uma descrição detalhada dos parâmetros normais da morfologia e morfometria do nervo safeno de ratos da linhagem Wistar, fêmeas, em diferentes fases do seu envelhecimento, bem como determinar se estes parâmetros mudam ao longo do nervo (estudo longitudinal) e/ou se existe diferença entre os níveis correspondentes dos lados direito e esquerdo do mesmo animal.

\subsection{Objetivos Específicos}

1 - Descrever os aspectos morfológicos e morfométricos gerais dos nervos safenos de ratos da linhagem Wistar, fêmeas, em diferentes segmentos do mesmo nervo.

2 - Descrever os aspectos morfológicos e morfométricos gerais dos nervos safenos de ratos da linhagem Wistar, fêmeas, nos lados direito e esquerdo do mesmo animal.

3 - Acompanhar as eventuais alterações morfológicas e morfoméricas dos nervos safenos de ratos da linhagem Wistar, fêmeas, decorrentes do envelhecimento, comparando 3 fases de vida dos animais entre si, em diferentes segmentos do mesmo nervo.

4 - Acompanhar as eventuais alterações morfológicas e morfoméricas dos nervos safenos de ratos da linhagem Wistar, fêmeas, decorrentes do envelhecimento, comparando 3 fases de vida dos animais entre si, nos lados direito e esquerdo do mesmo animal. 
MATERIAIS E MÉTODOS 


\section{MATERIAIS E MÉTODOS}

\subsection{Animais}

Foram utilizados ratas albinas da linhagem Wistar, provenientes do Biotério do Laboratório de Neurologia Aplicada e Experimental do Departamento de Neurociências e Ciências do Comportamento, da Faculdade de Medicina de Ribeirão Preto da Universidade de São Paulo (FMRP-USP). Os animais foram mantidos aos pares ou trios, em gaiolas plásticas grandes $(34 \times 42 \times 37 \mathrm{~cm})$, em ambiente com ventilação forçada, temperatura controlada entre 21 e $23^{\circ} \mathrm{C}$, umidade relativa do ar entre 40 e $70 \%$ e ciclo claro/escuro de 12 horas. Até o dia do experimento, tiveram livre acesso à água e a ração padrão para pequenos roedores (Nuvilab CR1 - Nuvital $®)$. A composição da ração encontra-se em anexo. Todos os procedimentos experimentais foram realizados de acordo com as Normas Éticas para experimentação em Animais de Laboratório, aprovadas pela Congregação da Faculdade de Medicina de Ribeirão Preto, em sua $667^{\mathrm{a}}$ reunião ordinária, e aprovados pelo Comitê de Ética em Experimentação Animal (CETEA) da (FMRP-USP), sob o protocolo de número 184/2005. Todos os esforços foram realizados no sentido de reduzir o número de animais utilizados.

\subsection{Grupos Experimentais}

Os experimentos foram realizados em três grupos experimentais, de acordo com o tempo de envelhecimento (contado em dias de vida):

1- Grupo I: Animais com 180 dias de vida $(\mathrm{N}=6)$

2- Grupo II: Animais com 360 dias de vida $(\mathrm{N}=6)$

3- Grupo III: Animais com 720 dias de vida $(\mathrm{N}=6)$

\subsection{Procedimentos Cirúrgicos}

Imediatamente antes do experimento, os animais foram pesados e profundamente anestesiados com tiopental sódico $(40 \mathrm{mg} / \mathrm{Kg})$. Os animais foram posicionados na mesa cirúrgica em decúbito dorsal, com as patas fixadas em abdução para a ampla abertura da cavidade abdominal, para a exposição e secção do diafragma, junto da sua origem esternocostal. A cavidade torácica foi aberta lateralmente através da secção das costelas, para 
a exposição do coração. Em seguida, foi realizada a punção do ventrículo cardíaco esquerdo, a secção do átrio direito e os animais foram perfundidos sistematicamente, com o auxílio de uma bomba de perfusão (Figura 3). Inicialmente, o leito vascular foi lavado com uma solução salina tamponada (PBS 0,05 M, pH 7,4), para a remoção do sangue no interior dos vasos. Em seguida, foi injetada uma solução fixadora, composta de glutaraldeído a 2,5\% em tampão cacodilato de sódio 0,1M, pH 7,2.

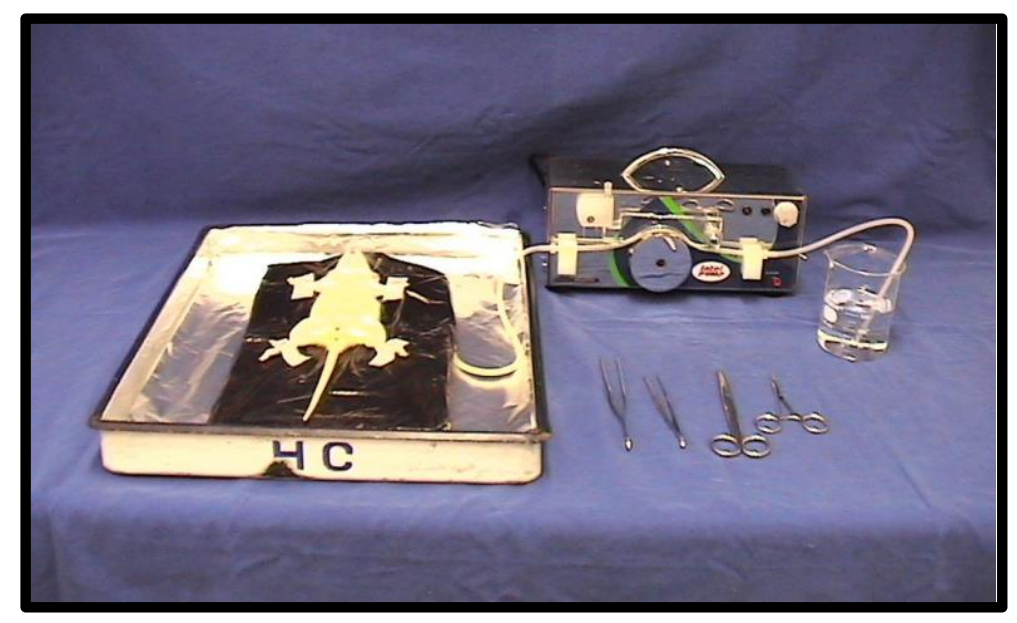

Figura 3: Fotografia ilustrativa da bomba de perfusão, instrumental cirúrgico e posicionamento do animal anestesiado para início da perfusão intra-cardíaca.

\subsection{Procedimentos Histológicos}

Após o término da perfusão os nervos safenos direitos e esquerdos foram dissecados (figura 4) e retirados, em toda sua extensão, desde sua origem na raiz da coxa, até sua ramificação terminal, próximo à face medial do tornozelo. Estes nervos foram esticados sobre uma tira de papel filtro (figura 5), para que não houvesse retração dos mesmos, para, então, serem armazenados em uma solução fixadora, com a mesma composição daquela utilizada na perfusão, por pelo menos 12 horas, a $4^{\circ} \mathrm{C}$. Após este período, foram lavados com solução tampão cacodilato de sódio a 0,1 M, pH 7,2 e dissecados os segmentos proximais e distais, que foram incluídas em resina epóxi (figura 6) . O restante dos nervos foi estocados a $4^{\circ} \mathrm{C}$, em tampão cacodilato de sódio $0,1 \mathrm{M}, \mathrm{pH} 7,2$, como material reserva. 


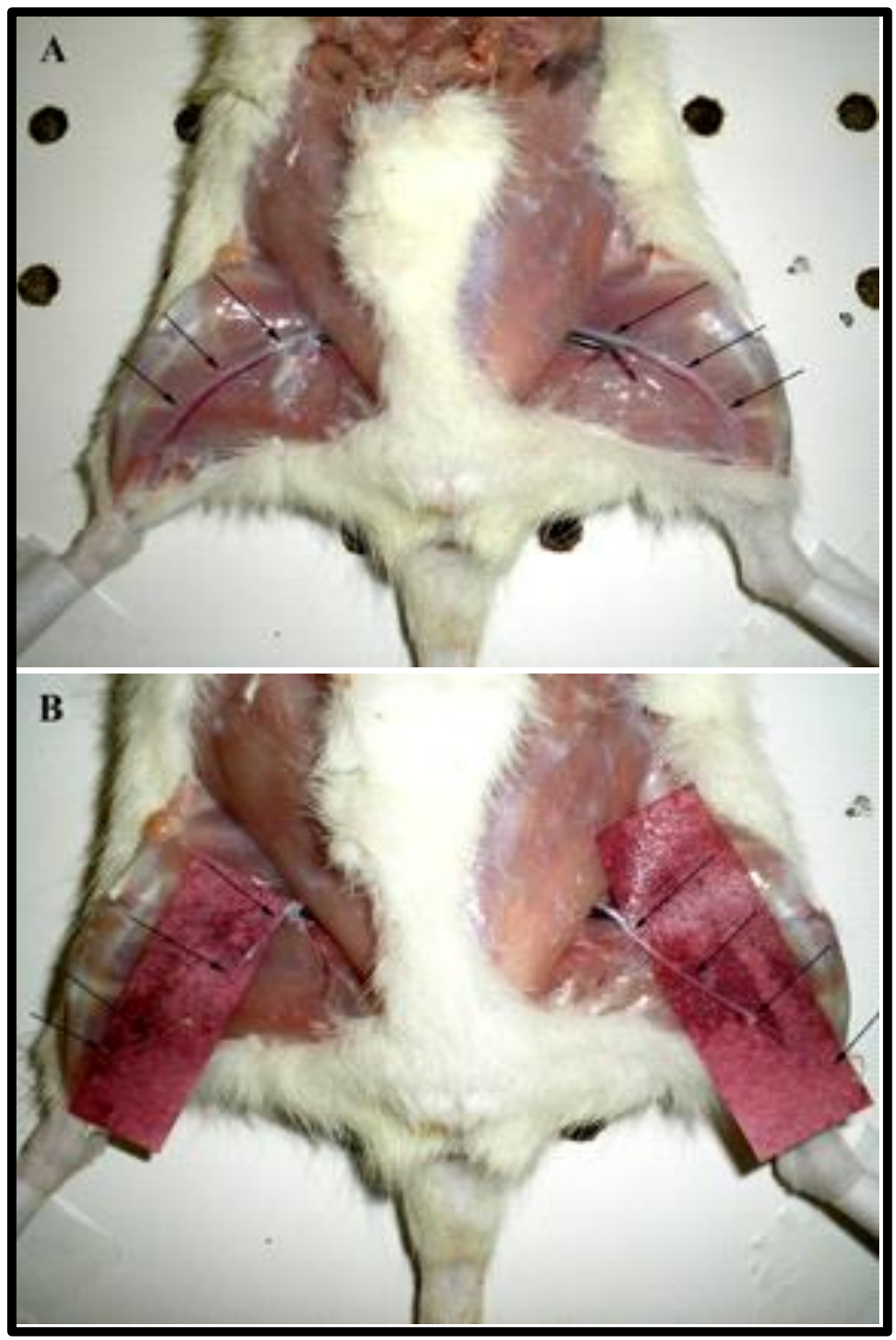

Figura 4: Dissecação do nervo safeno em rato. A: Nervos safenos (setas) direito e esquerdo, em seu trajeto subcutâneo, acompanhados pelas artéria e veia safenas, ainda envolvidos pela fáscia da coxa. B: Nervos safenos (setas) direito e esquerdo, isolados das estruturas vasculares e da fáscia da coxa, desde sua origem até a ramificação terminal, colocados sobre papel colorido para melhor contrastação. 
Os segmentos proximal e distal dos nervos safenos foram pós-fixados em uma solução de tetróxido de ósmio (OsO4) aquoso a 4\%,tampão cacodilato de sódio 0,2 M, pH 7,4 e ferrocianeto de potássio $(\mathrm{K} 4 \mathrm{Fe}(\mathrm{CN}) 6.3 \mathrm{H} 2 \mathrm{O})$ aquoso a $6 \%$, na proporção $1: 2: 1$, por duas horas em temperatura ambiente e agitação orbital contínua.

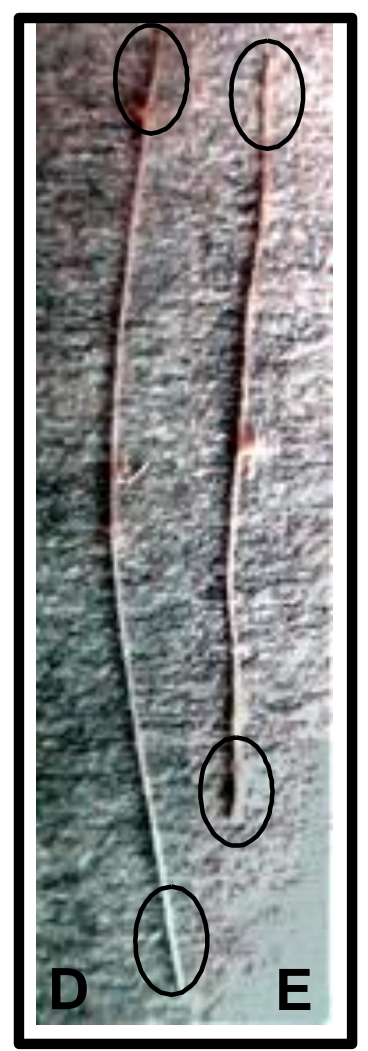

Figura 5: Nervos safenos direito (D) e esquerdo (E), dissecados e retirados, estirados sobre uma tira de papel filtro para evitar retração. Os círculos indicam os segmentos proximal (superior) e distal (inferior) que serão pós-fixados separadamente. O restante do nervo é armazenado como material reserva.

Lavados por uma hora, em temperatura ambiente, com tampão cacodilato de sódio a 0,1 M, pH 7,4, esses segmentos foram desidratados, em concentrações crescentes de etanol, como segue:

$\begin{array}{ll}\text { Etanol } 25 \% & 5 \text { minutos } \\ \text { Etanol } 35 \% & 5 \text { minutos } \\ \text { Etanol } 50 \% & 5 \text { minutos } \\ \text { Etanol } 70 \% & 5 \text { minutos } \\ \text { Etanol } 75 \% & 5 \text { minutos } \\ \text { Etanol } 80 \% & 5 \text { minutos } \\ \text { Etanol } 95 \% & 5 \text { minutos } \\ \text { Etanol } 100 \% & 5 \text { minutos, por duas vezes }\end{array}$


Em seguida, esses fragmentos foram infiltrados em uma mistura de resina epóxi EMbed 812® (Electron Microscopy Sciences) e etanol 100\% na proporção 1:2 por uma hora e, na proporção 2:1 por duas horas. A resina foi preparada na seguinte proporção:

$\begin{array}{lc}\text { Poly/Bed 812® ( Resina) } & 13 \mathrm{ml} \\ \text { NMA (plastificador) } & 9 \mathrm{ml} \\ \text { DDSA( endurecedor) } & 7 \mathrm{ml} \\ \text { DMP-30 (catalisador) } & 0,6 \mathrm{ml}\end{array}$

Após um período mínimo de 12 horas, imersos em resina plena, os segmentos proximais e distais foram colocados em moldes de silicone devidamente identificados e preenchidos com resina, e orientados, sob lupa estereoscópica, para a futura obtenção de secções transversais. Após a orientação desses segmentos, os moldes foram aquecidos em estufa a $60^{\circ}$, por 72 horas para polimerização da resina. Após a polimerização, os blocos foram removidos dos moldes e aparados com lâminas descartáveis para microtomia.

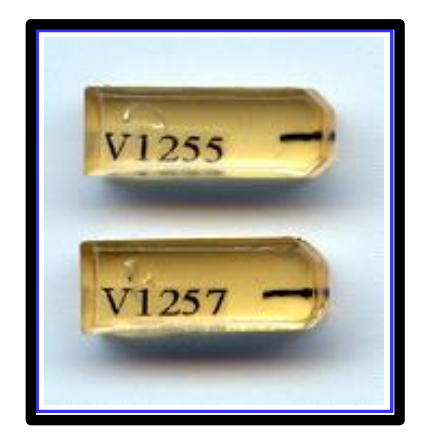

Figura 6: Nervos safenos direito, (v1255) e esquerdo (v1257), segmentos proximais, emblocados em resina epóxi, imediatamente antes do início da microtomia.

Os segmentos proximais e distais dos nervos estudados tiveram secções transversais semifinas $(0,2$ a $0,3 \mu \mathrm{m}$ de espessura) obtidas com navalhas de vidro através de um ultramicrótomo MT 6000-XL (RMC Inc), transferidas para lâminas de vidro com uma gota de água destilada, secadas em placa aquecedora a $60^{\circ} \mathrm{C}$ e coradas com azul de toluidina a $1 \%$ em àcido bórico saturado. Tais secções foram utilizadas para estudos de microscopia de luz. Os procedimentos histológicos utilizados nesse trabalho são aqueles utilizados de rotina no preparo de espécimes de nervos, para estudos tanto em nível de microscopia de luz (FAZAN e cols., 1999; JERONIMO e cols., 2004; JERONIMO e cols 2005; RODRIGUES FILHO e FAZAN, 2006; FAZAN e cols., 2006; SCHIAVONI e FAZAN, 2006) quanto em nível de microscopia eletrônica de transmissão (FAZAN e cols., 1997; FAZAN e cols., 2001; FAZAN e cols., 2003; SATO e cols., 2006). 
Todos os procedimentos cirúrgicos e histológicos descritos no presente estudo foram realizados no laboratório de microscopia e morfometria, do setor de Cirurgia Experimental do Departamento de Cirurgia e Anatomia da Faculdade de Medicina de Ribeirão Preto. Durante os procedimentos histológicos, alguns nervos foram descartados por não apresentarem uma morfologia adequada para a realização da morfometria. Assim, foram incluídos no presente estudo, um total de 6 nervos direitos e 6 nervos esquerdos, provenientes dos mesmos animais $(\mathrm{N}=6)$, para a análise morfológica e morfométrica apresentada a seguir.

\subsection{Análise Morfológica e Morfométrica}

As secções transversais semifinas dos segmentos proximais e distais dos nervos retirados foram observadas em um fotomicroscópio (Axiophot II, Carl Zeiss) usando as objetivas 40 e/ou 100 vezes, com imersão em óleo. Quando necessário, lentes auxiliares (optovar de 1,25 ou 1,6 vezes) foram utilizadas para proporcionar uma ampliação adicional das imagens. As imagens dos fascículos foram digitalizadas com o auxílio de uma câmara de alta resolução AxioCam MRc acoplada a um microcomputador. Foram obtidas,das imagens, as medidas da área e diâmetro mínimo dos fascículos, com o auxílio de um programa analisador de imagens Image J NHI. O diâmetro mínimo é o menor diâmetro obtido de uma estrutura de forma aparentemente circular. Após a obtenção da imagem dos fascículos, com o auxílio de uma platina motorizada acoplada ao microscópio, campos microscópicos adjacentes, da área endoneural dos mesmos, foram digitalizadas. Essa platina motorizada proporcionou o deslocamento automático das lâminas, em campos microscópicos, sem sobreposição dos mesmos.

Essas imagens adjacentes da área endoneural geraram um número entre 12 e 20 quadros (dependendo do tamanho do fascículo), que foram digitalizados com objetiva de 100 vezes com imersão em óleo, lente auxiliar (optovar) de 1,6 vezes e fator de ampliação da câmera de 1 vez. A montagem sequencial desses campos microscópicos (quadros) gera a imagem da secção transversal do fascículo correspondente (figura 7). Em cada campo microscópico digitalizado, as fibras mielínicas foram contadas na sua totalidade e, ao término desse processo, o número total e a densidade (número/ $\mathrm{mm}^{2}$ ) de fibras mielínicas foram obtidos. Todas essas imagens foram digitalizadas em cores, no formato RGC (vermelho, verde e azul). 

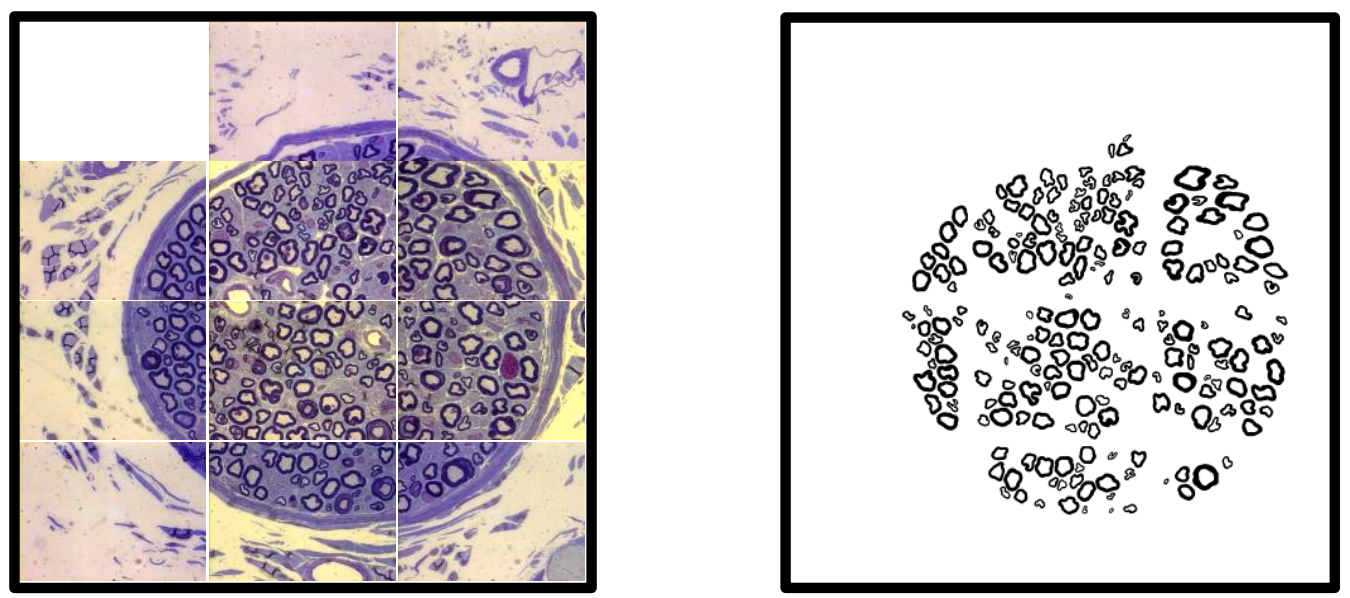

Figura 7: Painel esquerdo: Figura ilustrativa da montagem sequencial de campos microscópicos digitalizados com objetiva de 100 vezes com imersão a óleo, lente auxiliar (optovar) de 1,6 vezes e lente da câmera de 0,5 vezes. A montagem sequencial desses campos microscópicos (quadros) gera a imagem da secção transversal do fascículo correspondente. Coloração= azul de toluidina a 1\%. Painel direito: figura ilustrativa da montagem sequencial dos campos microscópicos do mesmo fascículo representado à esquerda, com imagens binárias em preto e branco. Notar que as fibras que tocavam as bordas dos quadros foram eliminadas na imagem binária.

Para as medidas das fibras mielínicas, as imagens dos campos microscópicos passaram por um processo de identificação da bainha de mielina, através de uma ferramenta do programa computacional, capaz de identificar, por seleção de cores, as estruturas desejadas. As estruturas marcadas, especificamente a bainha de mielina, foram então transformadas em uma imagem binária em preto e branco, para que pudessem ser identificadas de maneira automática (Figuras 7 e 8).
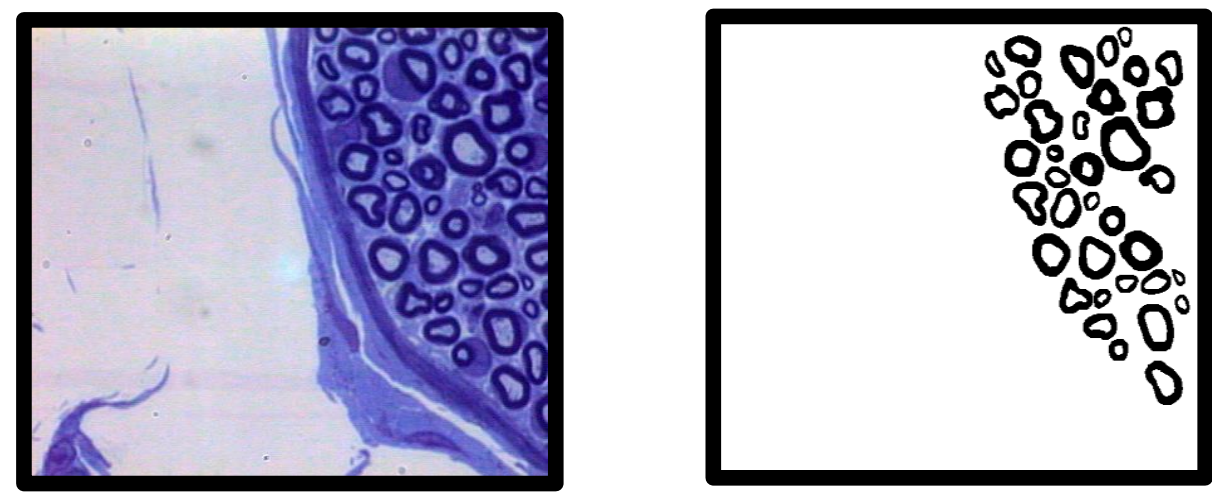

Figura 8: Painel esquerdo: Figura ilustrativa de um campo microscópio digitalizado com objetiva de 100 vezes com imersão em óleo, lente auxiliar (optovar) de 1,6 vezes e lente de câmera de 0,5 vezes. Coloração azul de toluidina a $1 \%$. Barra de escala $=10 \mu \mathrm{m}$. Painel direito: temos a mesma figura ilustrativa do mesmo quadro representativo no painel esquerdo, com imagem binária em preto e branco. Notar que as fibras que tocam as bordas dos quadros foram eliminadas na imagem binária 
Durante esse processo, as fibras irregulares, as que se apresentaram seccionadas no nível do nó de Ranvier ou nas incisuras de Schimidt-Lanterman e as que tocam as bordas dos quadros são automaticamente eliminadas. Neste estudo foram medidas 31 a $100 \%$ de todas as fibras mielínicas presentes no espaço endoneural. Após esse processo, o programa ainda permite um ajuste manual da imagem para que pequenas irregularidades e/ou artefatos possam ser eliminados antes da realização das medidas automáticas. Concluído o ajuste, foram obtidos, automaticamente, tanto do diâmetro mínimo axonal, definido pelo limite externo do axolema, quanto o diâmetro mínimo da fibra, definido pelo limite externo das lamelas de mielina. A razão entre ambos os diâmetros, conhecida como razão G, que é uma medida indicativa do grau de mielinização (SCHMITT e BEAR, 1937; RUSHTON, 1951; SMITH e KOLES, 1970), a área da fibra, do respectivo axônio e a área da bainha de mielina foram então calculadas. Os resultados dessas medidas possibilitaram a elaboração de planilhas eletrônicas utilizadas na representação gráfica e na análise estatística dos dados. A porcentagem da área fascicular total, ocupada pelas fibras mielínicas foi também calculada.

Histogramas de distribuição de tamanho das fibras mielínicas e dos seus respectivos axônios foram construídos, com intervalos de classe de 0,5 $\mu \mathrm{m}$. Histogramas de distribuição da razão $G$ foram construídos, com intervalos de classe de 0,1. Esses histogramas foram construídos com o auxílio do aplicativo Sigma Plot, versão 11.0 (Jandel Scientific).

Todos os procedimentos morfológicos e morfométricos descritos no presente estudo, foram realizados no Laboratório de Neurologia Aplicada e Experimental, do Departamento de Neurociências e Ciências do comportamento da Faculdade de Medicina de Ribeirão Preto.

\subsection{Análise estatística}

O teste de Kolmogorov-Smirnov foi aplicado para testar a normalidade da distribuição de todos os dados obtidos (ponderais), através do aplicativo Sigma Stat versão 3.5 (Jandel Scientific). Em seguida a equivalência das variâncias foi testada automaticamente, através do teste de medidas de Levene, por esse mesmo programa, antes de prosseguir com o teste desejado. 


\subsubsection{Comparações Morfométricas Intra-Grupos:}

Para a análise dos dados morfométricos, aqueles parâmetros que passaram no teste de normalidade e no teste de equivalência das variâncias, os valores médios foram comparados pelo teste de t de Student pareado (entre os segmentos proximais e distais), ou não pareado (entre os lados direito e esquerdo).

Os parâmetros morfométricos que não apresentaram distribuição normal, foram comparados entre os segmentos proximais e distais, através do teste não paramétrico de Wilcoxon. A comparação dos valores médios obtidos para os segmentos de mesmo nível, entre os lados direito e esquerdo, foram comparados através do teste de Mann-Whitney. Nenhum parâmetro analisado apresentou distribuição normal e não equivalência das variâncias.

Os histogramas de distribuição do tamanho das fibras, do tamanho dos axônios e da razão $\mathrm{G}$, foram comparados entre os segmentos proximal e distal de um mesmo lado e entre lados através de uma análise de variância para fator único (ONE WAY ANOVA), on Ranks, uma vez que todos os dados não apresentaram uma distribuição normal.

\subsubsection{Comparações Morfométricas entre os Grupos:}

Para a análise de dados morfométricos entre os grupos, aqueles parâmetros que passaram no teste de normalidade e no teste de equivalência das variâncias, os dados foram comparados entre grupos através de uma análise de variância para fator único (ONE WAY ANOVA), seguida de um pós-teste de Tukey.

Para a análise de dados morfométricos entre os grupos, aqueles parâmetros que não passaram no teste de normalidade e/ou no teste de equivalência das variâncias, os dados foram comparados entre grupos através de uma análise de variância para fator único (ONE WAY ANOVA) on Ranks, seguida de um pós-teste de Dunn.

Para as comparações dos histogramas entre os grupos, foi utilizada uma análise de variância bi-variada (TWO WAY ANOVA), seguida de um pós-teste de Dunn, uma vez que todos os dados não apresentaram distribuição normal.

O nível de significância adotado para todas as análises foi o de $\mathrm{p}<0,05$. 
RESULTADOS 


\section{RESULTADOS}

\subsection{Dados ponderais}

O peso corporal médio das ratas da linhagem Wistar, com 180 dias de vida foi de $302 \pm 14 \mathrm{~g}$; para as ratas com 360 dias de vida o peso médio foi de $327 \pm 10$ e para as ratas com 720 dias de vida o peso médio foi de $543 \pm 9 \mathrm{~g}$. A análise estatística mostrou diferença significativa entre os 3 grupos analisados $(\mathrm{p}<0,001)$, demonstrando aumento do peso corporal com o aumento da idade.

\subsection{Análise Morfológica Geral}

O exame das secções transversais semifinas dos nervos safenos, coradas com azul de toluidina a 1\%, à microscopia de luz, mostrou que esse nervo é, em geral, constituído por um, dois ou vários fascículos, sendo classificados como mono-, bi- ou polifasciculado, respectivamente (Figuras 9,10,11). Nossas observações morfológicas dos segmentos proximais do nervo safeno em ratos mostraram que nesse segmento, o nervo apresenta um único fascículo, de forma redonda ou oval, ora acompanhado de um segundo fascículo, de dimensões menores. Nos segmentos distais, mais de um fascículo foi evidenciado, sendo todos eles circundados por um perineuro bem definido . 

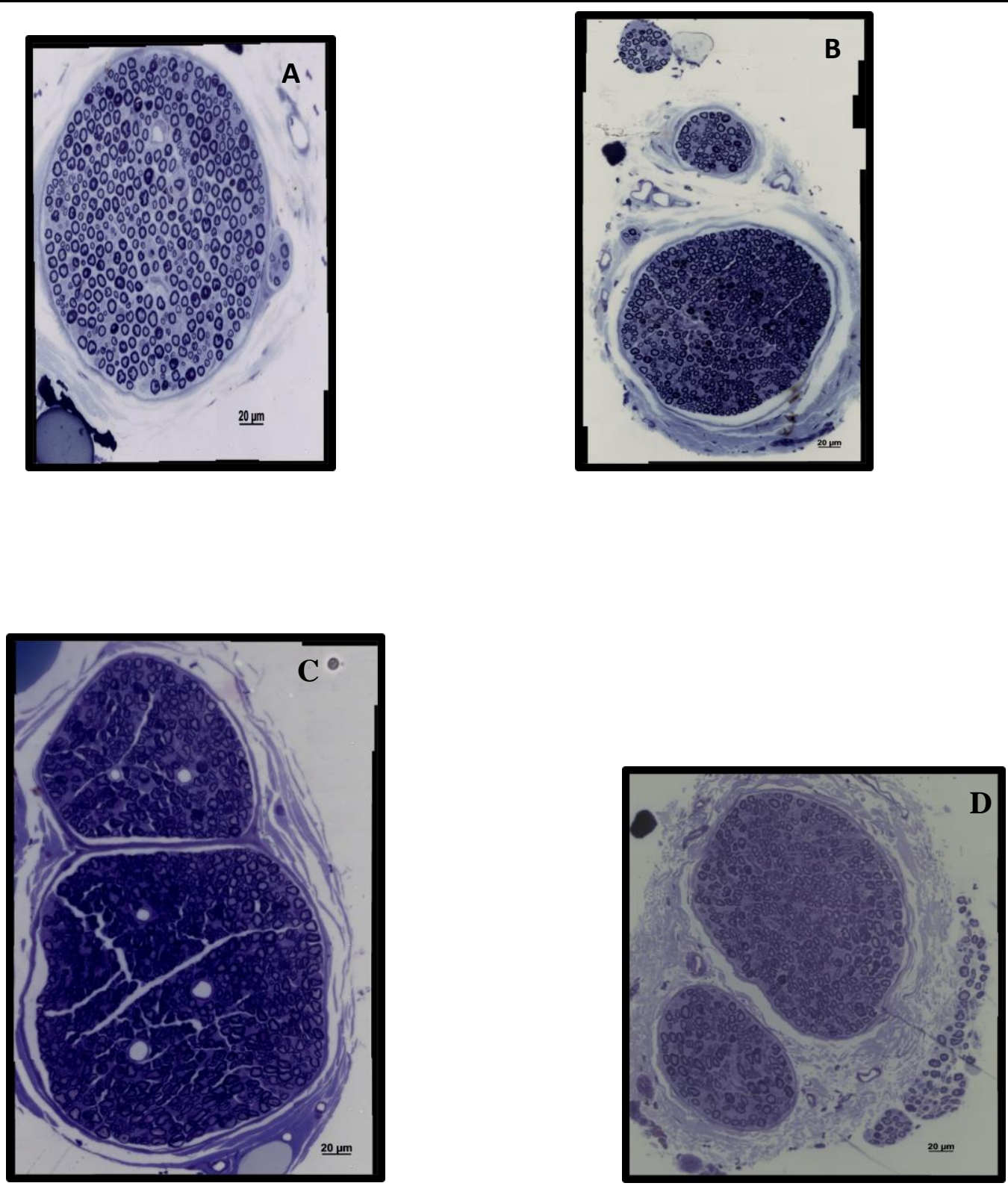

Figura 9: Secção transversal semifina do nervo safeno de rata Wistar de 180 dias de vida. Notar que no segmento proximal (imagem A e C) esses nervos se apresentam mono ou bifasciculado, ao passo que nos segmentos distais eles se apresentam polifasciculados (B e D).Notar também a presença de um perineuro bem definido envolvendo o fascículo, vasos sanguíneos endoneurais e centenas de fibras mielínicas de grande e pequeno calibre, dispersas no endoneuro. Coloração $=$ Azul de toluidina a 1\%, Barra $=20 \mu \mathrm{m}$ 


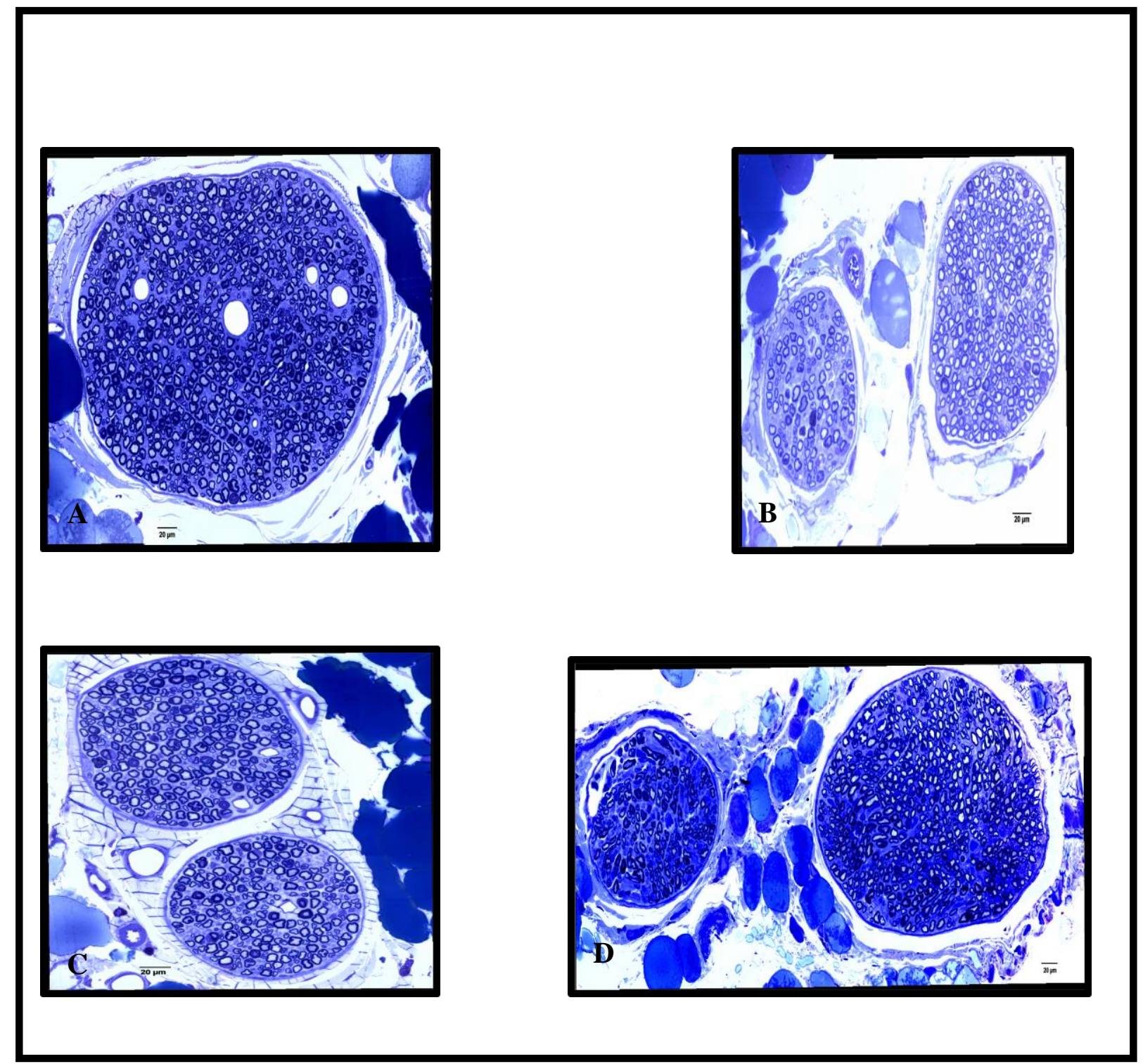

Figura 10: Secção transversal semifina do nervo safeno de rata Wistar de 360 dias de vida. Notar que no segmento proximal (imagem A e B) esses nervos se apresentam mono ou bifasciculado, ao passo que nos segmentos distais eles se apresentam bifasciculados (C e D).Notar também a presença de um perineuro bem definido envolvendo o fascículo, vasos sanguíneos endoneurais e centenas de fibras mielínicas de grande e pequeno calibre, dispersas no endoneuro. Coloração = Azul de toluidina a 1\%, Barra= $20 \mu \mathrm{m}$. 

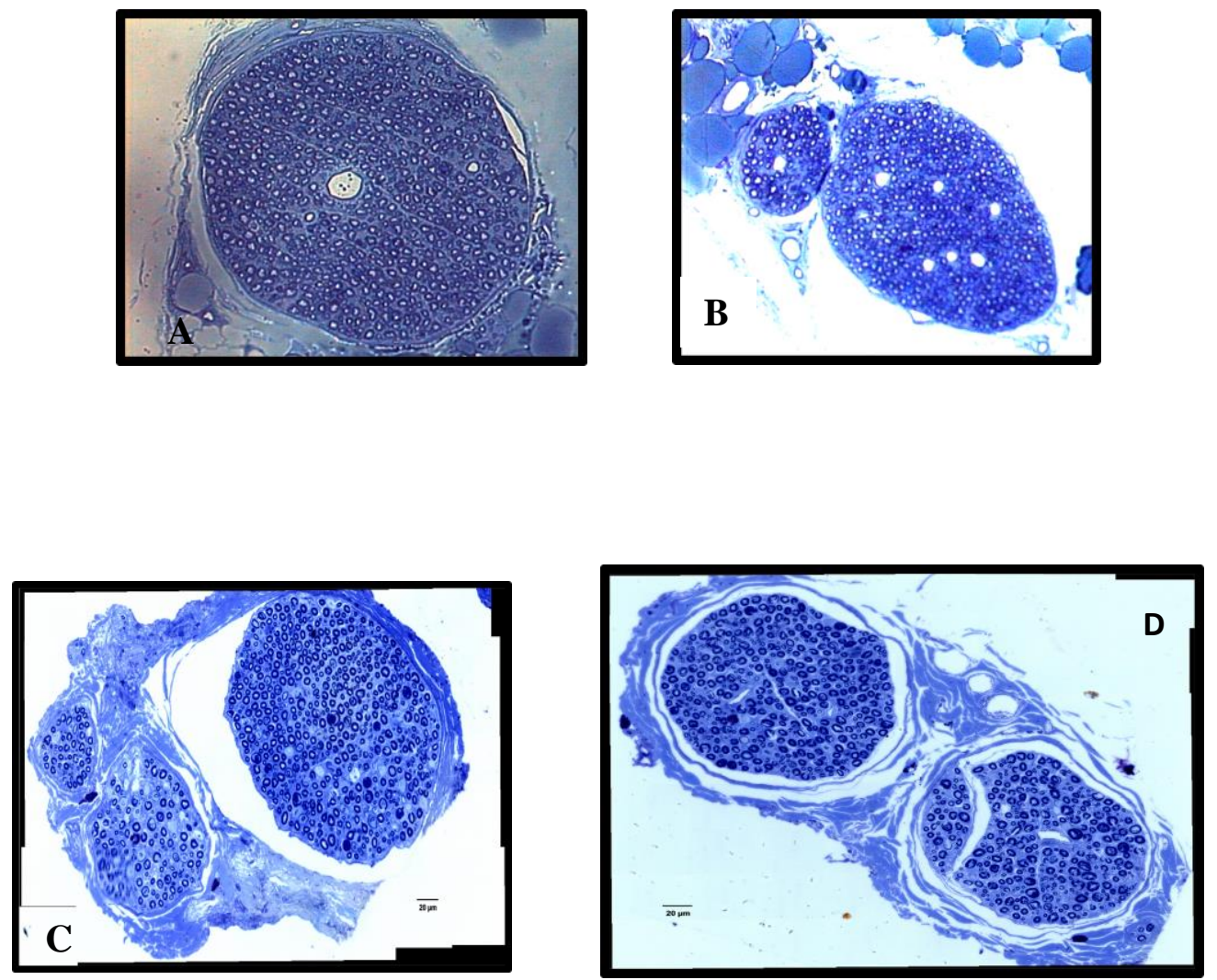

Figura 11: Secção transversal semifina do nervo safeno de rata Wistar de 720 dias de vida. Notar que no segmento proximal (imagem A e B) esses nervos se apresentam mono ou bifasciculado, ao passo que nos segmentos distais eles se apresentam bifasciculados ou polifasciculados (C e D).Notar também a presença de um perineuro bem definido envolvendo o fascículo, vasos sanguíneos endoneurais e centenas de fibras mielínicas de grande e pequeno calibre, dispersas no endoneuro. Coloração = Azul de toluidina a 1\%, Barra= $20 \mu \mathrm{m}$

Esse nervo está constituído por centenas de fibras mielínicas e amielínicas (não visíveis á microscopia de luz), de diversos diâmetros, imersos no endoneuro, acompanhando o longo eixo do nervo. Nota-se que as fibras mielínicas grandes predominam em número sobre as pequenas (Figura 12).

Verificou-se no espaço endoneural, a presença de elementos celulares usuais, como núcleos de células de Schwann associados às fibras mielínicas, núcleos de fibroblastos, células endoteliais de capilares, pericitos e mastócitos. Os núcleos dos fibroblastos aparecem em número menor que as das células de Schwann, sendo um núcleo fusiforme e de coloração mais clara e sem relação de proximidade com os axônios. Alguns mastócitos, em número bem menor que os núcleos de células de Schwann e fibroblastos, foram facilmente identificados, devido à presença de grânulos metacromáticos no seu citoplasma. 
A presença de vasos, geralmente um ou dois capilares centrais, acompanhando o eixo longitudinal do nervo, por entre as fibras nervosas, foi observada na maioria dos segmentos dos nervos estudados.

Essas características gerais, descritas para os nervos safenos, não se mostraram diferentes entre os grupos experimentais estudados. Entretanto, algumas diferenças morfológicas específicas e importantes apareceram entre os grupos, que serão apresentadas a seguir.
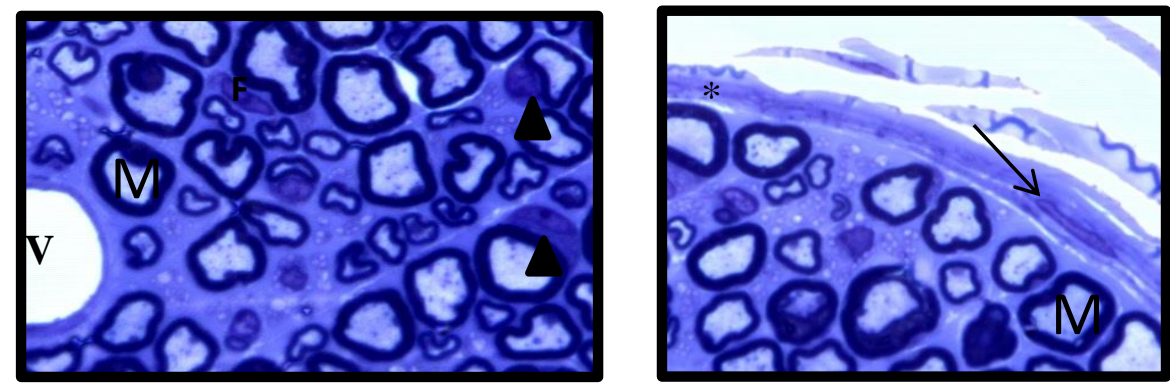

Figura 12: Painel esquerdo: detalhe do espaço endoneural do fascículo do nervo safeno de rata Wistar com 360 dias de vida utilizado no presente estudo. Notar a presença de fibras mielínicas grandes (M), dispersas no endoneuro, misturadas às fibras mielínicas de menor tamanho. $\mathrm{F}$ indica o núcleo de um fibroblasto. Notar, também, a presença de núcleos de células de Schwann (cabeças das setas) associadas às fibras mielínicas e a presença do vaso capilar (V). Painel direito: o perineuro é bem definido (asterisco), formando por várias camadas celulares, sendo essas células e seu respectivo núcleo de aspecto fusiforme (seta ). Coloração: Azul de toluidina a $1 \%$.

\subsubsection{Comparação entre os diferentes grupos}

Ao analisar a morfologia das fibras mielínicas entre os diferentes grupos experimentais, foi observado que, com o envelhecimento, houve um aumento na heterogeneidade da estrutura das fibras mielínicas: mudanças na espessura e forma da bainha, anormalidades na largura das incisuras de Schmit Lanterman, separação das lamelas das bainhas de mielina, aparecimento de figuras ovoides de mielina no interior do axônio, imagens sugestivas de desmielinização e degeneração axonal (figura 13). Nos animais do Grupo III, imagens de células espumosas com conteúdo de mielina no citoplasma, sugestivas de macrófagos em atividade, também foram identificadas. Verificou-se também que a proporção de fibras mielínicas irregulares aumentou progressivamente com a idade. 


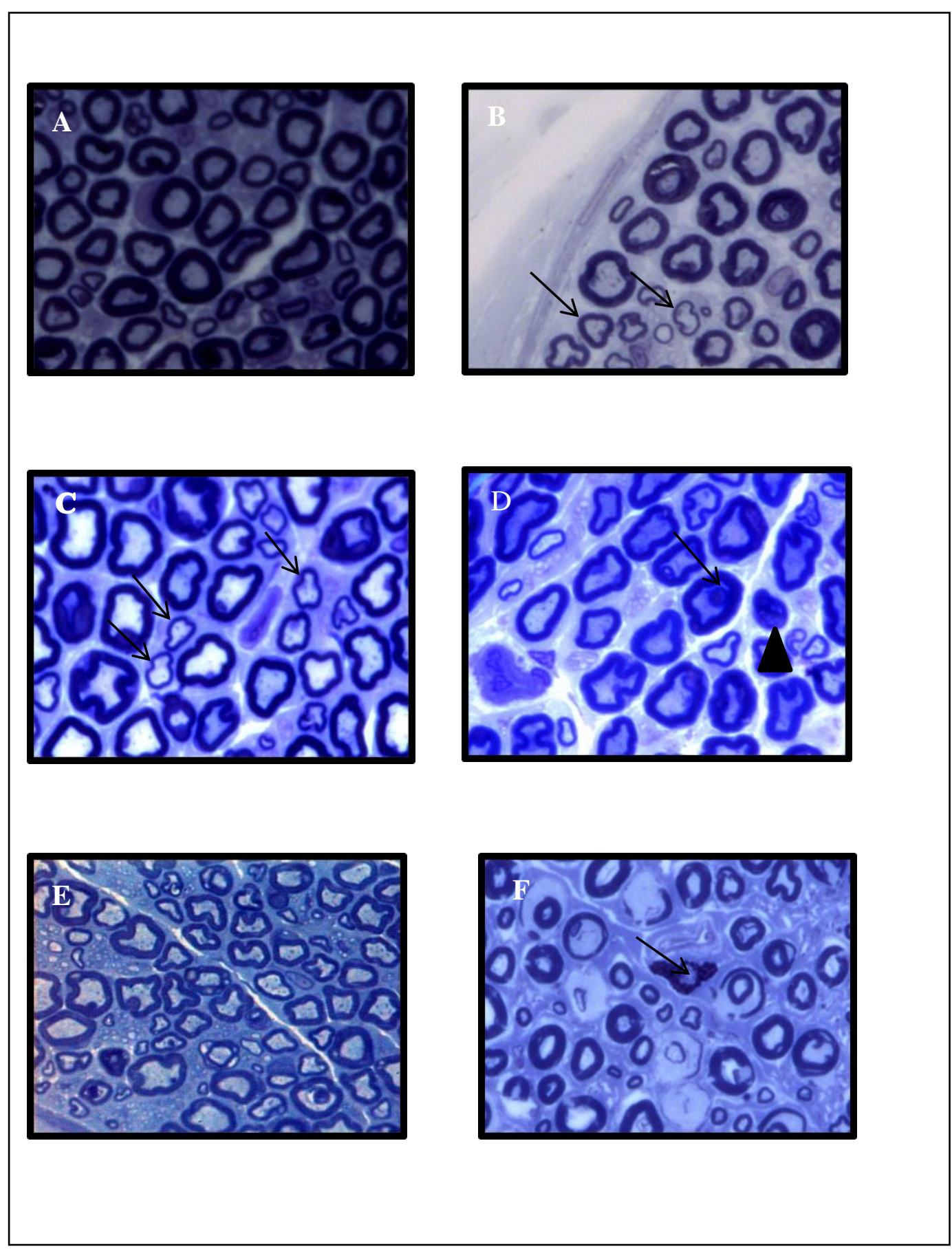

Figura 13: Secções transversais semifinas dos nervos safenos de ratas Wistar com 180 dias de vida (imagens A e B), 360 dias de vida (imagens C e D) e 720 dias de vida (imagens E e F). Essas imagens representam as alterações decorrentes do envelhecimento. Notar que nas imagens A e B as fibras mielínicas estão bem preservadas, com bainha de mielina regular. Notar que algumas fibras de grande calibre apresentam bainha de mielina fina, setas na imagem B. $\mathrm{O} *$ representa o perineuro. Nas imagens C e D as fibras mielínicas apresentam bainha mais irregular comparadas as imagens $\mathrm{A}$ e B. Na imagem $\mathrm{C}$ notar a presença de várias fibras de grande calibre com a bainha de mielina fina (setas pretas). Na imagem D, notar uma fibra com degeneração walleriana (cabeça da seta) e a presença de ovóide de mielina no interior do axônio (seta). Na imagem E, notar a irregularidade das bainhas de mielina mais acentuada. Na imagem $\mathrm{F}$ notar a presença de um mastócito(seta) ,aparente diminuição de fibras mielínicas, degeneração e atrofia axonal. 
Analisando a morfologia dos vasos endoneurais entre os diferentes grupos experimentais, foi observado que, com o envelhecimento, houve um aumento na espessura das paredes dos vasos, e colabamento dos mesmos nos animais do Grupo III.

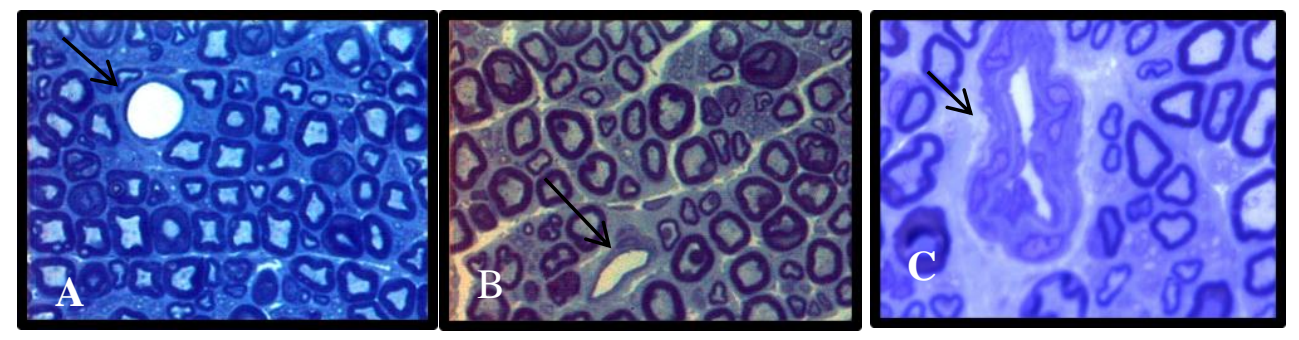

Figura 14: Secções transversais semifinas dos nervos safenos de ratas Wistar com 180 dias de vida (imagem A), 360 dias de vida (imagem B) e 720 dias de vida (imagem C). Essas imagens representam as alterações nos vasos decorrentes do envelhecimento (setas pretas). Notar na imagem C a espessura da parede do vaso e seu colabamento.

\subsection{Análise Morfométrica}

\subsubsection{Morfometria dos fascículos}

Os dados de morfometria dos fascículos (área fascicular total e diâmetro mínimo fascicular, número de fibras mielínicas e sua densidade, porcentagem da área fascicular ocupada pelas fibras mielínicas), dos diferentes grupos experimentais, estão demonstrados nas Tabelas 1, 2, 3. Os dados individuais estão apresentados nas tabelas em anexo.

\subsubsection{Animais do Grupo I - 180 dias de vida}

A área fascicular total do nervo safeno dos animais do Grupo I, no segmento proximal do lado direito, variou entre 45358,25 e 57584,89 $\mu \mathrm{m}^{2}$, com média de 50597,31 \pm 5335,50 $\mu^{2}$; no segmento distal, variou entre 13590,06 e 44397,67 $\mu^{2}$, com média de $31535,98 \pm 11444,73 \mu \mathrm{m}^{2}$. No lado esquerdo, segmento proximal, essa área variou entre 14262,23 e $57250,04 \mu^{2}$, com média de 42410,57 $\pm 16790,37 \mu \mathrm{m}^{2}$; no segmento distal deste 
mesmo lado, variou entre 35078,49 e 59541,74 $\mu \mathrm{m}^{2}$, com média de 52724,96 $\pm 28388,74$ $\mu \mathrm{m}^{2}$.

O diâmetro mínimo do fascículo do nervo safeno dos animais do Grupo I, no segmento proximal do lado direito, variou entre 117,95 e 260,99 $\mu \mathrm{m}$, com média de 219,35 \pm $52,08 \mu \mathrm{m}$; no segmento distal do lado direito, variou entre 90,38 e 197,79 $\mu \mathrm{m}$, com média de $118,73 \pm 41,17 \mu \mathrm{m}$. No segmento proximal do lado esquerdo, variou entre 77,23 e 258,08 $\mu \mathrm{m}$, com média de 176,85 \pm 72,71 $\mu \mathrm{m}$; no segmento distal desse mesmo lado, variou entre 119,05 e 359,46 $\mu \mathrm{m}$, com média de 218,87 $\pm 79,94 \mu \mathrm{m}$.

O número de fibras mielínicas do nervo safeno dos animais do Grupo I do lado direito, no segmento proximal, variou entre 83 e 10059, com média de $943 \pm 88,71$; no segmento distal, variou de 313 e 851, com média de 582,50 \pm 173,30. Para os nervos safenos do lado esquerdo, no segmento proximal, o número de fibras variou entre 325 e 969, com média de 744,83 $\pm 254,67$; no segmento distal deste mesmo lado variou entre 530 e 1800, com média de $940,83 \pm 454,55$.

A densidade das fibras mielínicas do nervo safeno dos animais do Grupo I, do lado direito, no segmento proximal, variou entre 13944,62 e 21295,02 fibras $/ \mathrm{mm}^{2}$, com média de $18816,05 \pm 2558,69$ fibras $/ \mathrm{mm}^{2}$; no segmento distal variou entre 13401,60 e 23827,13 fibras $/ \mathrm{mm}^{2}$, com média de $19418,97 \pm 4255$. Nos nervos safenos do lado esquerdo, no segmento proximal, variou entre 12157,2 e 20063,61 fibras $/ \mathrm{mm}^{2}$, com média de $18490,09 \pm$ 3562,88 fibras $/ \mathrm{mm}^{2}$; no segmento distal desse mesmo lado, variou entre 16173,53 e 21348,69 fibras $/ \mathrm{mm}^{2}$, com média de $18190 \pm 1850,98$ fibras $/ \mathrm{mm}^{2}$. 
Tabela 1- Parâmetros morfométricos fasciculares dos nervos safenos dos animais do Grupo I (180 dias). Valores expressos em média \pm DPM. $\mathrm{N}=$ número de animais analisados.

\begin{tabular}{|c|c|c|c|c|}
\hline & \multicolumn{2}{|c|}{ Lado Direito } & \multicolumn{2}{|c|}{ Lado Esquerdo } \\
\hline & $\begin{array}{l}\text { Proximal } \\
\qquad(\mathrm{N}=6)\end{array}$ & $\begin{array}{l}\text { Distal } \\
(\mathrm{N}=6)\end{array}$ & $\begin{array}{l}\text { Proximal } \\
\qquad(\mathrm{N}=6)\end{array}$ & $\begin{array}{l}\text { Distal } \\
(\mathrm{N}=6)\end{array}$ \\
\hline Dimensões Fasciculares & & & & \\
\hline Área fascicular total $\left(\mu \mathrm{m}^{2}\right)$ & $50597 \pm 5335$ & $31535 \pm 11444$ & $42410 \pm 16790$ & $52724 \pm 28388$ \\
\hline $\begin{array}{l}\text { Diâmetro mínimo fascicular } \\
(\mu \mathrm{m})\end{array}$ & $219 \pm 52,08$ & $118 \pm 41$ & $176 \pm 72$ & $218 \pm 79$ \\
\hline Número de fibras mielínicas & $943 \pm 88$ & $582 \pm 173$ & $744 \pm 254$ & $940 \pm 454$ \\
\hline $\begin{array}{l}\text { Densidade de fibras mielínicas } \\
\text { (fibras } / \mathrm{mm}^{2} \text { ) }\end{array}$ & $18816 \pm 2558$ & $19418 \pm 4255$ & $18490 \pm 3562$ & $18190 \pm 1850$ \\
\hline
\end{tabular}

Comparando os valores obtidos, não foram observadas diferenças significativas tanto entre segmentos do mesmo lado (proximal x distal) quanto entre lados para os mesmos segmentos (proximal direito $\mathrm{x}$ proximal esquerdo) para nenhum dos parâmetros acima descritos.

\subsubsection{Animais do Grupo II - $\mathbf{3 6 0}$ dias de vida}

A área fascicular total do nervo safeno dos animais do Grupo II, no segmento

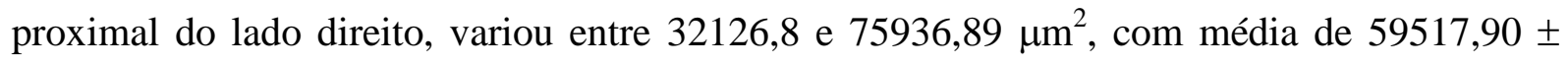
16266,04 $\mu^{2}$; no segmento distal, variou entre 21439,51 e 62558,47 $\mu^{2}$, com média de $43283,08 \pm 15699,47 \mu \mathrm{m}^{2}$. No lado esquerdo, segmento proximal, essa área variou entre

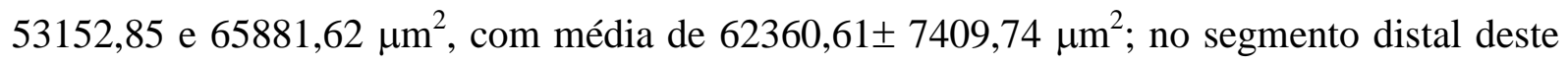
mesmo lado, variou entre 28907,87 e $69105,24 \mu \mathrm{m}^{2}$, com média de $38461,10 \pm 22288,88$ $\mu \mathrm{m}^{2}$. 
O diâmetro mínimo do fascículo do nervo safeno dos animais do Grupo II, no segmento proximal do lado direito, variou entre 118,29 e 289,65 $\mu \mathrm{m}$, com média de 235,07 \pm 62,91 $\mu \mathrm{m}$; no segmento distal do lado direito, variou entre 91,01 e 250,65 $\mu \mathrm{m}$, com média de $155,11 \pm 57,24 \mu \mathrm{m}$. No segmento proximal do lado esquerdo, variou entre 229,22 e 262,44 $\mu \mathrm{m}$, com média de $247,26 \pm 11,95 \mu \mathrm{m}$; no segmento distal desse mesmo lado, variou entre 83,87 e $181,64 \mu \mathrm{m}$, com média de $140 \pm 34,30 \mu \mathrm{m}$.

O número de fibras mielínicas do nervo safeno dos animais do Grupo II do lado direito, no segmento proximal, variou entre 517 e 1353, com média de 912,83 \pm 283,25; no segmento distal, variou de 377 e 1021, com média de 785,33 $\pm 218,98$. Para os nervos safenos do lado esquerdo, no segmento proximal, o número de fibras variou entre 889 e 1251, com média de 1038,50 \pm 140,59; no segmento distal deste mesmo lado variou entre 124 e 1111, com média de $662 \pm 327$.

A densidade das fibras mielínicas do nervo safeno dos animais do Grupo II, do lado direito, no segmento proximal, variou entre 13560,33 e 17817,42 fibras $/ \mathrm{mm}^{2}$, com média de $15330,01 \pm 1574,03$ fibras $/ \mathrm{mm}^{2}$; no segmento distal variou entre 14064,37 e 23298,32 fibras $/ \mathrm{mm}^{2}$, com média de $18752,73 \pm 3520,43$. Nos nervos safenos do lado esquerdo, no segmento proximal, variou entre 14577,05 e 18988,6 fibras $/ \mathrm{mm}^{2}$, com média de $16694,48 \pm$ 1677,22 fibras $/ \mathrm{mm}^{2}$; no segmento distal desse mesmo lado, variou entre 15100,80 e 20824,78 fibras $/ \mathrm{mm}^{2}$, com média de 18167,11 2469,15 fibras $/ \mathrm{mm}^{2}$. 
Tabela 2- Parâmetros morfométricos fasciculares dos nervos safenos dos animais do Grupo II (360 dias). Valores expressos em média \pm DPM. $\mathrm{N}=$ número de animais analisados.

\begin{tabular}{|c|c|c|c|c|}
\hline & \multicolumn{2}{|c|}{ Lado Direito } & \multicolumn{2}{|c|}{ Lado Esquerdo } \\
\hline & $\begin{array}{c}\text { Proximal } \\
\qquad(\mathrm{N}=6)\end{array}$ & $\begin{array}{l}\text { Distal } \\
(\mathrm{N}=6)\end{array}$ & $\begin{array}{c}\text { Proximal } \\
(\mathrm{N}=6)\end{array}$ & $\begin{array}{l}\text { Distal } \\
(\mathrm{N}=6)\end{array}$ \\
\hline Dimensões Fasciculares & & & & \\
\hline Área fascicular total $\left(\mu \mathrm{m}^{2}\right)$ & $59517 \pm 16266,04$ & $43283 \pm 15699,47$ & $62360 \pm 7409,74$ & $38461 \pm 22288,88$ \\
\hline $\begin{array}{l}\text { Diâmetro mínimo fascicular } \\
(\mu \mathrm{m})\end{array}$ & $235 \pm 62,91$ & $155 \pm 57,24$ & $247 \pm 11,95$ & $140 \pm 34,30$ \\
\hline Número de fibras mielínicas & $912 \pm 283,25$ & $785 \pm 218,98$ & $1038 \pm 140,59$ & $662 \pm 327,68$ \\
\hline $\begin{array}{l}\text { Densidade de fibras mielínicas } \\
\text { (fibras } / \mathrm{mm}^{2} \text { ) }\end{array}$ & $15330 \pm 1574,03$ & $18752 \pm 3520,43$ & $16694 \pm 1677,22$ & $18167 \pm 2469,15$ \\
\hline
\end{tabular}

Comparando os valores obtidos, não foram observadas diferenças significativas tanto entre segmentos do mesmo lado (proximal x distal) quanto entre lados para os mesmos segmentos (proximal direito $\mathrm{x}$ proximal esquerdo) para nenhum dos parâmetros acima descritos.

\subsubsection{Animais do Grupo III - 720 dias de vida}

A área fascicular total do nervo safeno dos animais do Grupo III, no segmento proximal do lado direito, variou entre 20622 e 64274,3 $\mu^{2}$, com média de 45025,63 \pm 14565,06 $\mu^{2}$; no segmento distal, variou entre 16004,96 e $75532 \mu \mathrm{m}^{2}$, com média de $44204,18 \pm 23558 \mu^{2}$. No lado esquerdo, segmento proximal, essa área variou entre

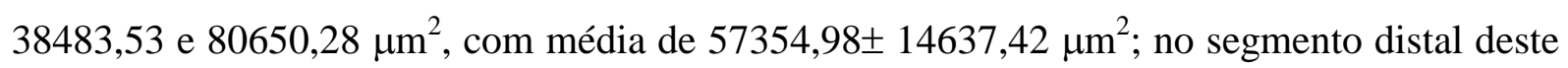
mesmo lado, variou entre 40327,73 e 114387,1 $\mu \mathrm{m}^{2}$, com média de $61879,45 \pm 27076,0 \mu^{2}$.

O diâmetro mínimo do fascículo do nervo safeno dos animais do Grupo III, no segmento proximal do lado direito, variou entre 94,34 e 119,88 $\mu \mathrm{m}$, com média de 151,93 \pm 47,70 $\mu \mathrm{m}$; no segmento distal do lado direito, variou entre 94,34 e 119,88 $\mu \mathrm{m}$, com média de $151,93 \pm 47,70 \mu \mathrm{m}$. No segmento proximal do lado esquerdo, variou entre 123,37 e 267,61 $\mu \mathrm{m}$, com média de $176,25 \pm 52,33 \mu \mathrm{m}$; no segmento distal desse mesmo lado, variou entre 142,06 e $266,75 \mu \mathrm{m}$, com média de 176,66 $\pm 50,22 \mu \mathrm{m}$. 
O número de fibras mielínicas do nervo safeno dos animais do Grupo III do lado direito, no segmento proximal, variou entre 397 e 962, com média de $603 \pm 299,45$; no segmento distal, variou de 160 e 916, com média de $490 \pm 319$. Para os nervos safenos do lado esquerdo, no segmento proximal, o número de fibras variou entre 371 e 1135, com média de 746,67 $\pm 261,92$; no segmento distal deste mesmo lado variou entre 353 e 1087, com média de 700,67 $\pm 238,30$.

A densidade das fibras mielínicas do nervo safeno dos animais do Grupo III, do lado direito, no segmento proximal, variou entre 8312,47 e 18888,36 fibras $/ \mathrm{mm}^{2}$, com média de $13025,05 \pm 4737,87$ fibras $/ \mathrm{mm}^{2}$; no segmento distal variou entre 6177 e 16244 fibras $/ \mathrm{mm}^{2}$, com média de 18752,73 $\pm 3520,43$. Nos nervos safenos do lado esquerdo, no segmento proximal, variou entre 7082,69 e 24493,14 fibras $/ \mathrm{mm}^{2}$, com média de 14068,95 \pm 7987,94 fibras $/ \mathrm{mm}^{2}$; no segmento distal desse mesmo lado, variou entre 6032,14 e 17512,97 fibras $/ \mathrm{mm}^{2}$, com média de 12495,44 $\pm 5270,03$ fibras $/ \mathrm{mm}^{2}$.

Tabela 3- Parâmetros morfométricos fasciculares dos nervos safenos dos animais do Grupo III (720 dias). Valores expressos em média \pm DPM. $\mathrm{N}=$ número de animais analisados.

\begin{tabular}{lcccc}
\hline & \multicolumn{2}{c}{ Lado Direito } & \multicolumn{2}{c}{ Lado Esquerdo } \\
\cline { 2 - 5 } & Proximal & Distal & Proximal & Distal \\
& $(\mathbf{N}=\mathbf{6})$ & $(\mathbf{N}=\mathbf{6})$ & $(\mathbf{N}=\mathbf{6})$ & $(\mathbf{N = 6 )}$ \\
\hline Dimensões Fasciculares & & & & \\
Área fascicular total $\left(\mu \mathrm{m}^{2}\right)$ & $45025 \pm 14565$ & $44204 \pm 23558$ & $57354 \pm 14637$ & $61879 \pm 27076$ \\
Diâmetro mínimo fascicular $(\mu \mathrm{m})$ & $151 \pm 47$ & $164 \pm 62$ & $176 \pm 52$ & $176 \pm 50$ \\
Número de fibras mielínicas & $603 \pm 299$ & $490 \pm 319$ & $746 \pm 261$ & $700 \pm 238$ \\
Densidade de fibras mielínicas (fibras $\left./ \mathrm{mm}^{2}\right)$ & $13025 \pm 4737$ & $11028 \pm 4027$ & $14068 \pm 7987$ & $12495 \pm 5270$ \\
\hline
\end{tabular}

Comparando os valores obtidos, não foram observadas diferenças significativas tanto entre segmentos do mesmo lado (proximal x distal) quanto entre lados para os mesmos segmentos (proximal direito $\mathrm{x}$ proximal esquerdo) para nenhum dos parâmetros acima descritos. 


\subsubsection{Comparação entre os diferentes grupos}

Ao compararmos os parâmetros morfométricos fasciculares dos nervos safenos, entre os grupos experimentais estudados, foram observadas diferenças significativas nos seguintes parâmetros: diâmetro fascicular, no Grupo III,720 dias, segmento proximal direito, em relação ao Grupo II, 360 dias, segmento proximal direito, sendo que esse parâmetro se apresentou menor no Grupo III. O mesmo parâmetro teve diferença significativa para o Grupo III, 720 dias, segmento proximal esquerdo, em relação ao Grupo II, 360 dias, para o segmento proximal esquerdo. O que foi observado é que o diâmetro fascicular para o Grupo III, 720 dias é menor do que para o Grupo II, 360 dias. Outro parâmetro com diferença significativa foi a densidade das fibras. A diferença foi observada no Grupo III, 720 dias, segmento proximal direito, em relação ao Grupo I, 180 dias, segmento proximal direito. O que foi observado é que a densidade das fibras do grupo III é menor em relação ao Grupo I, 180 dias. A diferença significativa para a densidade das fibras também foi observada no Grupo III, 720 dias, segmento distal direito, em relação ao Grupo I, 180 dias, segmento distal direito. Observou-se uma diminuição da densidade das fibras para o Grupo III, 720 dias. Os outros parâmetros não foram observadas diferenças significativas entre os segmentos e nem entre os lados (figuras 15 à 18). 


\section{Área fascicular total: comparação entre os grupos}

PROXIMAL DIREITO

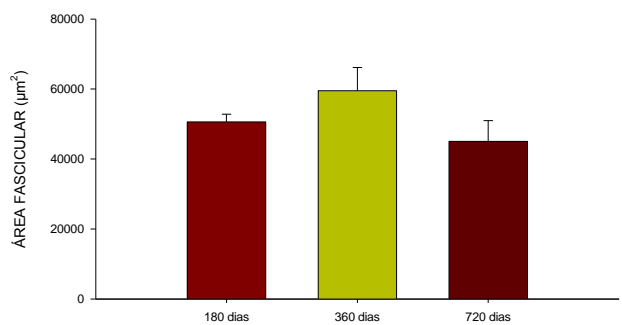

DISTAL DIREITO

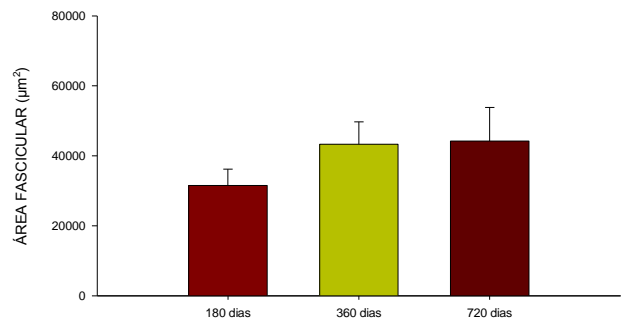

PROXIMAL ESQUERDO

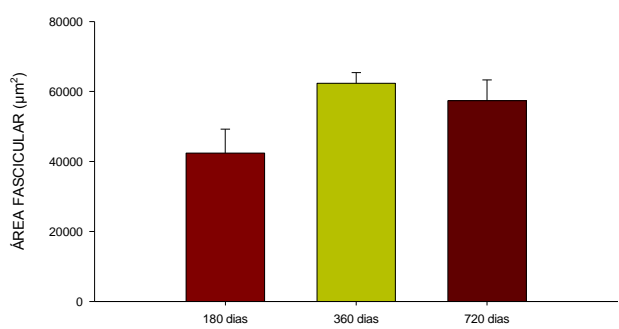

DISTAL ESQUERDO

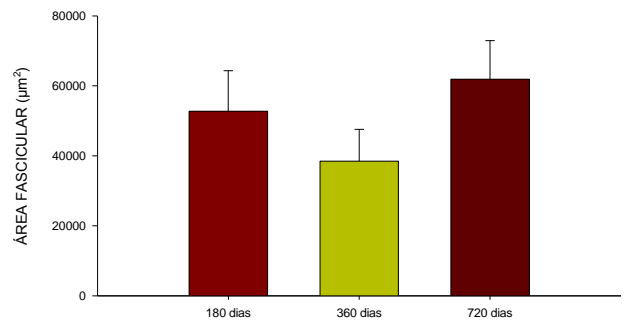

Figura 15: Área fascicular total dos nervos safenos de animais do Grupo I (180 dias - vermelho), Grupo II (360dias-verde, Grupo III (720 dia -marrom): comparação entre os grupos, lados e segmentos. Notar que não houve diferença significativa nas comparações intra-grupo (segmentos e lados) bem como nas comparações entre os grupos. 


\section{Diâmetro mínimo fascicular total: comparação entre os grupos}

PROXIMAL DIREITO

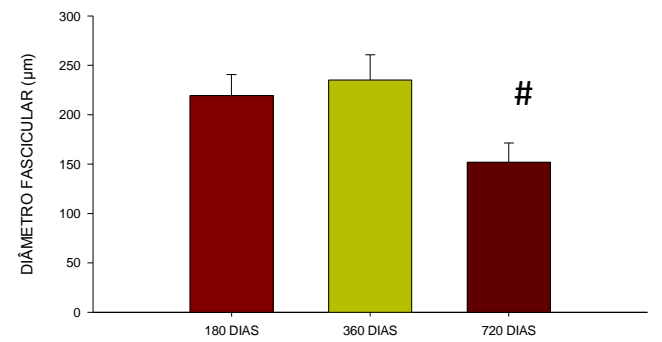

DISTAL DIREITO

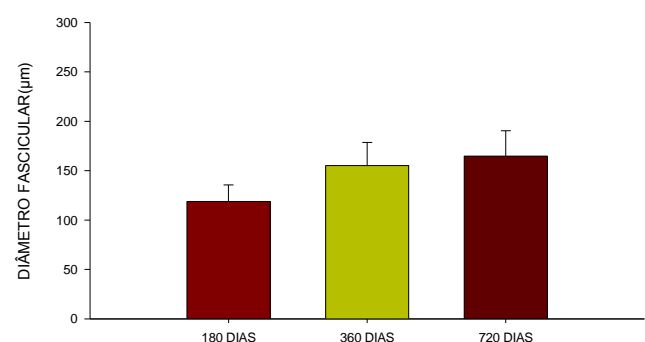

PROXIMAL ESQUERDO

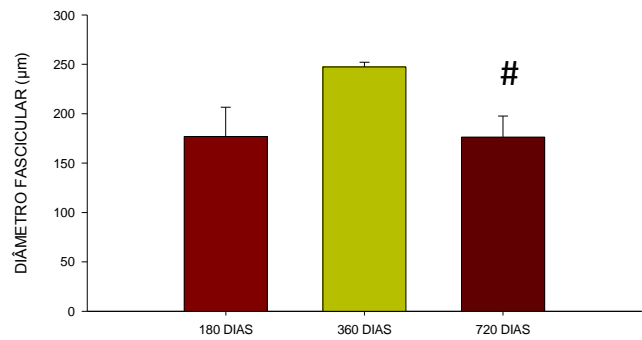

DISTAL ESQUERDO

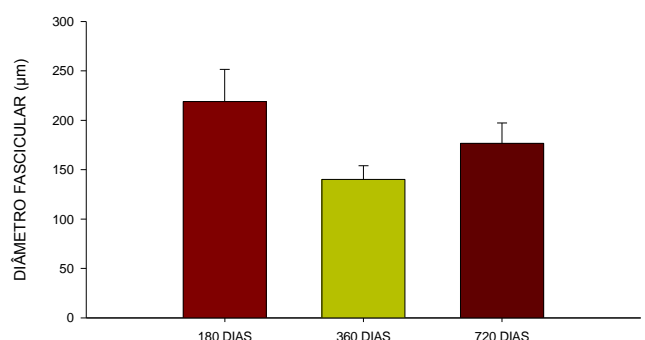

Figura 16: Diâmetro mínimo fascicular dos nervos safenos de animais do Grupo I (180 dias - vermelho), Grupo II (360dias - verde), Grupo III (720 dias - marrom): comparação entre os grupos, lados e segmentos. Notar a diferença significativa no segmento proximal direito e proximal esquerdo para a idade 720 (\#) comparado com 360 dias. 


\section{Número de fibras mielínicas: comparação entre os grupos}
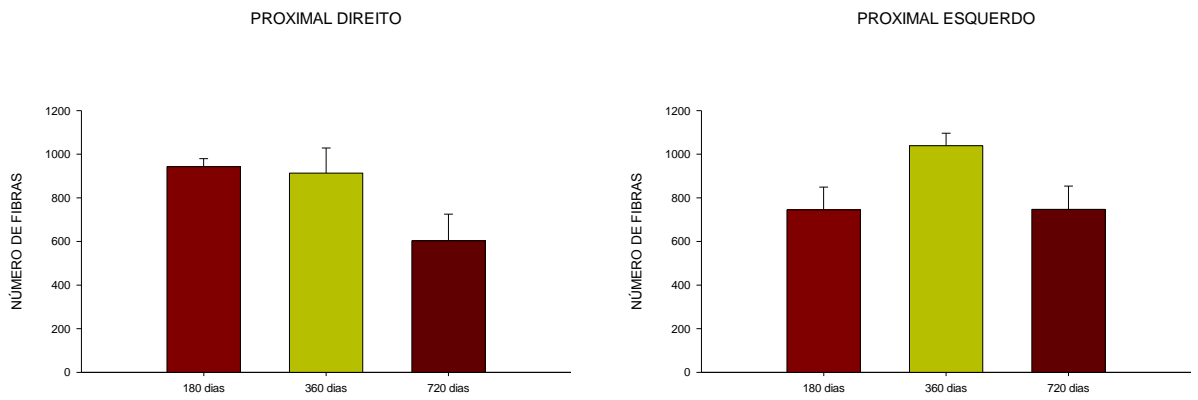

DISTAL DIREITO

DISTAL ESQUERDO
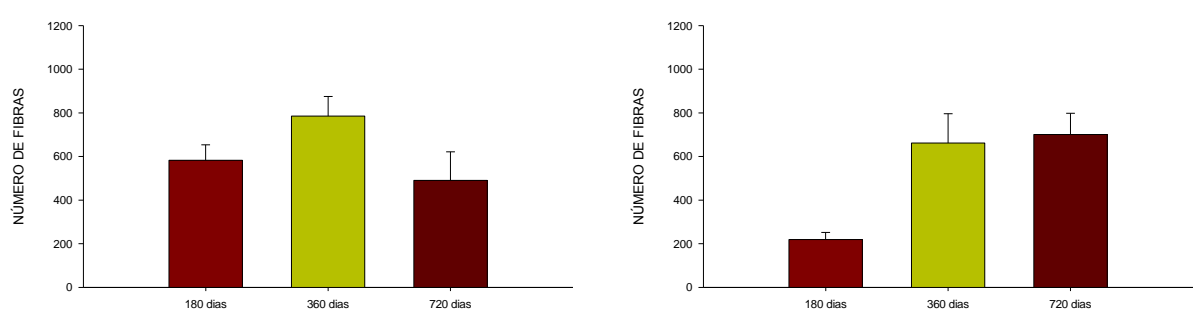

Figura 17: Número total de fibras mielínicas dos nervos safenos de animais do Grupo I (180 dias - vermelho), Grupo II (360 dias - verde), Grupo III (720 dias - marrom): comparação entre os grupos, lados e segmentos. Notar que não houve diferença significativa nas comparações intra-grupo (segmentos e lados) bem como nas comparações entre os grupos. 


\section{Densidade das fibras mielínicas: comparação entre os grupos}

PROXIMAL DIREITO

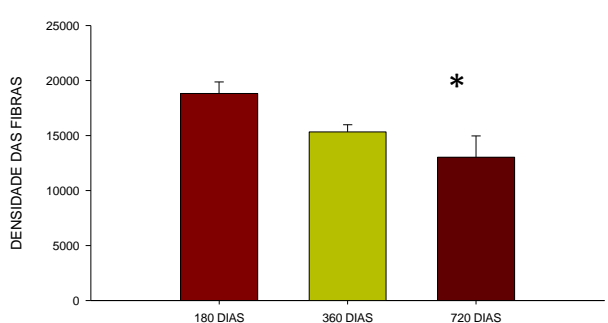

DISTAL DIREITO

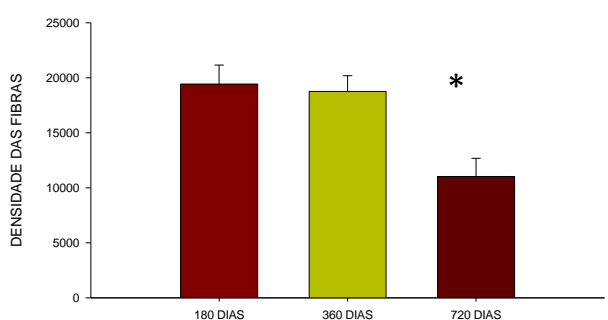

PROXIMAL ESQUERDO

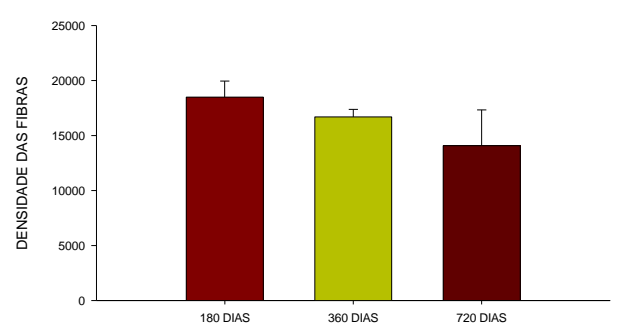

DISTAL ESQUERDO

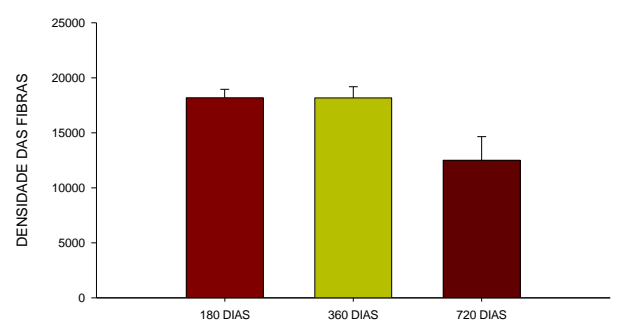

Figura 18: Densidade das fibras mielínicas dos nervos safenos de animais do Grupo I (180 dias - vermelho), Grupo II (360dias - verde), Grupo III (720 dias - marrom): comparação entre os grupos, lados e segmentos. Notar a diferença significativa no segmento proximal direito e distal direito para a idade 720 (*) comparado com 180 dias.

\subsubsection{Morfometria das Fibras Mielínicas}

As médias dos dados da morfometria das fibras mielínicas e dos axônios mielinizados (área da fibra, diâmetro mínimo da fibra, razão G, área da bainha de mielina, área do axônio e diâmetro mínimo do axônio) dos nervos safenos dos diferentes grupos experimentais estão demonstradas nas tabelas 4, 5 e 6 . Os dados individuais estão representados nas tabelas em anexo.

\subsubsection{Animais do Grupo I - 180 dias de vida}

A área média das fibras mielínicas do nervo safeno dos animais do Grupo I, do lado direito, no segmento proximal variou entre 23,12 e $31,71 \mu \mathrm{m}^{2}$, com média de $28,39 \pm 3,09$ $\mu \mathrm{m}^{2}$; no segmento distal variou entre 21,31 e $30,85 \mu \mathrm{m}^{2}$, com média de $26,85 \pm 4,78 \mu \mathrm{m}^{2}$. No lado esquerdo, segmento proximal, a área média das fibras mielínicas, variou entre 19,65 e 
29,72 $\mu \mathrm{m}^{2}$, com média de $24,47 \pm 4,29 \mu \mathrm{m}^{2}$; no segmento distal, essa área variou entre 19,96 e 43,51 $\mathrm{m}^{2}$, com média de $27,91 \pm 8,19 \mu \mathrm{m}^{2}$.

O diâmetro mínimo médio das fibras mielínicas do nervo safeno dos animais do Grupo I, do lado direito, segmento proximal, variou entre 4,5 e 5,42 $\mu \mathrm{m}$, com média de 5,05 \pm $0,33 \mu \mathrm{m}$; no segmento distal variou entre 4,52 e 5,68 $\mu \mathrm{m}$, com média de 5,01 $\pm 0,46 \mu \mathrm{m}$. No segmento proximal do lado esquerdo, o diâmetro mínimo médio das fibras mielínicas variou entre 4,39 e 5,20 $\mu \mathrm{m}$, com média de 4,81 $\pm 0,32 \mu \mathrm{m}$; no segmento distal desse mesmo lado, variou entre 4,36 e 6,51 $\mu \mathrm{m}$, com média de 5,12 $\pm 0,74 \mu \mathrm{m}$.

A área média da bainha de mielina das fibras mielínicas do nervo safeno dos animais do Grupo I, no segmento proximal, lado direito, variou entre 18,37 e 24,10 $\mu \mathrm{m}^{2}$, com média de 22,57 $\pm 2,21 \mu^{2}$; no segmento distal deste mesmo lado variou entre 14,79 e 25,01 $\mu^{2}$, com média de $20,36 \pm 4,83 \mu \mathrm{m}^{2}$. No segmento proximal do lado esquerdo, a área média da bainha de mielina das fibras mielínicas dos nervos safenos variou entre 14,17 e 21,92 $\mu^{2}$, com média de $17,25 \pm 2,55 \mu \mathrm{m}^{2}$; no segmento distal variou entre 36,94 e $17,69 \mu \mathrm{m}^{2}$, com média de $20,61 \pm 8,31 \mu \mathrm{m}^{2}$.

A área média dos axônios mielinizados do nervo safeno dos animais do Grupo I, lado direito, segmento proximal, variou entre 3,98 e $7,69 \mu \mathrm{m}^{2}$, com média de 5,82 $\pm 1,34 \mu \mathrm{m}^{2}$; no segmento distal deste mesmo lado, variou entre 5,57 e 7,96 $\mu^{2}$, com média de 6,49 $\pm 0,86$ $\mu \mathrm{m}^{2}$. No lado esquerdo, a área média dos axônios mielinizados, no segmento proximal, variou entre 3,83 e $12,38 \mu \mathrm{m}^{2}$, com média de $7,23 \pm 2,89 \mu \mathrm{m}^{2}$; no segmento distal variou entre 5,65 e $10,27 \mu \mathrm{m}^{2}$, com média de $7,28 \pm 1,90 \mu \mathrm{m}^{2}$.

O diâmetro mínimo médio dos axônios mielinizados do nervo safeno, dos animais do Grupo I, lado direito, segmento proximal, variou entre 1,58 e 2,44 $\mu \mathrm{m}$, com média de 2,05 \pm $0,31 \mu \mathrm{m}$; no segmento distal variou entre 1,82 e $2,37 \mu \mathrm{m}$, com média de $2,22 \pm 0,20 \mu \mathrm{m}$. No segmento proximal do lado esquerdo, o diâmetro mínimo médio dos axônios mielinizados variou entre 1,74 e 3,16 $\mu \mathrm{m}$, com média de 2,37 $\pm 0,46 \mu \mathrm{m}$; no segmento distal desse mesmo lado, variou entre 2,11 e $2,88 \mu \mathrm{m}$, com média de $2,38 \pm 0,31 \mu \mathrm{m}$.

A razão $\mathrm{G}$ média das fibras mielínicas do nervo safeno dos animais do Grupo I, do lado direito, segmento proximal, variou entre 0,34 e 0,46, com média de 0,42 $\pm 0,04$; no segmento distal variou entre 0,36 e 0,51 , com média de $0,46 \pm 0,06$. Do lado esquerdo, no segmento proximal, a razão G média das fibras mielínicas do nervo safeno variou entre 0,39 e 0,60 , com média de $0,49 \pm 0,07$; no segmento distal, essa razão variou entre 0,33 e 0,55 , com média de 0,47 $\pm 0,08$. 
Tabela 4- Parâmetros morfométricos das fibras mielínicas e dos axônios dos nervos safenos de ratas Wistar com 180 dias de vida. Valores expressos em média \pm DPM. $\mathrm{N}=$ número de animais analisados.

\begin{tabular}{lcccc}
\hline & \multicolumn{2}{c}{ Lado Direito } & \multicolumn{2}{c}{ Lado Esquerdo } \\
\cline { 2 - 5 } & $\begin{array}{c}\text { Proximal } \\
(\mathbf{N}=\mathbf{6})\end{array}$ & $\begin{array}{c}\text { Distal } \\
(\mathbf{N}=\mathbf{6})\end{array}$ & $\begin{array}{c}\text { Proximal } \\
(\mathbf{N}=\mathbf{6})\end{array}$ & $\begin{array}{c}\text { Distal } \\
(\mathbf{N}=\mathbf{6})\end{array}$ \\
\hline Fibras Mielínicas & & & & \\
Área $\left(\mu \mathrm{m}^{2}\right)$ & $28,39 \pm 3,09$ & $26,85 \pm 4,78$ & $24,47 \pm 4,29$ & $27,91 \pm 8,19$ \\
Diâmetro mínimo $(\mu \mathrm{m})$ & $5,05 \pm 0,33$ & $5,01 \pm 0,46$ & $4,81 \pm 0,32$ & $5,12 \pm 0,74$ \\
Razão G & $0,42 \pm 0,04$ & $0,46 \pm 0,06$ & 0,39 e 0,60 & $0,47 \pm 0,08$ \\
Área da bainha de mielina $\left(\mu \mathrm{m}^{2}\right)$ & $22,57 \pm 2,21$ & $20,36 \pm 4,83$ & $17,25 \pm 2,55$ & $20,61 \pm 8,31$ \\
Axônios Mielinizados & & & & \\
Área do Axônio & $5,82 \pm 1,34$ & $6,49 \pm 0,86$ & $7,23 \pm 2,89$ & $7,28 \pm 1,90$ \\
Diâmetro do Axônio & $2,05 \pm 0,31$ & $2,22 \pm 0,20$ & $2,37 \pm 0,46$ & $2,38 \pm 0,31$ \\
\hline
\end{tabular}

Comparando os valores obtidos, não foram observadas diferenças significativas tanto entre segmentos do mesmo lado (proximal $\mathrm{x}$ distal) quanto entre lados para os mesmos segmentos (proximal direito $\mathrm{x}$ proximal esquerdo) para nenhum dos parâmetros acima descritos.

\subsubsection{Animais do Grupo II - 360 dias de vida}

A área média das fibras mielínicas do nervo safeno dos animais do Grupo II, do lado direito, no segmento proximal variou entre 30,88 e 45,21 $\mu^{2}$, com média de 35,37 $\pm 5,41$ $\mu \mathrm{m}^{2}$; no segmento distal variou entre 25,90 e $41,87 \mu \mathrm{m}^{2}$, com média de $34,87 \pm 6,59 \mu \mathrm{m}^{2}$. No lado esquerdo, segmento proximal, a área média das fibras mielínicas, variou entre 29,64 e $43,25 \mu \mathrm{m}^{2}$, com média de $35,51 \pm 4,81 \mu \mathrm{m}^{2}$; no segmento distal, essa área variou entre 27,19 e $33,19 \mu \mathrm{m}^{2}$, com média de $31,30 \pm 2,93 \mu \mathrm{m}^{2}$.

O diâmetro mínimo médio das fibras mielínicas do nervo safeno dos animais do Grupo II, do lado direito, segmento proximal, variou entre 5,15 e 6,37 $\mu \mathrm{m}$, com média de 5,70 $\pm 0,39 \mu \mathrm{m}$; no segmento distal variou entre 4,89 e 6,52 $\mu \mathrm{m}$, com média de 5,67 $\pm 0,54 \mu \mathrm{m}$. No segmento proximal do lado esquerdo, o diâmetro mínimo médio das fibras mielínicas variou entre 5,29 e 6,42 $\mu \mathrm{m}$, com média de 5,73 $\pm 0,42 \mu \mathrm{m}$; no segmento distal desse mesmo lado, variou entre 5,03 e 5,89 $\mu \mathrm{m}$, com média de 5,41 $\pm 0,30 \mu \mathrm{m}$. 
A área média da bainha de mielina das fibras mielínicas do nervo safeno dos animais do Grupo II, no segmento proximal, lado direito, variou entre 21,89 e 33,30 $\mu \mathrm{m}^{2}$, com média de $25,71 \pm 4,47 \mu^{2}$; no segmento distal deste mesmo lado variou entre 16,52 e $31,11 \mu^{2}$, com média de $24,82 \pm 5,78 \mu \mathrm{m}^{2}$. No segmento proximal do lado esquerdo, a área média da bainha de mielina das fibras mielínicas dos nervos safenos variou entre 21,83 e $34,88 \mu \mathrm{m}^{2}$, com média de $26,36 \pm 5,12 \mu \mathrm{m}^{2}$; no segmento distal variou entre 18,73 e $26,92 \mu \mathrm{m}^{2}$, com média de $22,54 \pm 3,17 \mu \mathrm{m}^{2}$.

A área média dos axônios mielinizados do nervo safeno dos animais do Grupo II, lado direito, segmento proximal, variou entre 8,13 e $11,93 \mu^{2}$, com média de 9,63 $\pm 1,47$ $\mu \mathrm{m}^{2}$; no segmento distal deste mesmo lado, variou entre 6,78 e $15,29 \mu^{2}$, com média de $10,03 \pm 3,34 \mu \mathrm{m}^{2}$. No lado esquerdo, a área média dos axônios mielinizados, no segmento proximal, variou entre 6,90 e $12,02 \mu \mathrm{m}^{2}$, com média de $9,13 \pm 1,76 \mu \mathrm{m}^{2}$; no segmento distal variou entre 7,11 e $10,88 \mu \mathrm{m}^{2}$, com média de $8,76 \pm 1,22 \mu \mathrm{m}^{2}$.

O diâmetro mínimo médio dos axônios mielinizados do nervo safeno, dos animais do Grupo II, lado direito, segmento proximal, variou entre 2,47 e 3,07 $\mu \mathrm{m}$, com média de 2,75 \pm $0,26 \mu \mathrm{m}$; no segmento distal variou entre 2,19 e 3,71 $\mu \mathrm{m}$, com média de 2,79 $\pm 0,58 \mu \mathrm{m}$. No segmento proximal do lado esquerdo, o diâmetro mínimo médio dos axônios mielinizados variou entre 2,36 e 3,10 $\mu \mathrm{m}$, com média de 2,65 $\pm 0,27 \mu \mathrm{m}$; no segmento distal desse mesmo lado, variou entre 2,23 e 3,25 $\mu \mathrm{m}$, com média de $2,64 \pm 0,34 \mu \mathrm{m}$.

A razão $\mathrm{G}$ média das fibras mielínicas do nervo safeno dos animais do Grupo II, do lado direito, segmento proximal, variou entre 0,44 e 0,54 , com média de 0,49 $\pm 0,03$; no segmento distal variou entre 0,40 e 0,61 , com média de $0,50 \pm 0,08$. Do lado esquerdo, no segmento proximal, a razão $\mathrm{G}$ média das fibras mielínicas do nervo safeno variou entre 0,40 e 0,55 , com média de $0,48 \pm 0,05$; no segmento distal, essa razão variou entre 0,43 e 0,57 , com média de $0,50 \pm 0,05$. 
Tabela 5- Parâmetros morfométricos das fibras mielínicas e dos axônios dos nervos safenos de ratas Wistar com 360 dias de vida. Valores expressos em média \pm DPM. $\mathrm{N}=$ número de animais analisados.

\begin{tabular}{lcccc}
\hline & \multicolumn{2}{c}{ Lado Direito } & \multicolumn{2}{c}{ Lado Esquerdo } \\
\cline { 2 - 5 } & $\begin{array}{c}\text { Proximal } \\
(\mathbf{N}=\mathbf{6})\end{array}$ & $\begin{array}{c}\text { Distal } \\
(\mathbf{N}=\mathbf{6})\end{array}$ & $\begin{array}{c}\text { Proximal } \\
(\mathbf{N}=\mathbf{6})\end{array}$ & $\begin{array}{c}\text { Distal } \\
(\mathbf{N}=\mathbf{6})\end{array}$ \\
\hline Fibras Mielínicas & & & & \\
Área $\left(\mu \mathrm{m}^{2}\right)$ & $35,37 \pm 5,41$ & $34,87 \pm 6,59$ & $35,51 \pm 4,81$ & $31,30 \pm 2,93$ \\
Diâmetro mínimo $(\mu \mathrm{m})$ & $5,7 \pm 0,39$ & $5,67 \pm 0,54$ & $5,73 \pm 0,42$ & $5,41 \pm 0,12$ \\
Razão G & $0,49 \pm 0,01$ & $0,50 \pm 0,03$ & $0,48 \pm 0,02$ & $0,50 \pm 0,30$ \\
Área da bainha de mielina $\left(\mu \mathrm{m}^{2}\right)$ & $25,71 \pm 4,47$ & $24,82 \pm 5,78$ & $26,36 \pm 5,12$ & $22,54 \pm 3,17$ \\
Axônios Mielinizados & & & & \\
Área do Axônio & $9,63 \pm 1,47$ & $10,03 \pm 3,34$ & $9,13 \pm 1,76$ & $8,76 \pm 1,22$ \\
Diâmetro do Axônio & $2,75 \pm 0,26$ & $2,79 \pm 0,58$ & $2,65 \pm 0,27$ & $2,64 \pm 0,34$ \\
\hline
\end{tabular}

\subsubsection{Animais do Grupo III - 720 dias de vida}

A área média das fibras mielínicas do nervo safeno dos animais do Grupo III, do lado direito, no segmento proximal variou entre 12,64 e $39,91 \mu \mathrm{m}^{2}$, com média de $28,58 \pm 12,23$ $\mu \mathrm{m}^{2}$; no segmento distal variou entre 16,34 e 41,26 $\mu \mathrm{m}^{2}$, com média de $29,88 \pm 10,53 \mu \mathrm{m}^{2}$. No lado esquerdo, segmento proximal, a área média das fibras mielínicas, variou entre 15,71 e $41,11 \mu \mathrm{m}^{2}$, com média de $27,69 \pm 12,02 \mu \mathrm{m}^{2}$; no segmento distal, essa área variou entre 12,21 e $40,19 \mu \mathrm{m}^{2}$, com média de $28,10 \pm 10,66 \mu \mathrm{m}^{2}$.

O diâmetro mínimo médio das fibras mielínicas do nervo safeno dos animais do Grupo III, do lado direito, segmento proximal, variou entre 3,49 e 5,94 $\mu \mathrm{m}$, com média de 5,01 \pm $1,14 \mu \mathrm{m}$; no segmento distal variou entre 4,03 e 5,96 $\mu \mathrm{m}$, com média de 5,11 $\pm 0,86 \mu \mathrm{m}$. No segmento proximal do lado esquerdo, o diâmetro mínimo médio das fibras mielínicas variou entre 3,87 e 6,03 $\mu \mathrm{m}$, com média de 4,95 $\pm 1,00 \mu \mathrm{m}$; no segmento distal desse mesmo lado, variou entre 3,38 e $6,10 \mu \mathrm{m}$, com média de 5,07 $\pm 1,03 \mu \mathrm{m}$. 
A área média da bainha de mielina das fibras mielínicas do nervo safeno dos animais do Grupo III, no segmento proximal, lado direito, variou entre 10,48 e 30,09 $\mu \mathrm{m}^{2}$, com média de $21,65 \pm 8,85 \mu \mathrm{m}^{2}$; no segmento distal deste mesmo lado variou entre 13,05 e $30,50 \mu \mathrm{m}^{2}$, com média de 22,94 $\pm 7,95 \mu \mathrm{m}^{2}$. No segmento proximal do lado esquerdo, a área média da bainha de mielina das fibras mielínicas dos nervos safenos variou entre 12,24 e 30,98 $\mu \mathrm{m}^{2}$, com média de 21,33 $\pm 9,09 \mu \mathrm{m}^{2}$; no segmento distal variou entre 10,06 e 29,15 $\mu^{2}$, com média de $21,79 \pm 7,19 \mu \mathrm{m}^{2}$

A área média dos axônios mielinizados do nervo safeno dos animais do Grupo III, lado direito, segmento proximal, variou entre 2,16 e $9,82 \mu \mathrm{m}^{2}$, com média de $6,93 \pm 3,43 \mu \mathrm{m}^{2}$; no segmento distal deste mesmo lado, variou entre 3,29 e 10,75 $\mu \mathrm{m}^{2}$, com média de 6,94 $\pm 2,84$ $\mu \mathrm{m}^{2}$. No lado esquerdo, a área média dos axônios mielinizados, no segmento proximal, variou entre 3,84 e $11,18 \mu \mathrm{m}^{2}$, com média de $6,36 \pm 3,12 \mu \mathrm{m}^{2}$; no segmento distal variou entre 2,15 e $11,03 \mu \mathrm{m}^{2}$, com média de $6,32 \pm 3,66 \mu \mathrm{m}^{2}$.

O diâmetro mínimo médio dos axônios mielinizados do nervo safeno, dos animais do Grupo III, lado direito, segmento proximal, variou entre 1,37 e 2,88 $\mu \mathrm{m}$, com média de 2,33 \pm $0,68 \mu \mathrm{m}$; no segmento distal variou entre 1,63 e 2,99 $\mu \mathrm{m}$, com média de 2,34 $\pm 0,53 \mu \mathrm{m}$. No segmento proximal do lado esquerdo, o diâmetro mínimo médio dos axônios mielinizados variou entre 1,74 e 3,10 $\mu \mathrm{m}$, com média de 2,26 \0,55 $\mu \mathrm{m}$; no segmento distal desse mesmo lado, variou entre 1,30 e $2,91 \mu \mathrm{m}$, com média de $2,21 \pm 0,75 \mu \mathrm{m}$.

A razão G média das fibras mielínicas do nervo safeno dos animais do Grupo III, do lado direito, segmento proximal, variou entre 0,39 e 0,50, com média de 0,46 \pm 0,04; no segmento distal variou entre 0,39 e 0,50 , com média de $0,45 \pm 0,05$. Do lado esquerdo, no segmento proximal, a razão G média das fibras mielínicas do nervo safeno variou entre 0,41 e 
0,50, com média de 0,45 \pm 0,04; no segmento distal, essa razão variou entre 0,32 e 0,49 , com média de $0,43 \pm 0,07$.

Tabela 6: Parâmetros morfométricos das fibras mielínicas e dos axônios dos nervos safenos de ratas Wistar com 720 dias de vida. Valores expressos em média \pm DPM. $\mathrm{N}=$ número de animais analisados.

\begin{tabular}{|c|c|c|c|c|}
\hline & \multicolumn{2}{|c|}{ Lado Direito } & \multicolumn{2}{|c|}{ Lado Esquerdo } \\
\hline & $\begin{array}{l}\text { Proximal } \\
\qquad(\mathrm{N}=6)\end{array}$ & $\begin{array}{l}\text { Distal } \\
(\mathrm{N}=6)\end{array}$ & $\begin{array}{l}\text { Proximal } \\
\qquad(\mathrm{N}=6)\end{array}$ & $\begin{array}{l}\text { Distal } \\
(\mathrm{N}=6)\end{array}$ \\
\hline \multicolumn{5}{|l|}{ Fibras Mielínicas } \\
\hline Área $\left(\mu \mathrm{m}^{2}\right)$ & $28,58 \pm 12,23$ & $29,88 \pm 10,53$ & $27,69 \pm 12,02$ & $28,10 \pm 10,66$ \\
\hline Diâmetro mínimo $(\mu \mathrm{m})$ & $5,01 \pm 1,14$ & $5,11 \pm 0,86$ & $4,95 \pm 1,00$ & $5,07 \pm 1,03$ \\
\hline Razão G & $0,46 \pm 0,04$ & $0,45 \pm 0,05$ & $0,45 \pm 0,04$ & $0,43 \pm 0,07$ \\
\hline Área da bainha de mielina $\left(\mu \mathrm{m}^{2}\right)$ & $21,65 \pm 8,85$ & $22,94 \pm 7,95$ & $21,33 \pm 9,09$ & $21,79 \pm 7,19$ \\
\hline \multicolumn{5}{|l|}{ Axônios Mielinizados } \\
\hline Área do Axônio & $6,93 \pm 3,43$ & $6,94 \pm 2,84$ & $6,36 \pm 3,12$ & $6,32 \pm 3,66$ \\
\hline Diâmetro do Axônio & $2,33 \pm 0,68$ & $2,34 \pm 0,53$ & $2,26 \pm 0,55$ & $2,21 \pm 0,75$ \\
\hline
\end{tabular}

Comparando os valores obtidos, não foram observadas diferenças significativas tanto entre segmentos do mesmo lado (proximal x distal) quanto entre lados para os mesmos segmentos (proximal direito $\mathrm{x}$ proximal esquerdo) para nenhum dos parâmetros acima descritos. 


\subsubsection{Comparação entre os diferentes grupos}

Ao compararmos os parâmetros morfométricos médios das fibras mielínicas dos nervos safenos, entre os grupos experimentais estudados, foram observadas diferenças significativas no parâmetro razão G, segmento proximal direito, 360 dias em relação á 180 dias, segmento proximal direito, sendo a razão G do Grupo II, 360 dias, maior do que a razão G do Grupo I, 180 dias. Houve também diferença significativa no parâmetro área do axônio, observada no Grupo II, 360 dias, segmento proximal direito, em relação ao Grupo I,180 dias, segmento proximal direito. E mais uma vez, no Grupo II, 360 dias, o parâmetro mostrou-se maior do que o grupo I, 180 dias. Não foram observadas diferenças significativas em nenhum dos segmentos ou lados estudados, para os outros parâmetros comparados (figuras 19 à 24).

\section{Área média das fibras mielínicas: comparação entre grupos}

PROXIMAL DIREITO

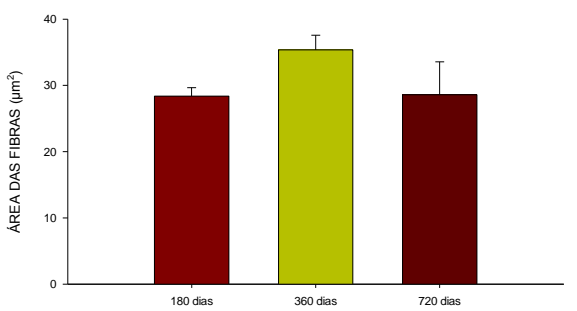

DISTAL DIREITO

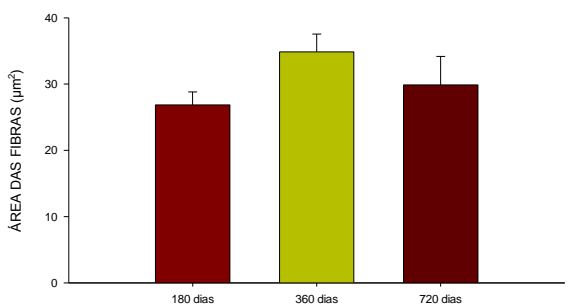

PROXIMAL ESQUERDO

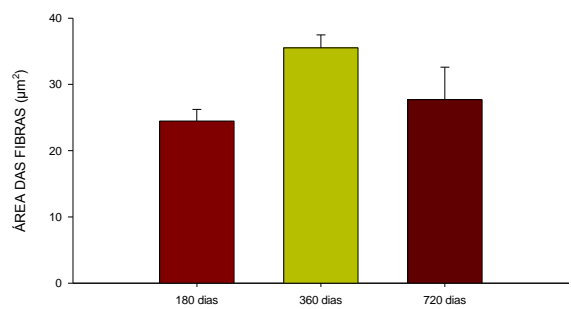

DISTAL ESQUERDO

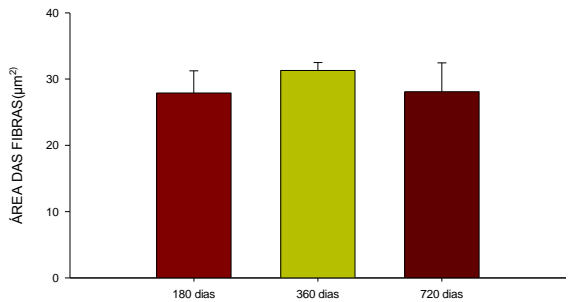

Figura 19: Área média das fibras mielínicas dos nervos safenos de animais dos grupos I (180 dias - vermelho), II (360 dias - verde), III (720 dias - marrom): comparação entre os grupos, lados e segmentos. Notar que não houve diferença significativa nas comparações intra-grupo (segmentos e lados) bem como nas comparações entre os grupos. 


\section{Diâmetro mínimo médio das fibras mielínicas: comparação entre grupos}

PROXIMAL DIREITO

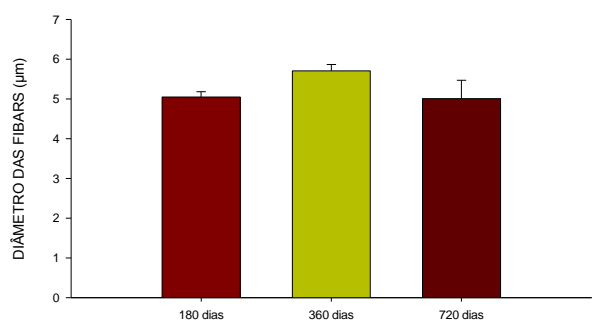

PROXIMAL ESQUERDO

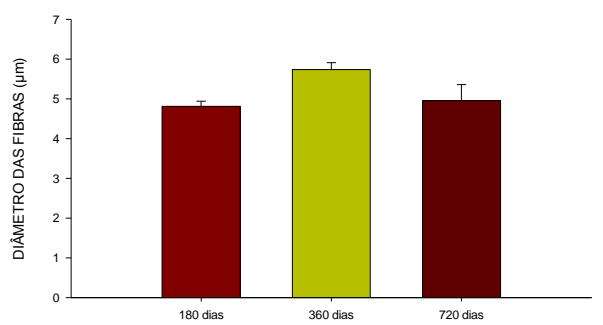

DISTAL DIREITO

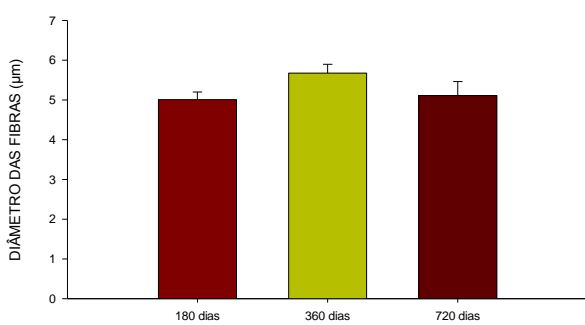

DISTAL ESQUERDO

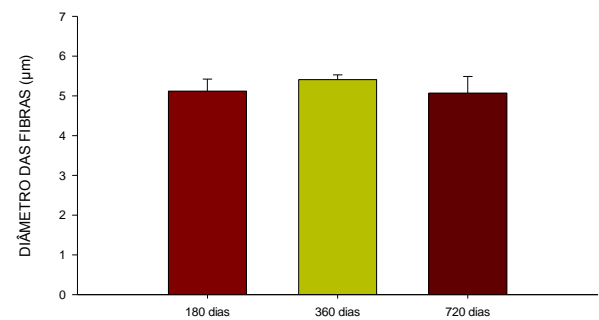

Figura 20: Diâmetro mínimo médio das fibras mielínicas dos nervos safenos de animais dos grupos I (180 dias vermelho), II (360 dias - verde), III (720 dias - marrom): comparação entre os grupos, lados e segmentos. Notar que não houve diferença significativa nas comparações intra-grupo (segmentos e lados) bem como nas comparações entre os grupos. 


\section{Área média das bainhas: comparação entre grupos}

PROXIMAL DIREITO

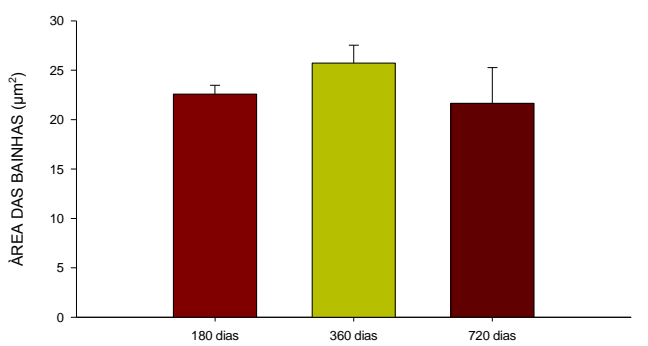

DISTAL DIREITO

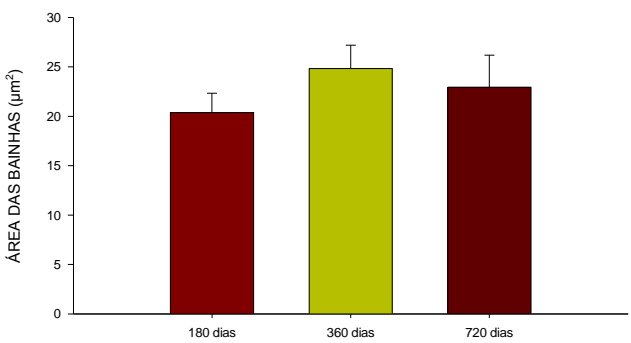

PROXIMAL ESQUERDO

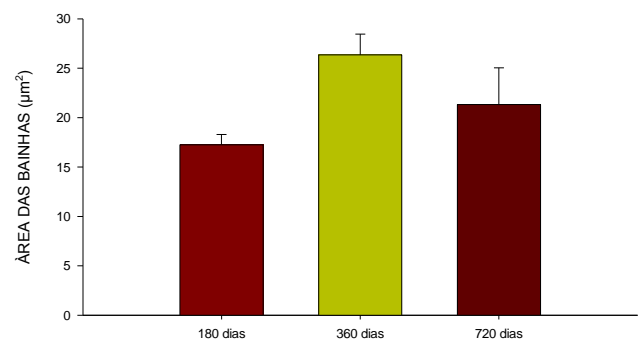

DISTAL ESQUERDO

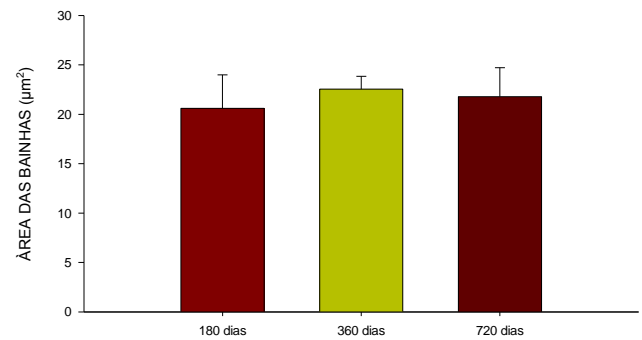

Figura 21: Área média da bainha de mielina das fibras mielínicas dos nervos safenos de animais dos grupos I (180 dias - vermelho), II (360 dias - verde), III (720 dias - marrom): comparação entre os grupos, lados e segmentos. Notar que não houve diferença significativa nas comparações intra-grupo (segmentos e lados) bem como nas comparações entre os grupos. 


\section{Área média do axônio mielinizado: comparação entre grupos}

PROXIMAL DIREITO

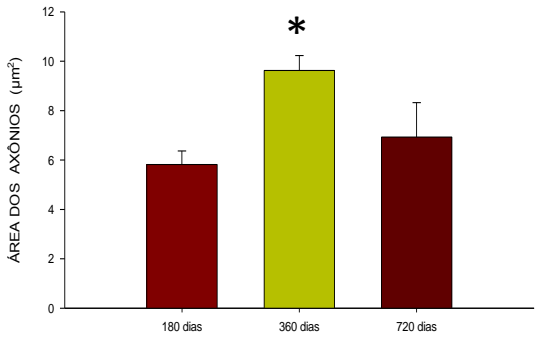

DISTAL DIREITO

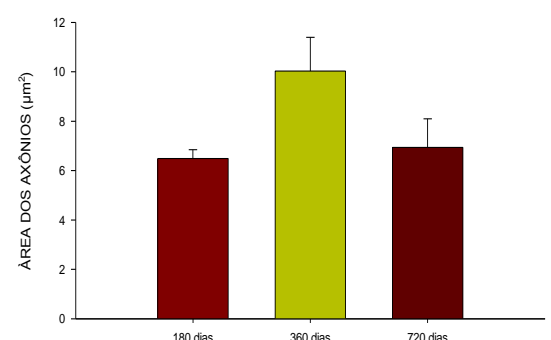

PROXIMAL ESQUERDO

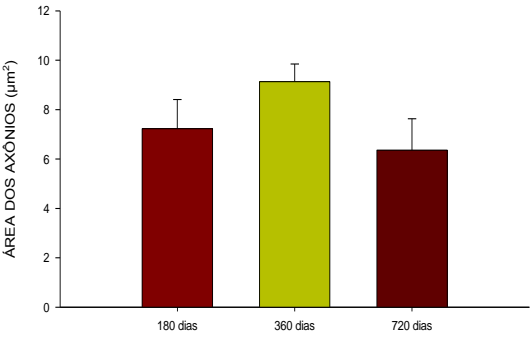

DISTAL ESQUERDO

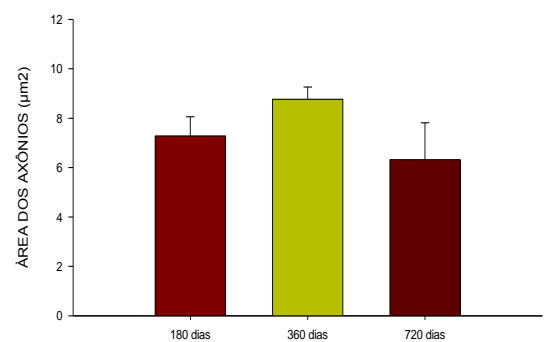

Figura 22: Área média dos axônios mielinizados dos nervos safenos de animais dos grupos I (180 dias vermelho), II (360 dias - verde), III (720 dias - marrom): comparação entre os grupos, lados e segmentos. Notar a diferença significativa no segmento proximal direito para a idade $360(*)$ comparado á 180 dias. 


\section{Diâmetro mínimo médio dos axônios mielinizados: comparação entre grupos}

PROXIMAL DIREITO

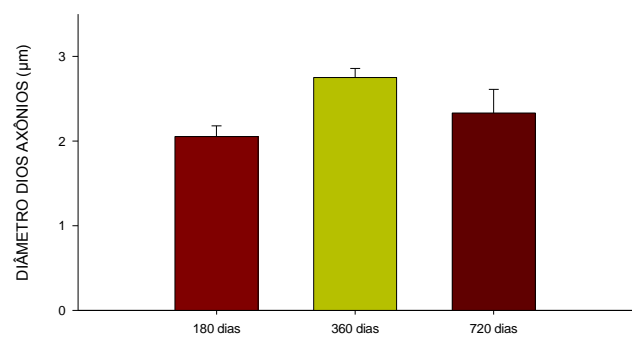

DISTAL DIREITO

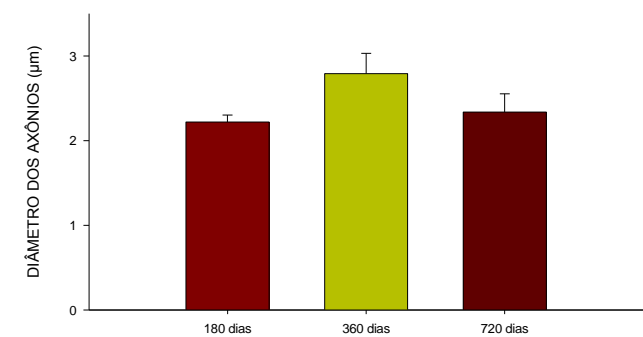

PROXIMAL ESQUERDO

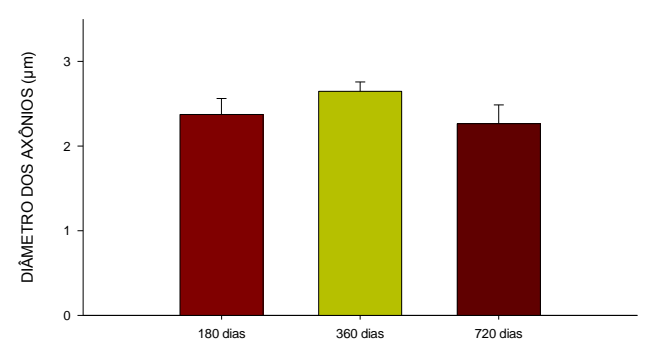

DISTAL ESQUERDO

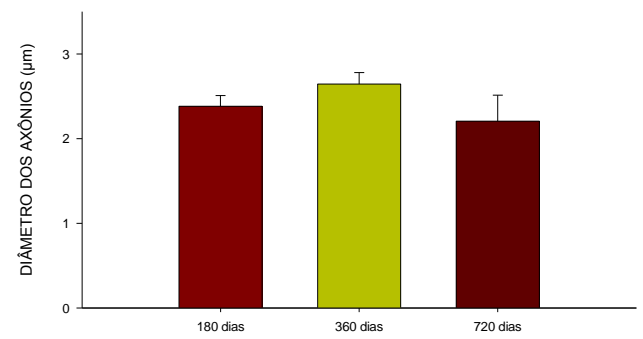

Figura 23: Diâmetro mínimo médio dos axônios das fibras mielínicas dos nervos safenos de animais dos grupos I (180 dias - vermelho), II (360 dias - verde), III (720 dias - marrom): comparação entre os grupos, lados e segmentos. Notar que não houve diferença significativa nas comparações intra-grupo (segmentos e lados) bem como nas comparações entre os grupos. 


\section{Razão G das fibras mielínicas: comparação entre grupos}
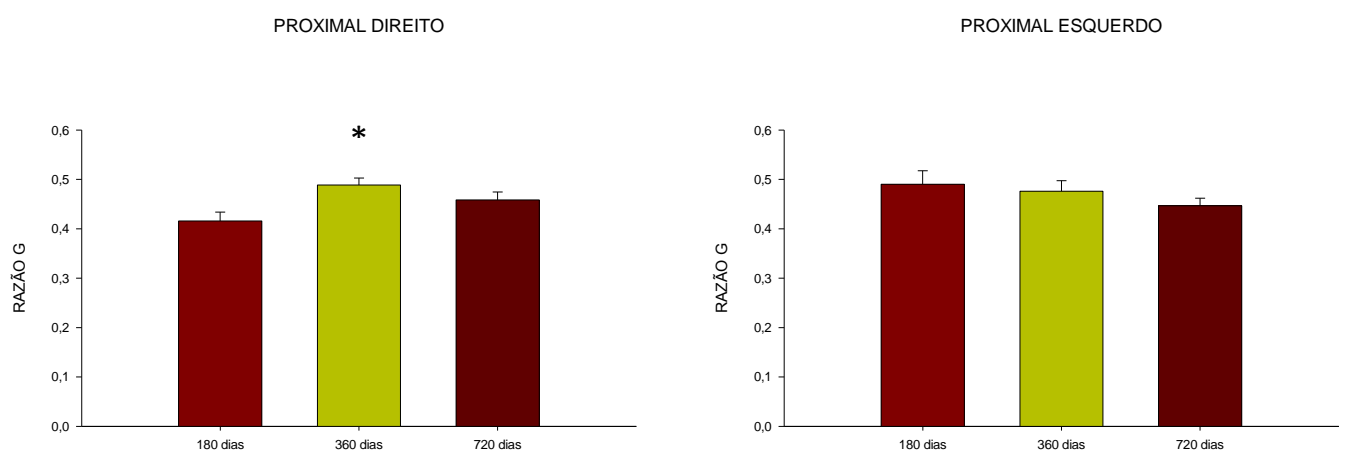

DISTAL DIREITO

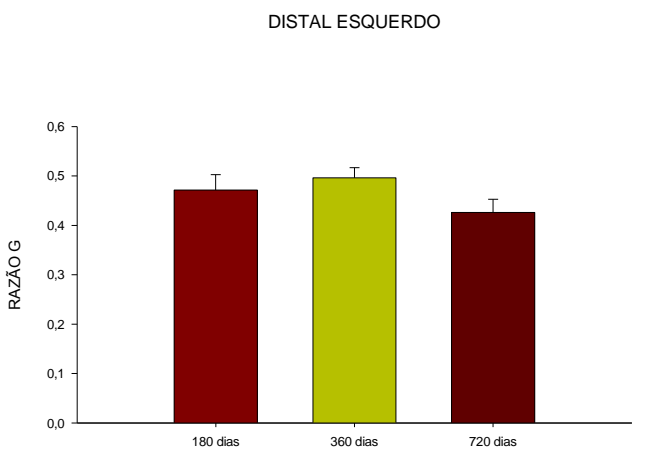

Figura 24: Razão G das fibras mielínicas dos safenos de animais dos grupos I (180 dias - vermelho), II (360 dias - verde), III (720 dias - marrom): comparação entre os grupos, lados e segmentos. Notar a diferença significativa no segmento proximal direito para a idade $360(*)$ comparado à 180 dias.

\subsection{Histogramas de Distribuição de Frequência do Diâmetro Mínimo das Fibras Mielínicas e seus Respectivos Axônios e da Razão G}

\subsubsection{Animais do Grupo I - 180 dias de vida}

O histograma de distribuição do diâmetro mínimo das fibras mielínicas dos nervos safenos direito, segmento proximal, dos ratos do Grupo I, mostrou-se unimodal, com o primeiro pico em $5 \mu \mathrm{m}$ de diâmetro. No segmento distal direito, essa distribuição foi unimodal, com o pico em $5 \mu \mathrm{m}$ de diâmetro. Do lado esquerdo, segmento proximal, essa distribuição mostrou-se bimodal, com o primeiro pico em 3,5 $\mu \mathrm{m}$ e o segundo pico em $6 \mu \mathrm{m}$ de diâmetro; no segmento distal desse mesmo lado, essa distribuição foi unimodal, com o pico em $4 \mu \mathrm{m}$ de diâmetro. 
A análise estatística não mostrou diferença significativa nas distribuições dos diâmetros das fibras mielínicas, nem entre segmentos, nem entre lados, nos animais do Grupo I.

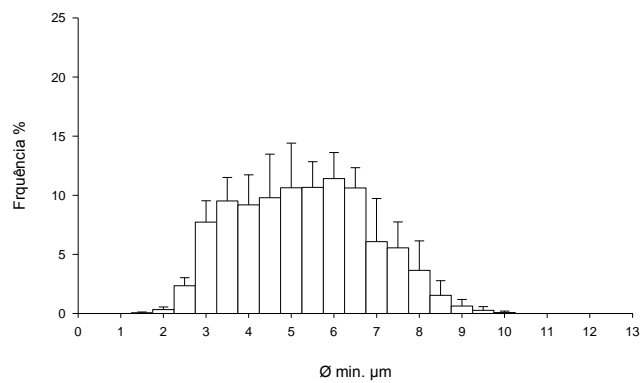

FIBRAS 180 DIAS DIREITO DISTAL

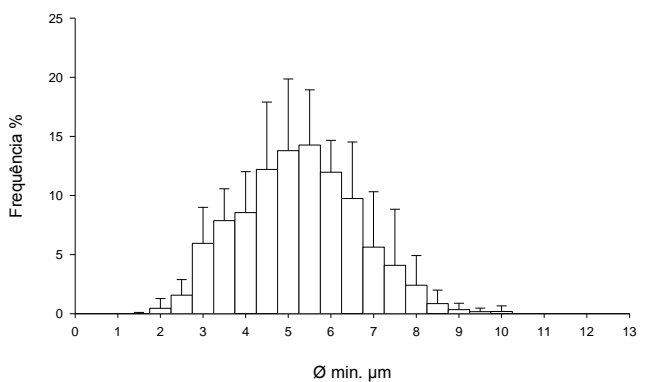

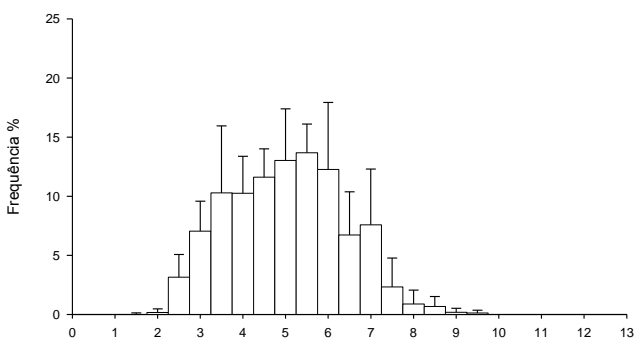

$\varnothing \min . \mu \mathrm{m}$

FIBRAS 180 DIAS ESQUERDO DISTAL

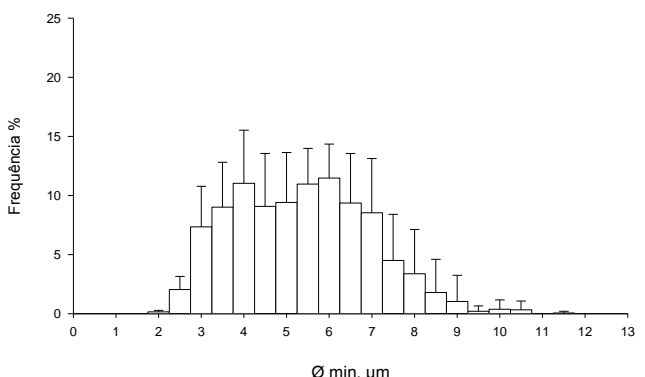

Figura 25: Histogramas de distribuição de frequência do diâmetro mínimo das fibras mielínicas dos nervos safenos de animais Wistar do Grupo I (180dias). Painel superior esquerdo: lado direito, segmento proximal. Painel superior direito: lado esquerdo, segmento proximal. Painel inferior esquerdo: lado direito segmento distal. Painel inferior direito: lado esquerdo segmento distal.

Os histogramas de distribuição do diâmetro mínimo dos axônios mielinizados dos nervos safenos direitos, segmento proximal, mostrou-se bimodal, com o primeiro pico em 0,5 $\mu \mathrm{m}$ e o segundo pico em $2 \mu \mathrm{m}$ de diâmetro. No segmento distal direito, essa distribuição também foi bimodal com o primeiro pico em $0,5 \mu \mathrm{m}$ e o segundo pico em $3 \mu \mathrm{m}$ de diâmetro. No lado esquerdo, o segmento proximal apresenta distribuição bimodal, com o primeiro pico em $0,5 \mu \mathrm{m}$ e o segundo pico em $3 \mu \mathrm{m}$ de diâmetro; no segmento distal, a distribuição é bimodal, com o primeiro pico em $0,5 \mu \mathrm{m}$ e o segundo pico em $2,5 \mu \mathrm{m}$.

A análise estatística não mostrou diferença significativa nas distribuições dos diâmetros dos axônios mielinizados, nem entre segmentos, nem entre lados nos animais do grupo I. 


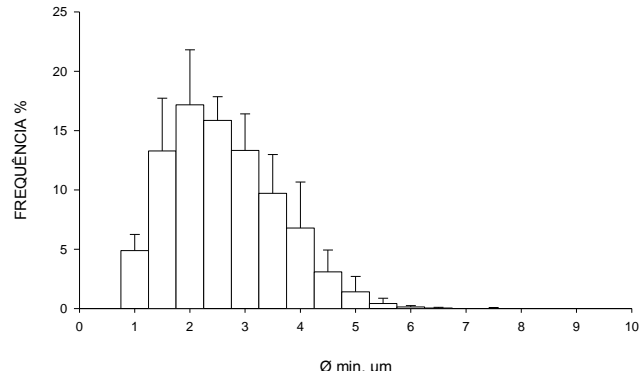

AXÔNIOS DIREITO DISTAL

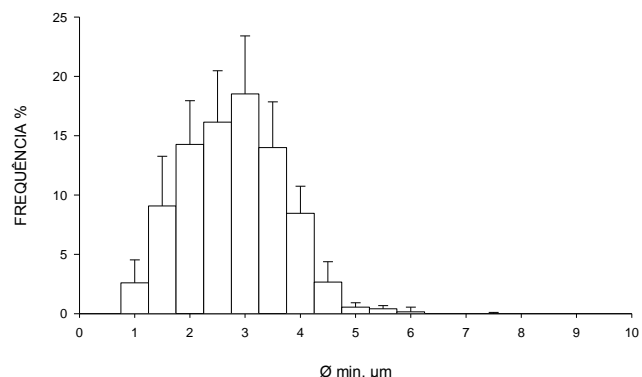

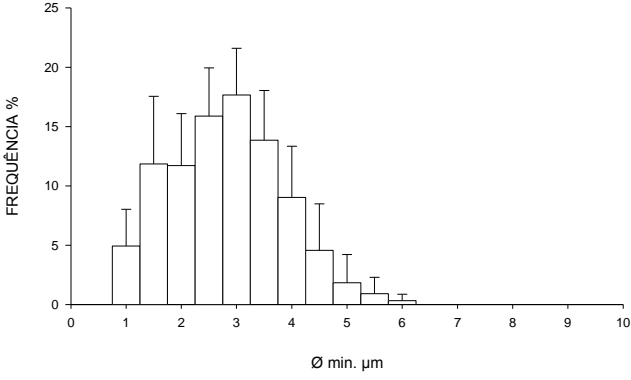

AXÔNIOS ESQUERDO DISTAL

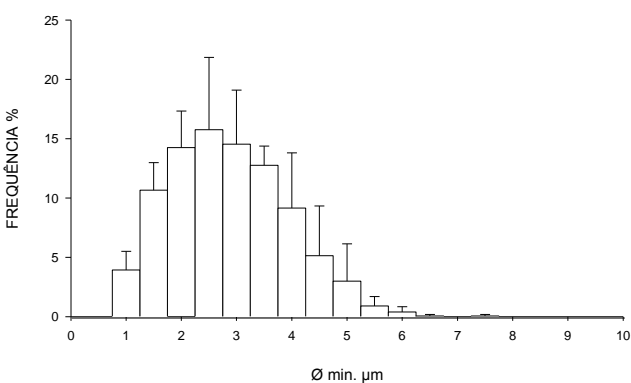

Figura 26: Histogramas de distribuição de frequência do diâmetro mínimo dos axônios mielinizados dos nervos safenos de animais Wistar do Grupos I (180 dias). Painel superior esquerdo: lado direito, segmento proximal. Painel superior direito: lado esquerdo, segmento proximal. Painel inferior esquerdo: lado direito segmento distal. Painel inferior direito: lado esquerdo segmento distal.

Os histogramas de distribuição de frequência da razão $\mathrm{G}$ dos nervos safenos direitos, segmento proximal, mostrou-se bimodal, com o primeiro pico em $0,1 \mu \mathrm{m}$ e o segundo pico em 0,6 $\mu \mathrm{m}$ de diâmetro. No segmento distal direito, essa distribuição também foi bimodal com o primeiro pico em $0,1 \mu \mathrm{m}$ e o segundo pico em $0,6 \mu \mathrm{m}$ de diâmetro. No lado esquerdo, o segmento proximal apresenta distribuição bimodal, com o primeiro pico em $0,1 \mu \mathrm{m}$ e o segundo pico em 0,6 $\mu \mathrm{m}$ de diâmetro; no segmento distal, a distribuição é bimodal, com o primeiro pico em $0,1 \mu \mathrm{m}$ e o segundo pico em $0,6 \mu \mathrm{m}$.

A análise estatística não mostrou diferença significativa nas distribuições da razão $G$ das fibras mielínicas, nem entre segmentos, nem entre lados nos animais do grupo I. 


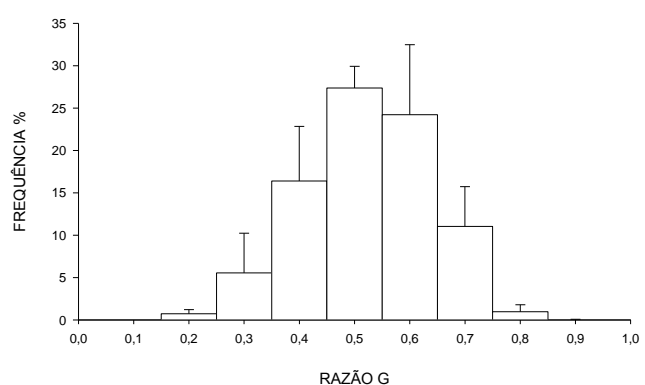

RAZÃO G DIREITO DISTAL

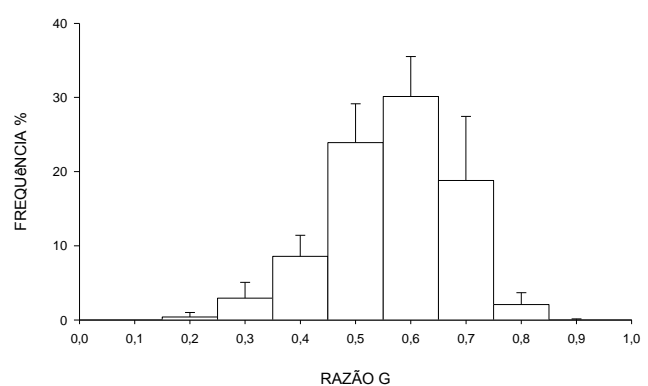

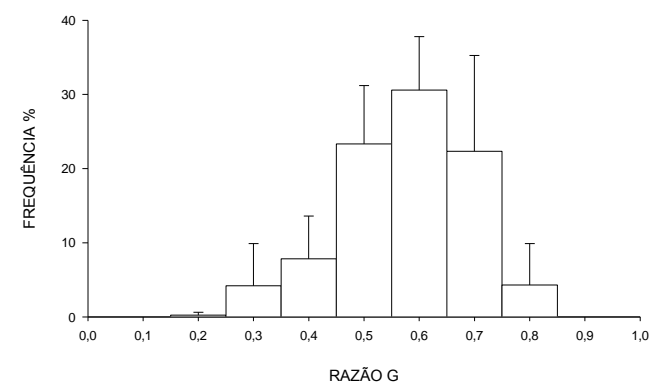

RAZÃO G ESQUERDO DISTAL

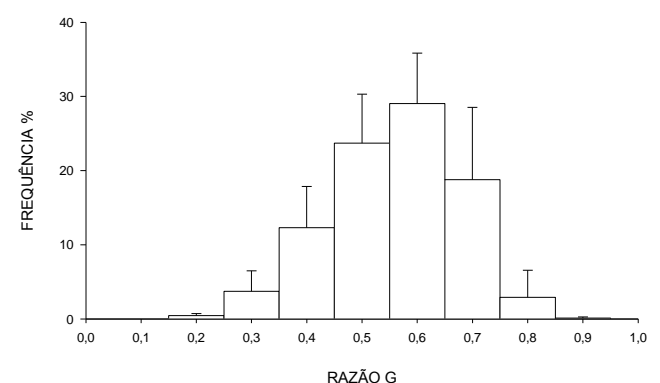

Figura 27: Histogramas de distribuição de frequência da razão G das fibras mielínicas dos nervos safenos de animais Wistar do Grupo I (180 dias). Painel superior esquerdo: lado direito, segmento proximal. Painel superior direito: lado esquerdo, segmento proximal. Painel inferior esquerdo: lado direito segmento distal. Painel inferior direito: lado esquerdo segmento distal.

\subsubsection{Animais do Grupo II - 360 dias de vida}

O histograma de distribuição do diâmetro mínimo das fibras mielínicas dos nervos safenos direito, segmento proximal, dos ratos do Grupo II, mostrou-se bimodal, com o primeiro pico em $3 \mu \mathrm{m}$ e o segundo pico em 6,0 $\mu \mathrm{m}$ de diâmetro. No segmento distal direito, essa distribuição foi unimodal, com o pico em 5,5 $\mu \mathrm{m}$ de diâmetro. Do lado esquerdo, segmento proximal, essa distribuição mostrou-se bimodal, com o primeiro pico em 3,5 $\mu \mathrm{m}$ e o segundo pico em 6,5 $\mu \mathrm{m}$ de diâmetro; no segmento distal desse mesmo lado, essa distribuição também foi bimodal, com o primeiro pico em 3,5 $\mu \mathrm{m}$ e o segundo pico em $6,0 \mu \mathrm{m}$ de diâmetro.

A análise estatística não mostrou diferença significativa nas distribuições dos diâmetros das fibras mielínicas, nem entre segmentos, nem entre lados, nos animais do Grupo II. 


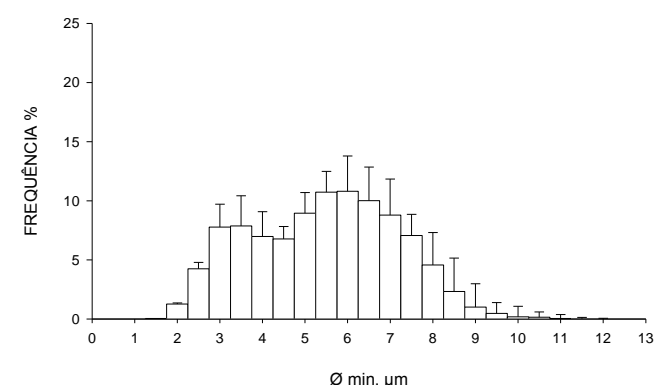

FIBRAS DIREITO DISTAL

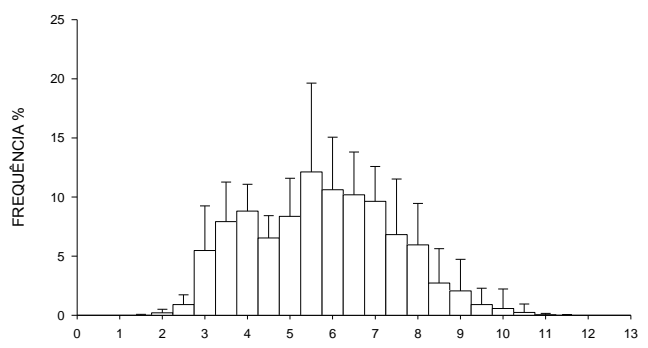

$\varnothing \mathrm{min} . \mu \mathrm{m}$

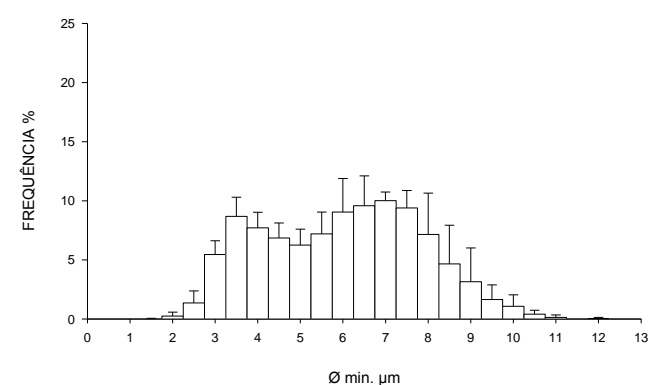

FIBRAS ESQUERDO DISTAL

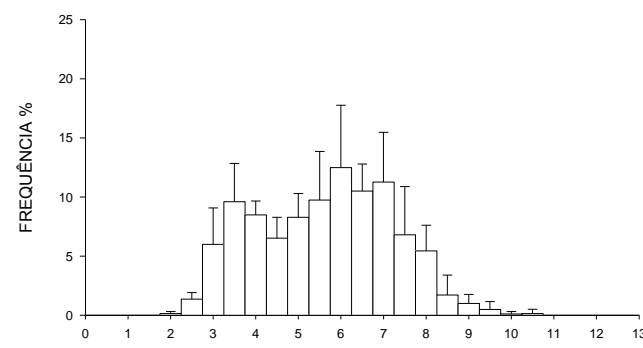

$\varnothing$ min. $\mu \mathrm{m}$

Figura 28: Histogramas de distribuição de frequência do diâmetro mínimo das fibras mielínicas dos nervos safenos de animais Wistar do Grupo II (360 dias). Painel superior esquerdo: lado direito, segmento proximal. Painel superior direito: lado esquerdo, segmento proximal. Painel inferior esquerdo: lado direito segmento distal. Painel inferior direito: lado esquerdo segmento distal.

Os histogramas de distribuição do diâmetro mínimo dos axônios mielinizados dos nervos safenos direitos, segmento proximal, mostrou-se unimodal, com o pico em $4 \mu \mathrm{m}$ de diâmetro. No segmento distal direito, essa distribuição também foi unimodal com o pico em 3,5 $\mu \mathrm{m}$ de diâmetro. No lado esquerdo, o segmento proximal apresenta distribuição unimodal, com o pico em $3 \mu \mathrm{m}$ de diâmetro; no segmento distal, a distribuição é bimodal, com o primeiro pico em $0,5 \mu \mathrm{m}$ de diâmetro e o segundo pico em 3,5 $\mu \mathrm{m}$ de diâmetro .

A análise estatística não mostrou diferença significativa nas distribuições dos diâmetros dos axônios mielinizados, nem entre segmentos, nem entre lados nos animais do grupo II. 


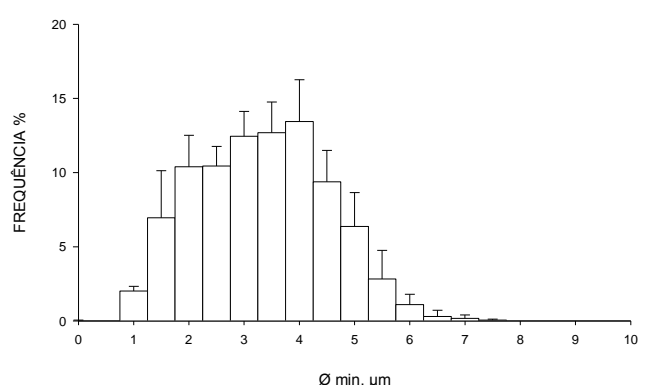

AXÔNIOS DIREITO DISTAL

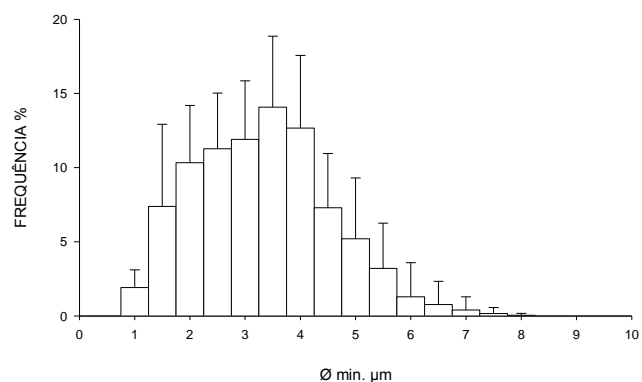

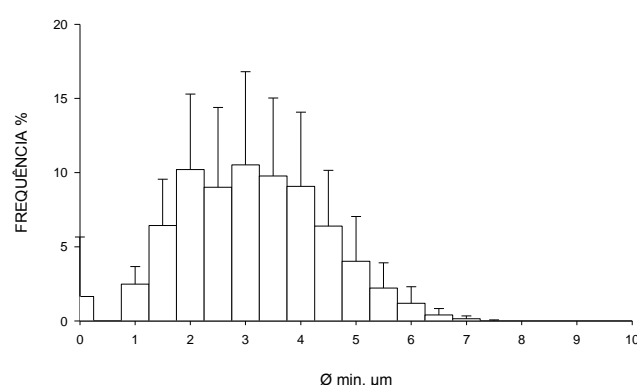

AXÔNIOS ESQUERDO DISTAL

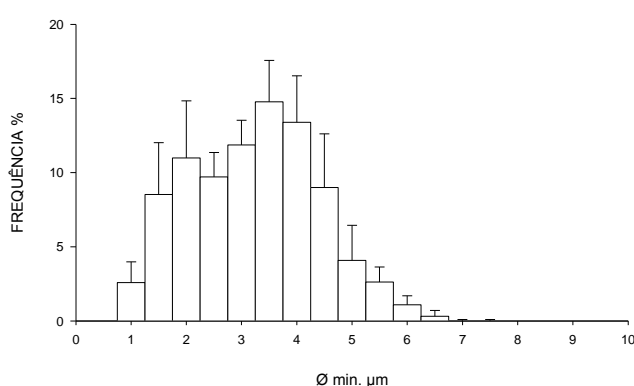

Figura 29: Histogramas de distribuição de frequência do diâmetro mínimo dos axônios mielinizados dos nervos safenos de animais Wistar do Grupo II (360 dias). Painel superior esquerdo: lado direito, segmento proximal. Painel superior direito: lado esquerdo, segmento proximal. Painel inferior esquerdo: lado direito segmento distal. Painel inferior direito: lado esquerdo segmento distal.

Os histogramas de distribuição de frequência da razão $G$ das fibras mielínicas do nervo safeno dos ratos do grupo II, 360 dias, segmento proximal lado direito ,mostrou-se unimodal, com o pico em 0,6 $\mu \mathrm{m}$ de diâmetro, No segmento distal direito, essa distribuição também foi unimodal com o pico em $0,7 \mu \mathrm{m}$ de diâmetro. No lado esquerdo, o segmento proximal apresenta distribuição unimodal, com o pico em $0,7 \mu \mathrm{m}$ de diâmetro; no segmento distal, a distribuição é unimodal, com o pico em $0,7 \mu \mathrm{m}$ de diâmetro .

A análise estatística mostrou diferença significativa nas distribuições da razão $\mathrm{G}$ das fibras mielínicas, nos animais do Grupo II comparados ao Grupo I. 


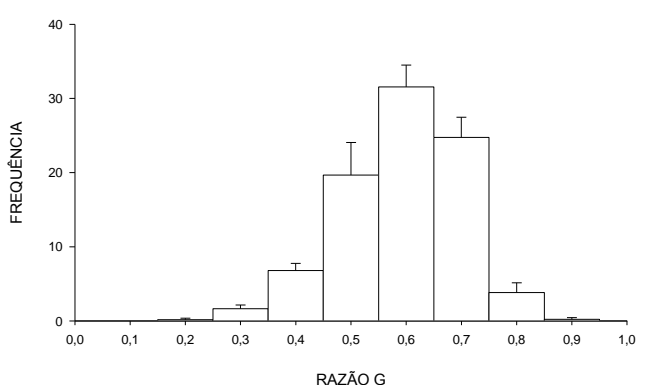

RAZÃO G DIREITO DISTAL

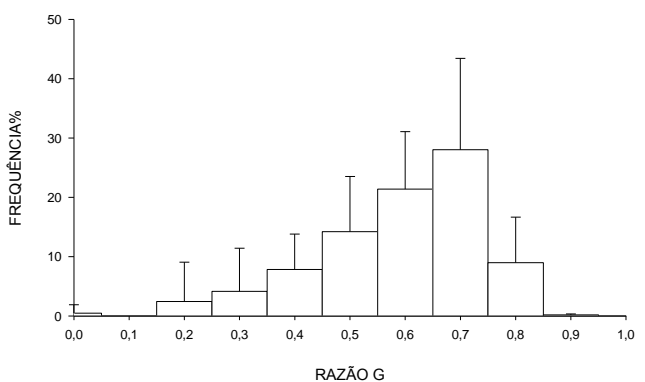

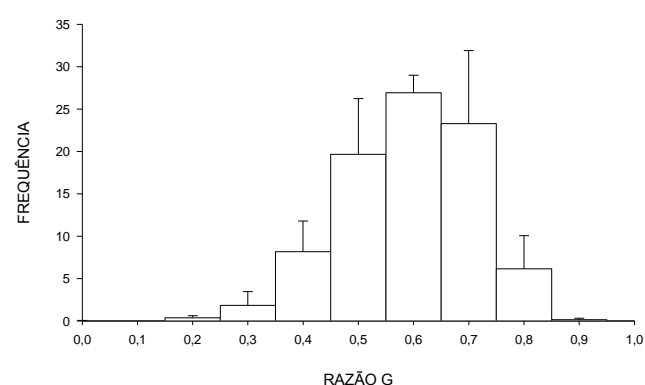

RAZÃO G ESQUERDO DISTAL

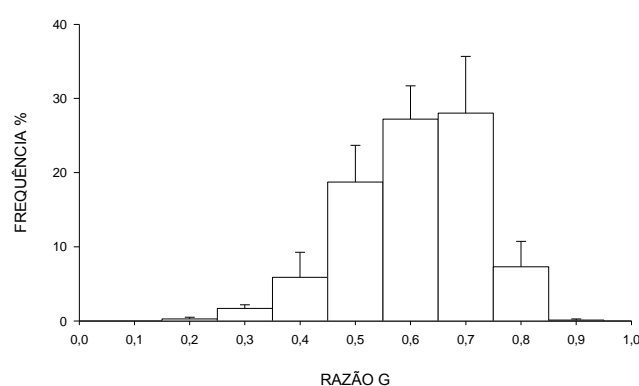

Figura 30: Histogramas de distribuição de frequência da razão G das fibras mielínicas dos nervos safenos de animais Wistar do Grupo II (360 dias). Painel superior direito: lado esquerdo, segmento proximal. Painel inferior esquerdo: lado direito segmento distal. Painel inferior direito: lado esquerdo segmento distal.

\subsubsection{Animais do Grupo III - 720 dias de vida}

O histograma de distribuição do diâmetro mínimo das fibras mielínicas dos nervos safenos direito, segmento proximal mostrou-se unimodal, com o pico em 2,5 $\mu \mathrm{m}$ de diâmetro. No segmento distal direito, essa distribuição foi unimodal, com o pico em 3,5 $\mu \mathrm{m}$ de diâmetro. Do lado esquerdo, segmento proximal, essa distribuição mostrou-se bimodal, com o primeiro pico em 3,0 $\mu \mathrm{m}$ e o segundo pico em 4,5 $\mu \mathrm{m}$ de diâmetro; no segmento distal desse mesmo lado, essa distribuição também foi bimodal, com o primeiro pico em $2,5 \mu \mathrm{m}$ e o segundo pico em 6,0 $\mu \mathrm{m}$ de diâmetro.

A análise estatística não mostrou diferença significativa nas distribuições dos diâmetros das fibras mielínicas, nem entre segmentos, nem entre lados nos animais do grupo III. 


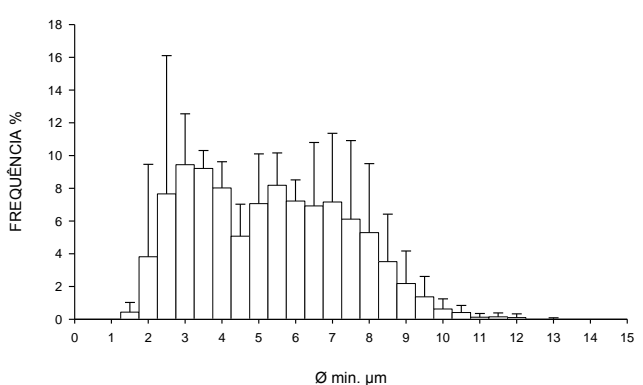

FIBRAS DIREITO DISTAL

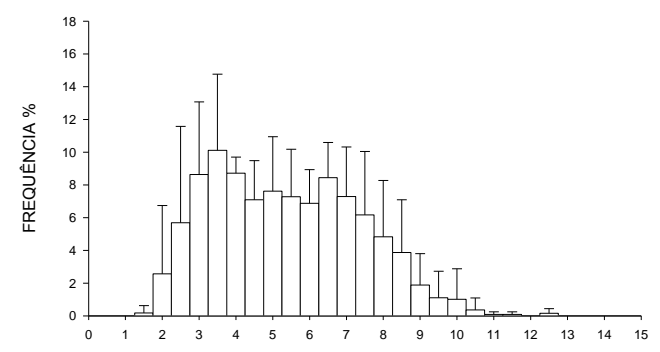

$\varnothing \min . \mu \mathrm{m}$

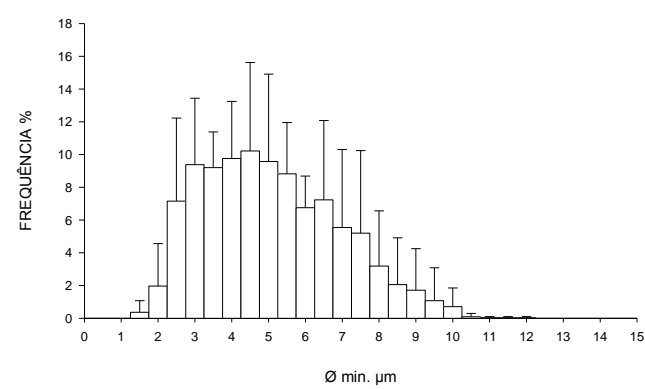

FIBRAS ESQUERDO DISTAL

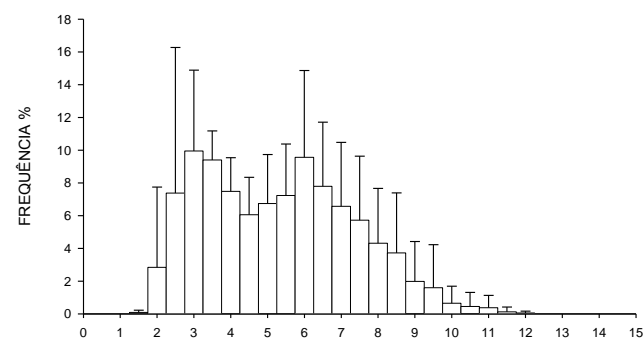

$\varnothing$ min. $\mu \mathrm{m}$

Figura 31: Histogramas de distribuição de frequência do diâmetro mínimo das fibras mielínicas dos nervos safenos de animais Wistar do Grupo III (720 dias). Painel superior esquerdo: lado direito, segmento proximal. Painel superior direito: lado esquerdo, segmento proximal. Painel inferior esquerdo: lado direito segmento distal. Painel inferior direito: lado esquerdo segmento distal.

Os histogramas de distribuição do diâmetro mínimo dos axônios mielinizados dos nervos safenos direitos, segmento proximal, mostrou-se unimodal, com pico em 1,5 $\mu \mathrm{m}$ de diâmetro . No segmento distal direito, essa distribuição foi unimodal com pico em $2 \mu \mathrm{m}$ de diâmetro. No lado esquerdo, o segmento proximal mostrou-se unimodal com pico em 2,0 $\mu \mathrm{m}$ de diâmetro e o segmento distal apresentou distribuição unimodal, com pico em 1,5 $\mu \mathrm{m}$ de diâmetro .

A análise estatística não mostrou diferença significativa nas distribuições dos diâmetros dos axônios mielinizados, nem entre segmentos, nem entre lados nos animais do grupo III. 


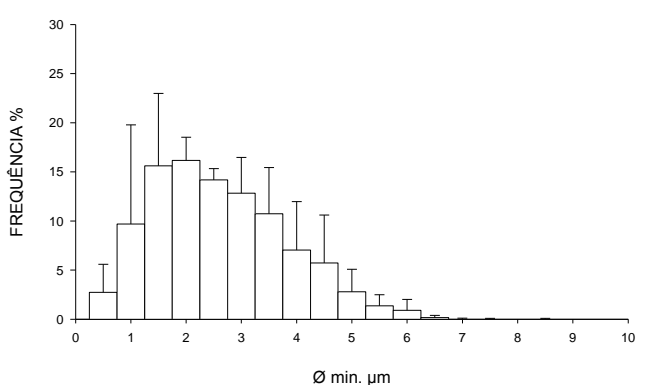

AXÕNIOS DIREITO DISTAL

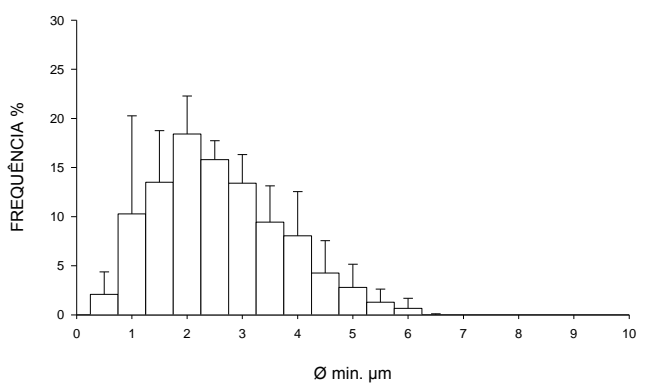

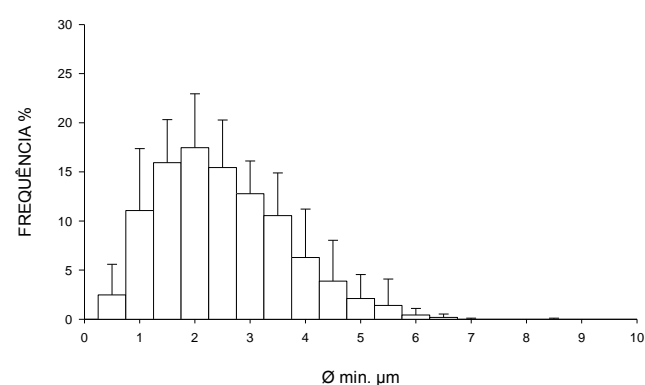

AXÔNIOS ESQUERDO DISTAL

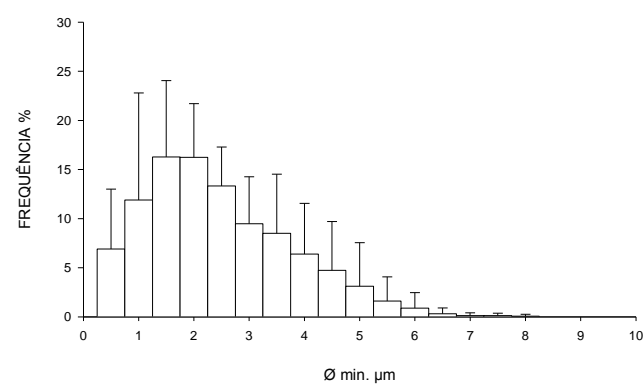

Figura 32: Histogramas de distribuição de frequência do diâmetro mínimo dos axônios mielinizados dos nervos safenos de animais Wistar do Grupo III (720 dias). Painel superior esquerdo: lado direito, segmento proximal. Painel superior direito: lado esquerdo, segmento proximal. Painel inferior esquerdo: lado direito segmento distal. Painel inferior direito: lado esquerdo segmento distal.

Os histogramas de distribuição de frequência da razão $G$ das fibras mielínicas dos nervos safenos direitos, mostrou-se unimodal, com pico em $0,5 \mu \mathrm{m}$ de diâmetro . No segmento distal direito, essa distribuição foi unimodal com pico em $0,5 \mu \mathrm{m}$ de diâmetro. No lado esquerdo, o segmento proximal mostrou-se unimodal com pico em $0,5 \mu \mathrm{m}$ de diâmetro e o segmento distal apresentou distribuição unimodal, com pico em 0,5 $\mu \mathrm{m}$ de diâmetro.

A análise estatística não mostrou diferença significativa nas distribuições da razão $G$ das fibras mielínicas, nem entre segmentos, nem entre lados nos animais do grupo III. 


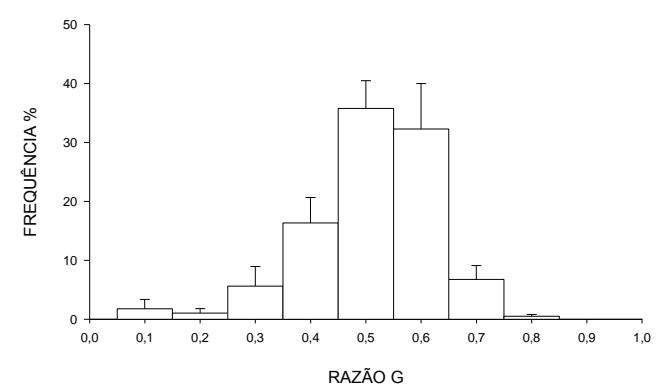

RAZÃO G PROXIMAL ESQUERDO

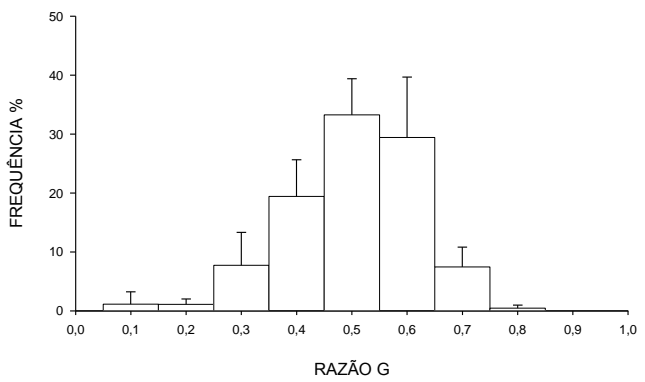

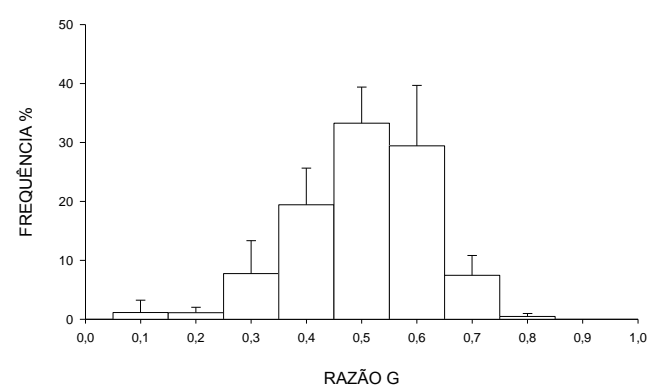

RAZÃO G DISTAL ESQUERDO

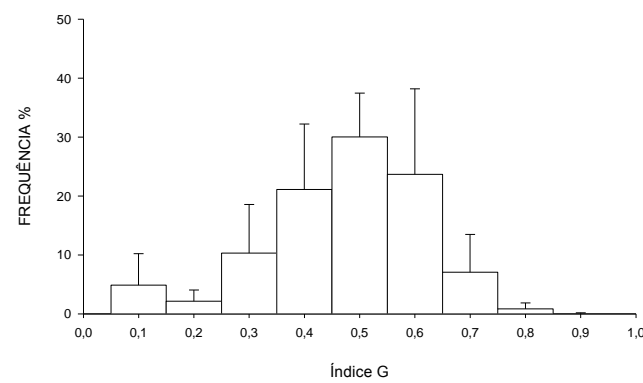

Figura 33: Histogramas de distribuição de frequência da razão $\mathrm{G}$ das fibras mielínicas dos nervos safenos de animais Wistar do Grupo III (720 dias). Painel superior esquerdo: lado direito, segmento proximal. Painel superior direito: lado esquerdo, segmento proximal. Painel inferior esquerdo: lado direito segmento distal. Painel inferior direito: lado esquerdo segmento distal.

\subsubsection{Comparação entre os Diferentes Grupos}

As comparações entre os histogramas de distribuição de frequência do diâmetro mínimo das fibras mielínicas entre os três grupos experimentais mostraram que não houve diferença significativa, tanto nas comparações entre os lados diferentes, quanto entre os segmentos de um mesmo lado (figura 34). 

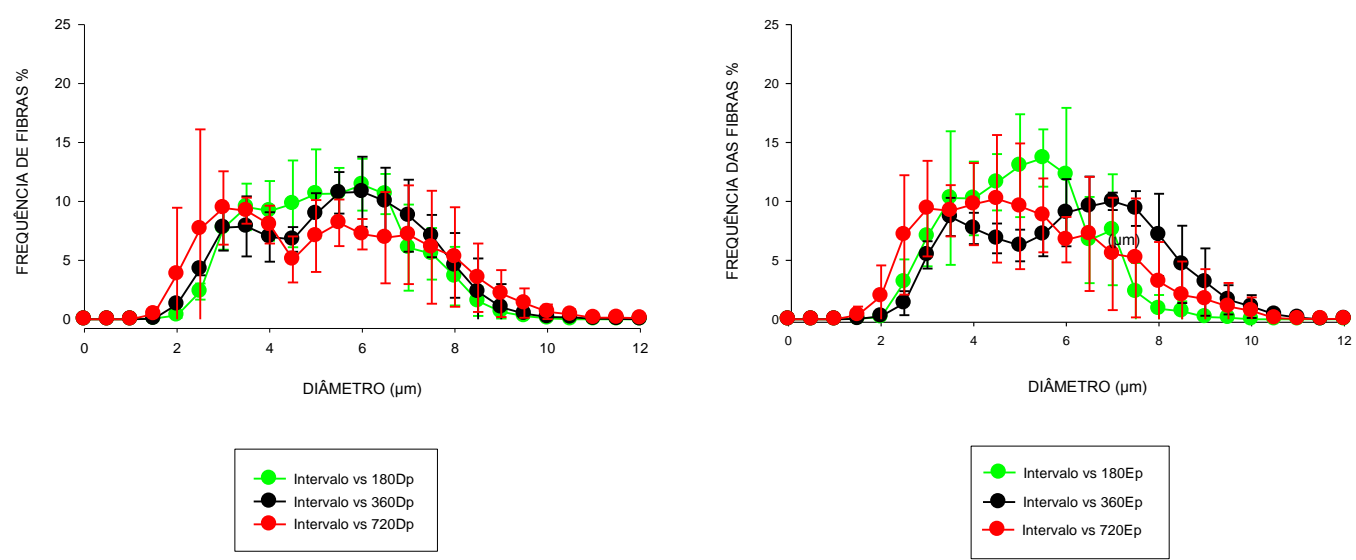

FIBRA DIREITO DISTAL

FIBRA ESQUERDO DISTAL
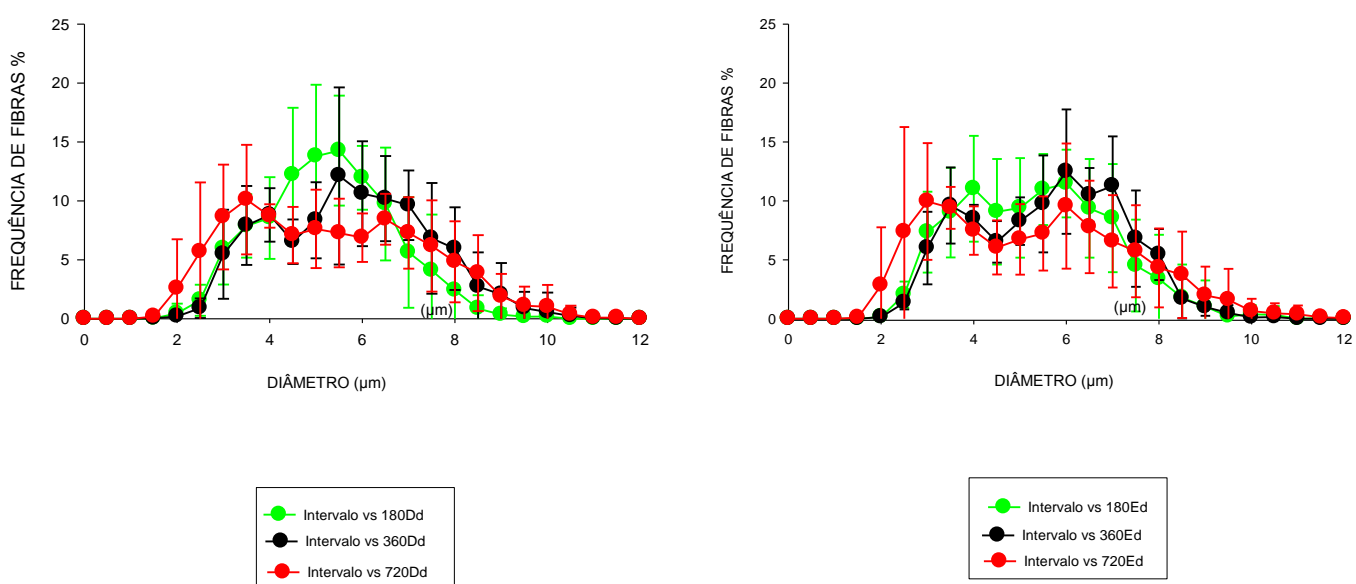

Figura 34: Histogramas de distribuição de frequência do diâmetro mínimo das fibras mielínicas dos nervos safenos de animais Wistar do Grupo I (180 dias - verde), Grupo II (360 dias - preto), Grupo III (720 dias vermelho)

As comparações entre os histogramas de distribuição de frequência do diâmetro mínimo dos axônios mielinizados entre os três grupos experimentais mostraram que não houve diferença significativa, tanto nas comparações entre os lados diferentes, quanto entre os segmentos de um mesmo lado (figura 35). 
AXÔNIO DIREITO PROXIMAL

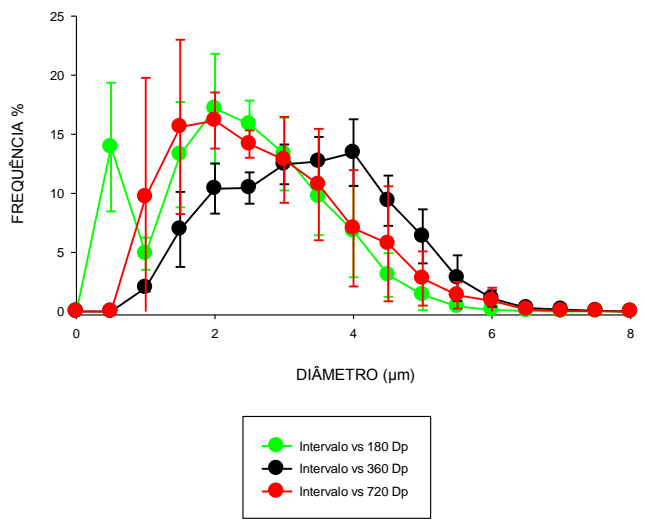

AXÔNIO DIREITO DISTAL

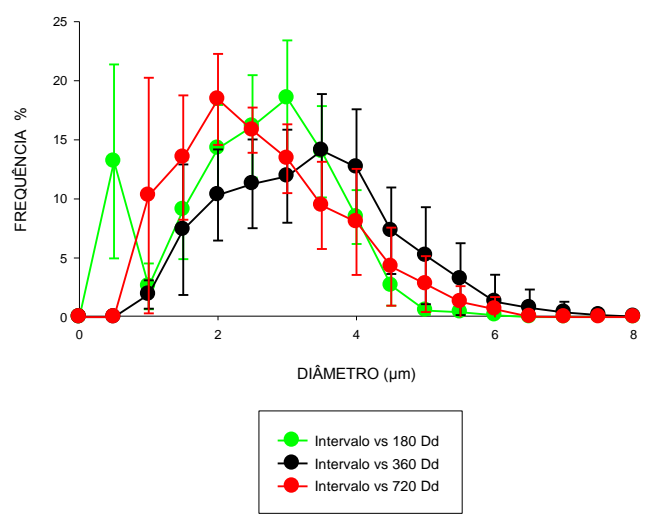

AXÔNIO ESQUERDO PROXIMAL

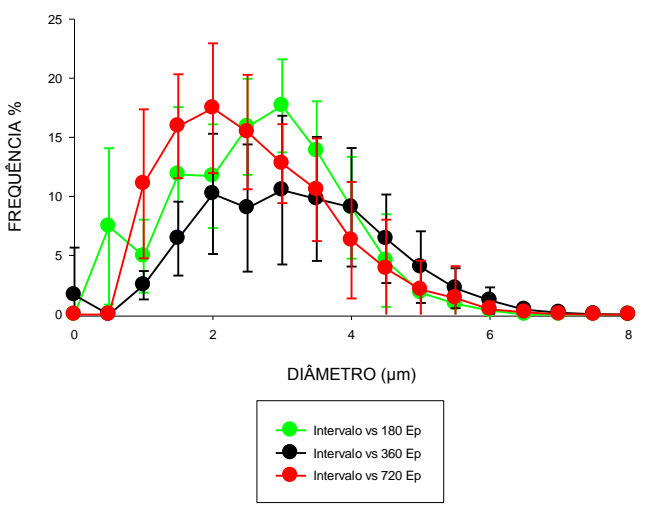

AXÔNIO ESQUERDO DISTAL

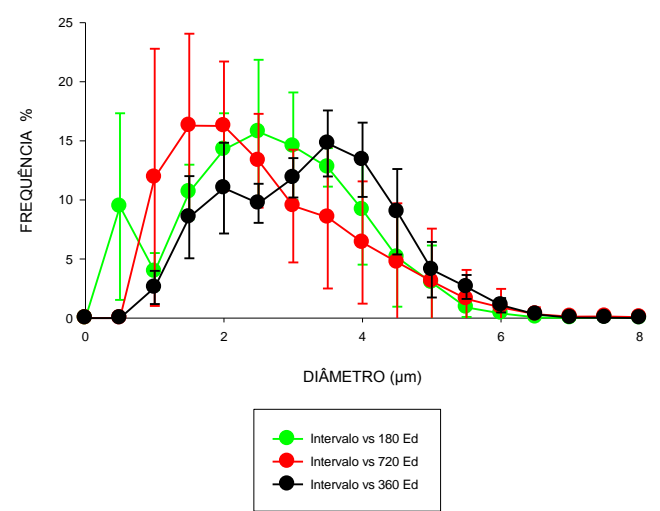

Figura 35: Histogramas de distribuição de frequência do diâmetro mínimo dos axônios mielinizados dos nervos safenos de animais Wistar do Grupo I (180 dias - verde), Grupo II (360 dias - preto), Grupo III (720 dias vermelho).

Para os histogramas de distribuição da razão $\mathrm{G}$ das fibras mielínicas, houve diferença significativa quando comparamos o segmento proximal direito para a idade de 360 dias em relação ao Grupo I, 180 dias. (figura 32). Apesar de os outros segmentos não apresentarem a diferença significativa , há um nítido desvio dos histogramas da razão $\mathrm{G}$ dos animais do grupo III, para a esquerda (atrofia axonal) em relação aos outros dois grupos. 
RAZ̃̃O G DIREITO PROXIMAL

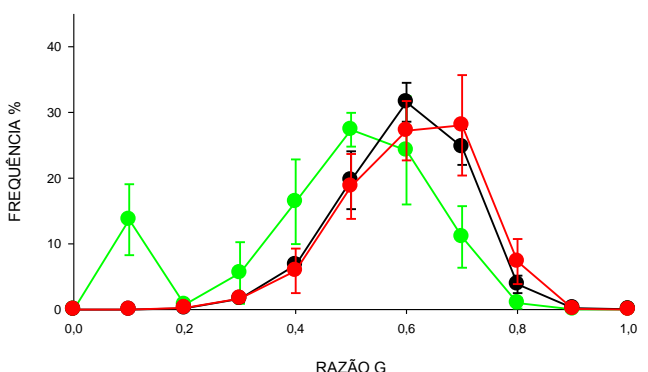

- INTERVAlo vs 180 Dp

- INTERVALO vs 360 D D

RAZÃO G DIREITO DISTAL

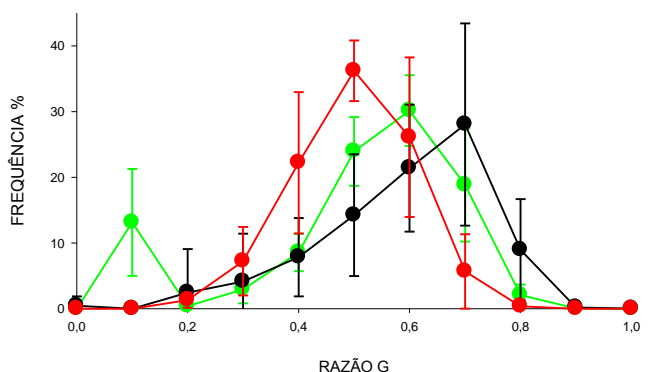

- INTERVAlo vs 180 Dd

INTERVAlo vs 720 Dd
RAZÃO G ESQUERDO PROXIMAL

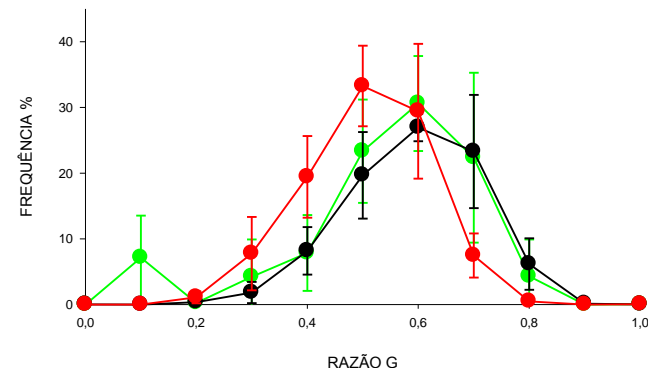

- INTERVALO vs 180 Ep

- inTervalo vs 720 ep

RAZÃO G ESQUERDO DISTAL

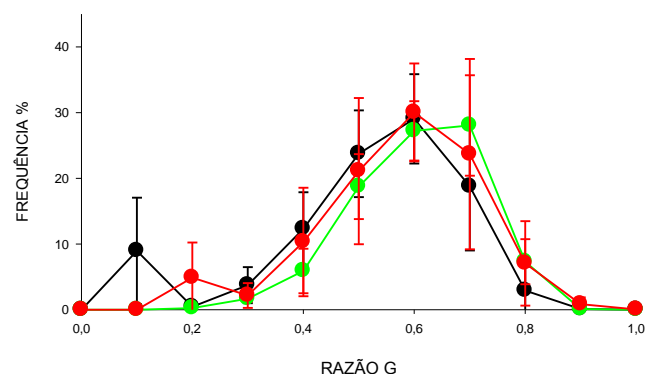

- interValo vs 360 Ed

- intervalo vs 720 Ed

Figura 36: Histogramas de distribuição de frequência da razão G das fibras mielínicas dos nervos safenos de animais Wistar do Grupos I (180 dias - verde), Grupo II (360 dias - preto), Grupo III (720 dias - vermelho). Notar o desvio da curva para a esquerda no Grupo III (720 dias) para os segmentos esquerdo proximal e direito distal. 
DISCUSSÃO 


\section{DISCUSSÃO}

\subsection{Modelo animal e escolha do nervo}

Ratos têm sido utilizados em experimentos que envolvem a regeneração nervosa, com bastante frequência (MENDONÇA et al., 2003; DE SÁ et al., 2004; OLIVEIRA et al, 2004; RASO et al., 2005;). Isso porque esses animais são de pequeno porte e fácil manuseio, fácil manutenção em biotérios de criação com baixo custo, e porque a literatura é rica em dados sobre esses animais, para uma adequada comparação dos nossos resultados. Além de suportarem bem as condições experimentais desses estudos. A linhagem Wistar foi escolhida, pois muitos dos experimentos de regeneração, inclusive envolvendo o nervo safeno (CARTER \& LISNEY, 1987) utilizaram essa linhagem de animais, o que permite uma comparação mais fiel com os dados obtidos no presente estudo. Por fim, fêmeas foram escolhidas porque se mostraram menos susceptíveis ao desenvolvimento de uma neuropatia espontânea (MAJJED, 1992) e também porque nosso estudo é com idades mais avançadas, e sabe-se que as fêmeas sobrevivem mais tempo e em melhores condições que os machos (VAN STEENIS \& KROES, 1971).

Importante mencionar que a maioria dos estudos de regeneração nervosa utiliza ratos em idade adulta. Dessa forma, se faz necessário o conhecimento do padrão normal de nervos, desde o nascimento até o envelhecimento, uma vez que a função desses é afetada pela idade, sendo os déficits funcionais consequência de perda de fibras, anormalidades da bainha de mielina ou alterações do tecido conjuntivo e vascularização nervosa (CEBALLOS e cols., 1999). A idade também influencia a capacidade dos nervos se regenerarem e reinervarem os órgãos-alvo, com diferentes padrões para fibras motoras, sensitivas a autonômicas (VERDÚ e cols., 1996).

O crescimento, afeta diretamente os fascículos e fibras, sem, entretanto, afetar o número das estruturas. Entretanto, é interessante pensar que o crescimento do nervo, acompanhando o do animal, poderá alterar proporções morfométricas das estruturas de interesse. Dessa forma, não existem relatos na literatura sobre a anatomia microscópica normal do nervo safeno de animais acompanhados no envelhecimento sendo muitos dos dados aqui apresentados, de caráter original. Dessa forma, consideramos que nossos resultados vão acrescentar conhecimentos sobre as características morfométricas desse nervo, 
em decorrência do envelhecimento, podendo servir de suporte para os estudos de neuropatias, tanto morfológicos e morfométricos, quanto eletrofisiológicos.

\subsection{Dados morfológicos}

Um dos achados mais importantes do presente trabalho foram as alterações da bainha de mielina que apareceram com o avançar da idade dos animais. Essas alterações também foram observadas por Jerônimo, et al, 2008, ao estudar o nervo sural em diferentes fases do envelhecimento. Algumas das características observadas no presente estudo também foram descritas para nervos de ratos e camundongos com idade avançada. Em camundongos com idades entre 12 e 20 meses (aproximadamente 360 e 600 dias de vida) há o aumento do aparecimento de dobras na bainha de mielina ("outfolded myelin loops") e uma redução do número e densidade de fibras (Verdú et al., 2000; Ceballos et al., 1999). Em camundongos com mais de 20 meses de idade, aparece uma redução do tamanho das fibras mielínicas, redução da circularidade das mesmas e também uma redução da bainha de mielina (Verdú et al, 2000). Macrófagos e mastócitos podem aumentar de número no endoneuro (Ceballos et al., 1999). Verdú et al. (2000) mostram imagens muito semelhantes às observadas no presente estudo, de degeneração de mielina com macrófago associado, fibras mielínicas com alargamento da incisura de Schmidt-Lanterman e presença de ovóides de mielina ("compact myelin body") em nervos de camundongos com 30 a 33 meses de idade. Esses estudos foram realizados em nervos tibiais.

Em ratos, alterações da mielina foram descritas para animais com 30 meses de idade, principalmente na raiz ventral do nervo espinal. Tais alterações foram a formação de balões de mielina ("myelin ballons"), quebras da bainha, dobras da bainha para dentro ("infolding"), reduplicação e remielinização (Knox et al., 1989). Os autores descrevem que tais alterações também estiveram presentes em animais com 10 e 20 meses, mas em graus menos severos. Descrevem, também, que tais achados estiveram presentes também na raiz dorsal do nervo espinal, no nervo fibular, e talvez no nervo sural. Os autores descrevem que a desmielinização foi raramente observada, mesmo nos animais mais velhos. Esses achados diferem dos achados do presente estudo, em que foi observado muitas fibras desmielinizadas, principalmente, no Grupo III, de 720 dias. Ainda, macrófagos foram encontrados adjacentes ou no interior de fibras mielínicas. As alterações encontradas foram mais evidentes nas fibras de maior calibre. Achados esses que corroboram com o do presente estudo. 
Em nervos isquiáticos de fêmeas da linhagem Wistar, com 34 meses de idade, imagens de degeneração Walleriana foram identificadas (VAN STEENIS, KROES, 1971). Em adição, alterações da bainha de mielina tais como edema, dilatação e a presença de macrófagos sugeriram degeneração. Pouca diferença na severidade das lesões foi identificada entre as porções proximais e distais dos nervos.

Em um estudo com ratos Wistar machos, de até 720 dias de vida, os autores observaram $30 \%$ de fibras com anormalidades. Dentre estas anormalidades, desmielinização paranodal e internodal e remielinização, bem como degeneração e regeneração axonal foram evidenciadas, sendo as últimas predominando sobre as primeiras (SHARMA et al., 1980). Os nervos estudados foram o plantar lateral e o tibial.

Um estudo dos nervos plantares de ratos CD-CRL:COBS CD (SD) BR, com pelo menos 2 anos de vida (aproximadamente 720 dias) mostrou a presença de fibras mielínicas com bainhas contorcidas e dobradas ("infolded") e axônios edemaciados e desmielinizados. Remielinização e fibras regeneradas foram achados ocasionais (GROVER-JOHNSON; SPENCER, 1981).

Em um estudo das alterações radiculares de ratos Charles River CD ®, com 28 meses de idade (aproximadamente 840 dias) mostrou sinais de degeneração das fibras, sendo que aquelas das raízes ventrais mostraram maior grau de severidade, comparado às raízes dorsais (GILMORE, 1972). As alterações observadas foram degeneração da mielina, com preservação dos axônios e algum infiltrado macrofágico. Apesar da relativa extensão das alterações das raízes nervosas, o estado neurológico dos animais era aparentemente normal, sem perda de função motora (GILMORE, 1972).

Um número muito grande de ratos da linhagem Sprague-Dawley (5271 machos e 4714 fêmeas), com idades entre 80 e 104 semanas de vida (aproximadamente 560 e 720 dias de vida) teve seu nervo isquiático investigado para neuropatias de aparecimento espontâneo (MAJEED, 1992). O autor demonstrou a presença de fragmentação da bainha de mielina, formação de ovóides de mielina e degeneração axonal. Também demonstrou que machos foram mais acometidos que as fêmeas.

Todos os achados descritos nesses estudos foram encontrados em nosso material, com a diferença de que, no presente estudo, um nervo puramente sensitivo foi avaliado, sendo que nos outros trabalhos experimentais, a maioria dos autores utilizou um nervo misto.

É importante ressaltar que alças de mielina (“myelin loops”) e quebra da mielina (“myelin spliting”) estão presentes em nervos normais, como resultado de mudanças no 
tamanho dos axônios e um ajuste apropriado em suas bainhas de mielina. Alças de mielina foram descritas durante os primeiros estágios do desenvolvimento e interpretado como passos do processo de reciclagem de mielina (JACOBS; LOVE, 1985). Entretanto, aumento da frequência de aparecimento das alças de mielina com a idade tem sido relacionada com uma resposta precoce de uma fibra mielínica de grande calibre à atrofia axonal (KRINKE et al., 1988).

Um resumo dos principais achados morfológicos com o envelhecimento, no sistema nervoso periférico de ratos, está representado na tabela 7, a seguir.

Uma alteração morfológica importante que foi identificada em nosso material foi a presença de lesão vascular, que foi de intensidade mais severa quanto maior a idade dos animais. Além do aumento da espessura das paredes vasculares, um grande número de vasos se apresentou colabado nos nervos dos animais mais velhos. Nossos dados vão ao encontro dos dados obtidos no estudo de Jerônimo, et al, em 2008, para os nervos surais em diferentes fases do envelhecimento. Jacobs, Love (1985) descreveram a presença de reduplicação da membrana basal vascular em nervos surais de humanos após os 60 anos de idade. Esses autores compararam essa alteração com aquelas observadas em indivíduos diabéticos. Por outro lado, Grover-Johnson; Spencer (1981), descrevem ausência de alterações ateroscleróticas e vasos patentes em nervos plantares de ratos com pelo menos 2 anos de idade, com presença de neuropatia. Entretanto, Van Steenis; Kroes (1971) encontraram, em ratos com até 1020 dias de vida, espessamento da adventícia dos pequenos vasos dos nervos estudados, com uma camada de tecido conjuntivo circundando esses vasos. Esse achado também é compatível com nossa observação de espessamento das paredes vasculares. Por fim, Ceballos et al (1999) demonstraram, em nervos tibiais de camundongos com até 33 meses de idade (990 dias de vida), que o número de vasos não se alterou com a idade, mas que o tamanho dos mesmos aumentou com a idade. Entretanto, os vasos pequenos estavam frequentemente colabados nos nervos dos animais mais velhos. Tal achado também é compatível com o nosso resultado. Assim sendo, observando a morfologia dos nervos safenos , há uma sugestão de que os vasos dos nervos periféricos, também estão afetados pelo envelhecimento. 
Tabela 7: Resumo dos principais achados no sistema nervoso periférico, decorrentes do envelhecimento

\begin{tabular}{|c|c|c|c|l|l|}
\hline Autor e ano & Linhagem & Sexo & Idade (dias) & \multicolumn{1}{|c|}{ Tecido } & \multicolumn{1}{|c|}{ Achados } \\
\hline $\begin{array}{c}\text { Van Steenis e } \\
\text { Kroes, 1971. }\end{array}$ & Wistar & M/F & Até 1020 & $\begin{array}{l}\text { Raíz dorsal, plexo braquial } \\
\text { e nervo isquiático. }\end{array}$ & $\begin{array}{l}\text { Presença de degeneração Walleriana, edema e dilatação da bainha de } \\
\text { mielina, presença de macrófagos nas bainhas. }\end{array}$ \\
\hline Gilmore, 1972. & $\begin{array}{c}\text { Charles River } \\
\text { CD® }\end{array}$ & NI & Até 840 & Raiz ventral. & $\begin{array}{l}\text { Degeneração da mielina, com preservação dos axônios e infiltrado } \\
\text { macrofágico. }\end{array}$ \\
\hline $\begin{array}{c}\text { Sharma et al, } \\
1980 .\end{array}$ & Wistar & M & Até 720 & $\begin{array}{l}\text { Nervos tibial e plantares } \\
\text { medial e lateral. }\end{array}$ & $\begin{array}{l}\text { Desmielinização segmentar e remielinização, degeneração Walleriana e } \\
\text { regeneração. }\end{array}$ \\
\hline $\begin{array}{c}\text { Grover-Johnson } \\
\text { e Spencer, 1981. }\end{array}$ & $\begin{array}{c}\text { CD-CRL:COBS } \\
\text { CD (SD) BR }\end{array}$ & M & $\begin{array}{c}\text { Pelo menos } \\
720\end{array}$ & $\begin{array}{l}\text { Nervos tibial e plantares } \\
\text { medial e lateral. }\end{array}$ & $\begin{array}{l}\text { Bainhas de mielina contorcidas e dobradas. Axônios edemaciados. } \\
\text { Ocasionais fibras remielinizadas e regeneradas. Raras fibras degeneradas. }\end{array}$ \\
\hline $\begin{array}{c}\text { Knox et al, 1989. } \\
\text { Fischer }\end{array}$ & F & Até 900 & $\begin{array}{l}\text { Raízes ventral e dorsal, } \\
\text { nervos fibular e sural. }\end{array}$ & $\begin{array}{l}\text { Formação de balões de mielina, quebras da mielina, dobras da mielina, } \\
\text { reduplicação e remielinização. Anormalidades axonais foram menos } \\
\text { evidentes. Fibras mielínicas maiores foram mais afetadas que as menores. }\end{array}$ \\
\hline Majeed, 1992. & Sprague-Dawley & M/F & Até 728 & Nervo isquiático. & $\begin{array}{l}\text { Degeneração axonal, fragmentação da bainha de mielina, desmielinização } \\
\text { segmental, vacuolização da fibra, formação de corpos ovóides de mielina, } \\
\text { degeneração mitocondrial. }\end{array}$ \\
\hline
\end{tabular}

$\mathrm{NI}=$ não informado; $\mathrm{M}=$ machos, $\mathrm{F}=$ Fêmeas 


\subsection{DADOS FASCICULARES}

Na literatura, tanto em estudos experimentais como clínicos, não há dados sobre o número e o tamanho dos fascículos do nervo safeno em diferentes fases do envelhecimento, como descritas no presente trabalho, apenas em ratos recém-desmamados. O nervo safeno de ratas com 30 dias de idade mostrou-se monofasciculado em seu segmento proximal. Entretanto, um número variável de fascículos esteve presente no segmento distal desse nervo, indicando sua ramificação ao longo do trajeto descendente. (CAMPOS et al; 2008).

As observações morfológicas dos nervos safenos nas secções transversais dos segmentos proximais dos lados direito e esquerdo, em sua maioria, no presente estudo, demonstraram um único fascículo, redondo ou oval em sua forma. Para os segmentos distais, lados direito e esquerdo, mais de um fascículo foi observado, indicando sua ramificação ao longo do trajeto descendente. Dessa forma, como foi padronizado procedimento de retirada dos nervos colhidos sempre no mesmo local, as diferenças no número de fascículos entre os animais, bem como entre os lados de um mesmo animal, indicam a presença de variações anatômicas no nível de ramificação desse nervo em seu segmento distal. Esses resultados são semelhantes aos encontrados por Jerônimo et al, 2008, porém, para o nervo sural em diferentes fases do envelhecimento, como no presente estudo. Os resultados para o nervo safeno são semelhantes aos encontrados em Alpsan e Lal (1980) e Carter e Lisney (1987). De forma interessante, ambos os autores mencionados anteriormente estudaram o segmento médio do nervo safeno de ratos adultos, machos. ALPSAN \& LAL (1980) descrevem o nervo como monofasciculado. Já CARTER \& LISNEY (1987), realizando estudos de regeneração nervosa, com secção do nervo em seu segmento médio, descreveram que, no segmento proximal à lesão, $60 \%$ dos nervos se apresentou monofasciculado, enquanto que $30 \%$ apresentou 2 fascículos, sendo um deles bem menor que o outro e apenas $10 \%$ apresentou dois fascículos de tamanhos semelhantes. Esses mesmos autores apresentam resultados de um número mais variável de fascículos nos segmentos distais à lesão, variando entre 1 e 4 . De qualquer forma, nenhum dos autores mencionados refere o tamanho desses fascículos, nem em forma de área, nem em forma de diâmetro. Em nosso estudo apresentamos resultados relacionados a área e diâmetro fascicular em 3 diferentes grupos acompanhados no envelhecimento.

THOMAS et al. em 1980; GROVER-JOHNSON; SPENCER em 1981 descreveram a importância de se explorar diferentes segmentos do mesmo nervo que se deve ao fato de que alterações patológicas são mais acentuadas distalmente e, escassas são as informações do que 
seria esperado em um nervo normal para a comparação e a interpretação dos achados patológicos. O estudo da lateralidade é também de extrema importância visto que muitos estudos experimentais utilizam a pata contralateral como controle de lesões cirúrgicas do nervo isquiático e/ou seus ramos (BERTHOLD et al., 1984; KIM et al., 1994; NAGAMATSU et al., 1993; KOVACIC et al., 2003; HU; MCLACHLAN, 2003).

Um dado fascicular bem documentado é a densidade de fibras mielínicas (DYCK et al., 1968; OCHOA; MAIR, 1969; CEBALLOS et al., 1999; VERDÚ et al., 2000; JACOBS; LOVE,1985; SCHELLENS et al., 1993), que é dada pelo número de fibras pela área fascicular total. Observa-se uma correlação negativa da densidade de fibras mielínicas com a idade (JACOBS; LOVE, 1985; SCHELLENS et al., 1993; CEBALLOS et al., 1999), alguns autores explicam que este aumento se deve na mesma ordem em que a área fascicular total aumenta (JACOBS; LOVE, 1985; SCHELLENS et al., 1993), visto que o número de fibras não se correlaciona com a idade (SHARMA et al., 1980; BERTHOLD et al., 1984; SCHELLENS et al., 1993), tendendo a manter-se constante. Não encontramos nenhum relato sobre a densidade das fibras mielínicas dos nervos safenos em ratos, sendo o dado apresentado nesse trabalho, de aproximadamente 29492 fibras $/ \mathrm{mm}^{2}$, original. No presente estudo os resultados referentes à densidade das fibras diferem dos acima citados, sendo que foi encontrado uma redução para a idade de 720 dias, com diferença significativa. Resultados semelhantes ao estudo de Jerônimo, et al, 2005 que ao analisar o nervo sural de ratas Wistar de 30, 90 e 180 dias de vida, observaram uma diminuição da densidade de fibras mielínicas, principalmente entre 30 e 90 dias, período em que ocorreu maior aumento da área fascicular total deste nervo. No entanto, Ceballos et al. (1999) mostraram que houve uma acentuada diminuição da densidade de fibras mielínicas acima de 27 meses. Estes autores referem que a redução deve-se ao fato de ocorrer uma diminuição no número de fibras mielínicas enquanto a área fascicular permanece a mesma. Em um outro estudo, Jerônimo ,et al, 2008 não encontraram diferença significativa ao analisar a densidade de fibras mielínicas dos grupos experimentais de 360, 640 e 720 dias de vida, fato que atribuíu a não haver diferença no número de fibras mielínicas e no tamanho da área fascicular dos grupos analisados. Entretanto, houve redução desses valores com o aumento da idade dos animais. Como não houve alteração do tamanho dos fascículos entre as idades, o dado é sugestivo de uma redução no número de fibras mielínicas com a idade.

A densidade de fibras mielínicas nos nervos varia de acordo com a idade dos animais (SAITUA \& ALVAREZ,1988; YAGIHASHI e cols., 1993). Uma vez que o número de fibras em animais normais é constante, o acréscimo de tecido conjuntivo endoneural que ocorre 
durante o crescimento, resulta em uma redução dos valores de densidade dessas fibras. Consideramos o valor da densidade das fibras mielínicas um parâmetro importante a ser observado porque, além dessa alteração decorrente do desenvolvimento normal dos nervos, esse parâmetro pode estar alterado como resultado da perda de fibras ou do aumento anormal do tecido conjuntivo endoneural ou, ainda, da proliferação das células de Schwann, como consequência de neuropatias, bem como da presença de brotamentos axonais distais nos estudos de regeneração. Em muitas situações de morfometria de nervos, diferentes autores não acessam $100 \%$ da área endoneural, como no presente estudo. Assim, esses autores contam fibras em uma determinada área do espaço endoneural e usam a densidade de fibras como parâmetro morfométrico a ser avaliado, ao invés do número absoluto.

Em relação ao número de fibras mielínicas no nervo safeno de ratos, cinco diferentes trabalhos mencionaram esse parâmetro, com similaridade relativa com nossos resultados. SCADDING (1980) relatou o achado de 929 fibras no nervo safeno de ratos Sabra com 3 meses de idade. Como o objetivo desse trabalho não era a investigação morfométrica das fibras mielínicas, os autores utilizaram apenas um rato, sem inclusive mencionar o sexo. No mesmo ano, ALPSAN \& LAL (1980) descreveram um valor médio de 730 fibras mielínicas, com valores entre 599 e 856, em nervos safenos de ratos adultos. Esses autores investigaram um total de 5 ratos. Posteriormente, Lynn (1984) descreveu um número médio de $1003 \pm 37$ fibras mielínicas em 4 ratos SD/G albinos, adultos. CARTER \& LISNEY (1987) descreveram valor médio de $1045 \pm 81$ fibras mielínicas nos segmentos proximais e $972 \pm 104$ nos distais, definidos como 10 a $12 \mathrm{~mm}$ dos proximais. CAMPOS, et al, 2008, ao analisarem o número de fibras mielínicas do nervo safeno para os animais com 30 dias de idade, os valores médios ficaram entre 500 à 700 para os segmentos distais e em torno de 800 para os proximais, sem diferenças entre segmentos e lados. No presente estudo os valores variaram para o segmento proximal, de 603 á 1038 fibras e para o segmento distal de 490 à 940, sem diferença significativa para lados nem segmentos. Observa-se, dessa forma, uma tendência à redução no número de fibras como avançar da idade. Embora tenhamos encontrado diferenças metodológicas significativas entre os trabalhos acima citados e o presente estudo, tanto em termos de preparo do tecido quanto em termos da análise das imagens, o número de fibras investigado pelos diferentes autores não se alterou e parece ser um parâmetro morfométrico estável, pouco vulnerável aos diferentes procedimentos histológicos. A redução do número de fibras no sentido distal, embora não significativa, também foi descrita por CARTER \& LISNEY (1987), sendo que os autores discutem que alguns axônios deixam o tronco principal do nervo ao longo do seu trajeto na perna. Em um estudo sobre o envelhecimento com nervos 
surais, JERÔNIMO, et al, em 2008 observaram as mesmas características que o presente trabalho com relação ao número de fibras mielínicas, uma tendência à redução do número com o envelhecimento, sem, no entanto, apresentar diferença significativa. Número de fibras constante com o envelhecimento foi uma característica observada também em outros estudos, mesmo os que estenderam o tempo de observação além do utilizado no presente estudo (SHARMA et al., 1980; SAITUA, ALVAREZ, 1988; KNOX et al., 1989).

Outro importante dado a ser considerado em um estudo morfométrico de nervos periféricos é a área fascicular total ocupada pelas fibras mielínicas, porém, estes dados são escassos na literatura. Não encontramos relatos prévios sobre a porcentagem da área fascicular ocupada pelas fibras mielínicas nos nervos safenos de ratos, acompanhados em diferentes fases do envelhecimento, porém, CAMPOS, et al, 2008, obtiveram o resultado de aproximadamente $36 \%$ para os nervos safenos de animais com 30 dias de vida. Knox et al. (1989) ao estudar o nervo sural citaram-na relatando que houve uma diminuição de 71,02 \% para $62,85 \%$ e $43,32 \%$ da área fascicular total ocupada pelas fibras mielínicas entre os grupos de 10, 20 e 30 meses, respectivamente. Jerônimo et al. (2004), relatam que a porcentagem da área ocupada pelas fibras mielínicas variou entre 28 e $42 \%$ quando analisado o nervo sural de ratas Wistar dos grupos de 30, 90 e 180 dias de vida. Em outro estudo, Jerônimo et al em 2008, ainda com nervos surais, em idades de 360, 640 e 720 ,esta porcentagem variou entre 26,40 a $37,25 \%$,n não havendo diferença significativa entre os segmentos, lados e grupos analisados.

No presente estudo esta porcentagem variou entre 13,27 a $48 \%$, não havendo diferença significativa entre os segmentos, lados e grupos analisados.

\subsection{FIBRAS MIELÍNICAS E SEUS RESPECTIVOS AXÔNIOS}

Os parâmetros mais comumente medidos em estudos morfométricos são o diâmetro das fibras e a espessura da bainha de mielina, em nível de microscopia de luz (HOLLAND, 1982). O diâmetro das fibras é usado como base para a classificação da população de fibras de um nervo e esse parâmetro tem sido correlacionado com as características funcionais dessas fibras, bem como com o estágio de desenvolvimento e regeneração dos nervos. Embora a espessura da bainha de mielina seja importante, a sua representação pode variar entre os estudos, sendo apresentada em forma de espessura, área ou número de lamelas.

Estudos experimentais sobre envelhecimento mostram que as mudanças morfológicas e morfométricas de nervos periféricos de ratos não são lineares durante a vida 
(CEBALLOS et al., 1999). Verdu et al. (2000), em sua revisão, cita que o formato circular das fibras mielínicas está relacionado com o tamanho do axônio: fibras de pequeno calibre são mais irregulares no formato do que as de grande calibre. Estes autores relatam também que, com o avançar da idade, a proporção de fibras mielínicas de diversos tamanhos com formato irregular em uma secção transversal do nervo aumenta em 50\%. Esses dados são, mais uma vez, compatíveis com nossas observações morfológicas, principalmente de um aumento na heterogeneidade da estrutura das fibras mielínicas com um aumento progressivo da proporção de fibras mielínicas irregulares com a idade.

Ao estudar o nervo sural de ratos Wistar fêmeas em diferentes fases do envelhecimento, JERÔNIMO, et al, em 2008, encontraram um discreto crescimento da área e do diâmetro da fibra, da área e do diâmetro do axônio e da área da bainha entre o grupo de 640 dias de vida em relação ao de 360 dias de vida, não havendo diferença significativa entre os grupos, lados e segmentos analisados, indicando que houve estabilização dos parâmetros morfométricos das fibras mielínicas. No grupo de 720 dias, foi verificado que, apesar de não haver diferença significativa, houve discreta diminuição da área e do diâmetro da fibra, e uma redução mais acentuada da área e diâmetro do axônio e da área da bainha em relação aos grupos de 360 e 720 dias de vida.

Em nosso estudo, com o nervo safeno de ratos Wistar fêmeas, também em diferentes fases do envelhecimento, nossos dados, apesar de serem com um nervo diferente do estudado, vão ao encontro com os dados do estudo acima citado, em que também verificamos um crescimento da área e do diâmetro da fibra, entre o grupo de 360 dias de vida em relação ao de 180 dias de vida, e não encontramos diferença significativa entre os grupos, lados e segmentos analisados, indicando que houve estabilização dos parâmetros morfométricos das fibras mielínicas. No grupo de 720 dias, foi verificado que, apesar de não haver diferença significativa, houve discreta diminuição da área e do diâmetro da fibra. Com relação a área e diâmetro do axônio e da área da bainha nossos resultados mostraram como no estudo de JERÔNIMO,et al, 2008, que há uma aumento desses parâmetro na idade de 360 dias em relação com 180 dias e uma diminuição na idade de 720 dias em relação à idade de 360 dias, com diferença significativa para a área dos axônios segmento proximal direito na idade de 360 dias. Verdú et al. (2000) relataram que alguns parâmetros mofométricos das fibras mielínicas, como a diminuição no tamanho da área e do diâmetro da fibra mielínica e da bainha de mielina, estão relacionados à idade e às características degenerativas progressivas. Outro importante fator a ser considerado quando verificamos a diferença entre a área das fibras mielínicas dos grupos analisados é a mudança no formato das fibras mielínicas com o 
decorrer da idade, que pode influenciar no tamanho da área medida (CEBALLOS et al., 1999).

Dados que também indicam os sinais degenerativos em nosso estudo, no grupo de 720 dias, é a distribuição do diâmetro das fibras mielínicas e dos axônios. Os histogramas de distribuição de frequência do diâmetro das fibras mielínicas e dos axônios deste grupo apresentam-se unimodais e discretamente deslocados para a esquerda, mostrando que houve uma redução do número de fibras mielínicas e axônios de pequeno calibre. Semelhante a este estudo, Sharma et al. (1980), ao analisar a distribuição do diâmetro de fibras mielínicas do nervo plantar medial de ratos Wistar machos, observaram que houve um aumento do diâmetro mínimo e máximo no grupo de 9 meses de 7,5 $\mu \mathrm{m}$ e $12,8 \mu \mathrm{m}$, respectivamente, em relação aos de 2 meses, com diâmetro de 4,4 $\mu \mathrm{m}$ e $8,4 \mu \mathrm{m}$, respectivamente. Estes autores ressaltam que nos grupos de 12,15, 18, 21 e 24 meses não houve diferença significativa em relação ao de 9 meses, mas que no grupo de 24 meses houve uma discreta diminuição. Neste estudo, Sharma et al. (1980) apresentaram histogramas dos grupos de 2, 4 e 6 meses unimodais, deslocados para a esquerda, enquanto os grupos de 9, 12, 15 meses eram bimodais, deslocados para a direita. O grupo de 18, 21 e 24 meses apresentaram-se bimodais, discretamente deslocados para a esquerda, indicando que há um grande número de fibras mielínicas de pequeno calibre.

Verdú et al. (2000), em sua revisão sobre a influência do envelhecimento sobre a atividade e a regeneração do nervo periférico, cita que a diminuição da velocidade de condução com o avançar da idade parece estar relacionada com a diminuição no número e na densidade de fibras mielínicas, a diminuição de fibras amielínicas e o aumento das irregularidades no formato das fibras mielínicas. Verdú et al. (2000) citaram também outros autores que referem como causa da diminuição da velocidade de condução com o avançar da idade, a diminuição do diâmetro do axônio, sendo a desmielinização e a remielinização eventos secundários à diminuição do tamanho do axônio.

A razão $G$ relaciona-se com a condução saltatória e foi designada como sendo a relação entre o diâmetro axonal/diâmetro total da fibra (SCHMITT; BEAR, 1937). RUSHTON (1951) referiu que os valores da razão $G$ entre 0,6 e 0,7 seriam aqueles nos quais a velocidade de condução de uma determinada fibra mielínica seria máxima. Razão G entre 0,6 e 0,7 para fibras mielínicas foram referidas por SCHMITT \& BEAR (1937), SANDERS (1948), EVANS \& VIZOSO (1951), WILLIAMS \& WENDELL-SMITH (1971), FAZAN e cols. (1997, 1999, 2005), JERÔNIMO e cols. (2005) e SATO e cols. (2006). Ceballos et al.(1999), ao analisar camundongos Swiss de 6, 9, 12, 16, 22 e 27-33 meses, verificaram que 
houve uma variação de $8 \%$ na razão $G$ dos grupos analisados, havendo diminuição significativa entre o grupo de 22 e 27-33 meses (0,70 e 0,65, respectivamente). Jerônimo et al, em 2008, verificaram que a média da razão G nos grupos 360, 640 e 720 dias de vida foi de 0,53, 0,56 e 0,47, respectivamente. Possivelmente, esta diminuição da razão G no grupo com 720 dias de vida é dada pela diminuição no tamanho do axônio. Em nosso estudo verificamos que a média da razão $\mathrm{G}$ nos grupos 180, 360 e 720 dias de vida foi de 0,47; 0,48 e 0,45; respectivamente. Possivelmente, esta diminuição da razão $G$ no grupo com 720 dias de vida também é dada pela diminuição no tamanho do axônio, sendo compatível ao estudo citado por Verdú et al. (2000) e Jerônimo et al (2008) sugerindo a presença de fibras degeneradas, com atrofia axonal.

Esse dado é reforçado pelo estudo dos histogramas de distribuição da razão G, comparando os três grupos experimentais do presente estudo. Percebemos nitidamente que a distribuição da razão $\mathrm{G}$ dos nervos safenos dos animais com 720 dias de vida é deslocada para valores menores que 0,6, com diferença significativa para a idade de 360 dias em relação á 180 dias, indicando um grande número de fibras mielínicas com sinais morfométricos de atrofia axonal.

Os dados morfológicos e morfométricos apresentados no presente estudo sugerem que nervos safenos de animais com 360 dias (aproximadamente um ano) de vida já apresentam alguns sinais de neuropatia, que pode ser decorrente do envelhecimento. Esses sinais se agravam com o aumento da idade dos animais, acompanhando raras descrições de literatura, quando os autores estenderam seus estudos além dos 720 dias de vida. 
CONCLUSÕES 
Os resultados do presente estudo permitem as seguintes conclusões:

1- Os nervos safenos de animais Wistar fêmeas com 180 dias de vida são morfometricamente simétricos, tanto no sentido longitudinal quanto lateral.

2- Os nervos safenos de animais Wistar fêmeas com 360 dias de vida são morfometricamente simétricos, tanto no sentido longitudinal quanto lateral.

3- Os nervos safenos de animais Wistar fêmeas com 720 dias de vida são morfometricamente simétricos, tanto no sentido longitudinal quanto lateral.

4- Na comparação entre as idades, os nervos safenos de animais com 720 dias de vida mostraram discreta redução do tamanho médio dos axônios, bem como da razão G média.

5- Ainda na comparação entre as idades, os nervos safenos de animais com 720 dias de vida mostraram desvio para a esquerda das distribuições do tamanho das fibras e da razão G, sugerindo redução do tamanho das fibras, bem como a presença de atrofia axonal.

6- A morfologia do nervo safeno dos ratos é afetada pelo envelhecimento, principalmente a bainha de mielina das fibras de grande calibre, o que pode se refletir morfometricamente nas diferenças observadas nos histogramas de distribuição das fibras e da razão G. 
REFERÊNCIAS BIBLIOGRÁFICAS 


\section{REFERÊNCIAS BIBLIOGRÁFICAS}

ALLNAT, J. P.; DICKSON, K. E.; LISNEY, S. J. Saphenous nerve injury and regeneration on one side of a rat suppresses the ability of the contralateral nerve to evoke plasma extravasation. Neurosci., v. 118, p. 219-222, 1990.

ALPSAN, D.; LAL, S. Combined light- and electron microscopic study of the rat saphenous nerve. Acta. Anat., v. 106, n. 1, p. 141-149, 1980.

BARANOWSKI, A. P; PRIESTLEY, J. V; MCMAHON, S. B. The consequence of delayed versus immediate nerve repair on the properties of regenerating sensory nerve fibers in the adult rat. Neurosci Lett., v. 168, p. 197-200, 1994.

BEHSE, F. Morphometric studies on the human sural nerve. Acta Neurol. Scand., v. 82, n. 132 , p. 5-38, 1990.

BERTHOID, C. H; LUGNEGARD, H; RYDMARK. Ultrastructural morphometric studies on regeneration of the lateral sural cutaneos nerve in the white rat after transsection of the sciatic nerve. Scandinavian Journal of Plastic and Reconstructive Sugery. v. 20, p. 05-13, 1984.

BERTHOLD, C. H. A study on the fixation of large mature myilinated ventral lumbar spinal root fibers. Acta societatis medicorum upsaliensis. v.73, suppl 9, 1968.

BOUCHE, P; CATTELIN, F; SAINT-JEAN, O; LÉGER, J. M; QUESLATI, S; GUEZ, D. Clinical and electrophysiological study on the peripheral nervous system in the elderly. J. Neurol., v. 240, p. 263-268, 1993.

BOYCOTT, A. E. On the number of nodes of Ranvier in different stages of the growth of nerve fibers in the frog. J. Physiol., v. 30, p. 370-380, 1904.

BRENAN, A.; JONES, L.; OWAIN, N. R. The demonstration of the cutaneous distribution of saphenous nerve $\mathrm{C}$-fibre using a plasma exttravasation technique in the normal rat and following nerve injury. J. Ant., v. 157, p. 57-66, 1988.

CAMPOS, S. A. R.; SANADA, L. S.; SATO, K. L.; FAZAN, V. P. S. Morphometry of saphenous nerve in young rats. J. Neurosci. Methods., v. 168, n. 1, p. 8-14, 2008.

CARTER, D. A.; LISNEY, S. J. W. The numbers of unmyelinated and myelinated axons in normal and regenerated rat saphenous nerves. J. Neurol. Sci., v. 80, p. 163-171, 1987.

CAUSEY, G; BARTON, A. A. The cellular content of the endoneurium of peripheral nerve. Brain, v. 82, p. 594-598, 1959.

CEBAllos, D; CUARDAS, J; VERDÚ, E; NAVARRO, X. Morphometric and ultrastructural changes with ageing in mouse peripheral nerve. J. Anat., v. 195, p. 563-576, 1999. 
COQ, J.O; Xerri C. Age-related alteration of the forepaw representation in the rat primary somatosensory cortex. Neuroscience. 2000;99(3):403-11, 2000.

COLEMAN, P; FINCH, C; JOSEPH, J. The need for multiple time points in aging studies. Neurobiology of aging, v. 11, p. 1-2, 1990.

CUNHA M. T. R; SILVA, A. L; FENELON, S. B. Comparison of nerve graft integration after segmentar resection versus epineurial burying in crushed rat sciatic nerves. Acta Cir. Bras., v. 12, p. 221-225, 1997.

DECOSTERED, I; WOOLF, C. J. Spared nerve injury: in animal model of persistent peripheral neuropathic pain. Pain, v. 87, p. 149-158, 2000.

DE SÁ, J. M; MAZZER, N; BARBIERI, C. H; BARREIRA, A. A. The end-to-side peripheral nerve repair. Function and morphometric study using the peroneal nerve of rats. J. Neurosci Methods, v. 136, p. 45-53, 2004

DONALDSON, H. H; HOKE, G. W. On the areas of the axis cylinder and medullary sheath as seen in cross sections of the spinal nerves in vertebrates. J. Comp. Neurol., v. 15, p. 1-16, 1905.

DOUBELL, T. P.; MANNION, R. J.; WOOF, C. J. Intact sciatic myelinated primary afferent terminals collaterally sprout in the adult rat dorsal horn following section of a neighboring peripheral nerve. J. Comp. Neurol., v. 380, p. 95- 104, 1997.

DORFMAN, L. J; BOSLEY, T. M. Age-related changes in peripheral and central nerve conduction in man. Neurology, v. 29, p. 38-44, 1979.

DYCK, P. J.; LOFGREN, E. P. Method of fascicular biopsy of human peripheral nerve for electrophysiologic and histologic study. Mayo. Clin. Proc., v. 41, p. 778-784, 1966.

ECLES, J. C.; SHERRINGTON, C. S. Numbers and contraction values of the individual motor units examined in some muscle of the limb. Proc. Roy. Soc. B., v. 106, p. 326-357, 1930.

FAZAN, V. P. S.; BARREIRA, A. A. A Aortic depressor nerve myelinated fibers in acute and chronic experimental diabetes. Am. J. Hypertens., v.19 (2), p. 130-136, 2006.

FAZAN, V. P. S.; FAZAN JUNIOR, R.; SALGADO, H. C.; BARREIRA, A. A. Aortic depressor nerve myelinated fibers morphology in normotensive Wistar-Kyoto and spontaneously hypertensive rats. J. Aunton. Nerv. Sys., v.77, p. 133-139,1999.

FAZAN, V. P. S.; SALGADO, H. C.; BARREIRA, A. A. A descriptive and quantitative light and electron microscopy study of the aortic depressor nerve in normotensive rats. Hypert., v. 30, p. 693-698, 1997.

FAZAN, V. P. S.; SALGADO, H. C.; BARREIRA, A. A. A Aortic depressor nerve unmyelinated fibers in spontaneously hypertensive rats. Am. J. Physiol. Heart. Circ. Physiol., v.280, p. H.1560-H1564, 2001. 
FAZAN, V. P. S.; SALGADO, H. C.; DOS REIS, G. C.; BARREIRA, A. A. Relation between myelin area and axon diameter in the aortic depressor nerve of spontaneously hypertensive rats. J. Neurosci. Methods., v.148, p. 130-136, 2005.

FAZAN, V. P. S.; XIUYING, M. A.; CHAPLEAU, M. W.; BARREIRA, A. A. Qualitaive and quantitative morphology of renal nerve in C57BL/6J mice. Anat. Rec., v. 268, p. 399404, 2002.

FITZGERALD, M. The sprouting os saphenous nerve terminals in the spinal cord following early postnatal sciatic nerve section in the rat. J. Comp. Neurol., v. 240, p. 407-413, 2004.

FRAHER, J. P. Quantitative studies on the maturation of central and peripheral parts of individual ventral motoneuron axons. I. Myelin sheath and axon caliber. J. Anat., v. 126, p. $509,1978$.

FRAHER, J. P. Myelin-axon relationships in the rat phrenic nerve: longitudinal variation and lateral asymmetry. J. Comp. Neurol., v. 323, p. 551-557, 1992.

FRIDE, R. L.; BEUCHE W. A new approach toward analyzing peripheral nerve fiber populations I. Variance in sheath thickness corresponds to different geometric proportions of the internodos. J. Neuropathol. Exp. Neurol., v. 44, p. 60-72, 1985.

FRIEDE, R. L; SAMORAJSKI, T. Relation between the number of lamellae and axon circumference in fibers of vagus and sciatic nerve of mice. J. Comp. Neurol. v. 130, p. 223$232,1967$.

GAMBLE, H. J.; EAMES, R. An electron microscope study of the connective tissues of human perpheral nerve. J. Anat., v. 98, p. 655, 1964.

GARDNER, E.; GRAY, D. J.; O'RAHILLY, R. Anatomia. 4. ed. Rio de Janeiro: Guanabara Koogan, 1978. p. 815.

GASSER, H. S.; ERLANGER, J. The role played by the sizes of the constituent of a nerve trunk in determining the form of its action potential wave. Am. J. Physiol., v. 80, p. 522-547, 1927.

GASSER, H. S.; GRUNDFEST, H. Axon diameters in relation to the spike dimensions and the conduction velocity in mammalian A fibers. Am. J. Physiol., v. 127, p. 393-414, 1939.

GILMORE, S. A. Spinal nerve root degeneration in aging laboratory rats: A light microscopic study. Anat. Rec. v. 174, p. 251-258, 1972.

GREENE, C. E. Anatomy of the rat. New York: Philadelphia, 1963.

GROVER-JOHNSON N; SPENCER P. S. Peripheral nerve abnormalities in aging rats. $\quad$ J. Neuropathol. Exp. Neurol., v. 40, p.155-165, 1981. 
HESS, J.R; BRENNER ,J.R, MYCKATYN, J.R, HUNTER,J.R. Influence of aging on regeneration in end-to-side neurorrhaphy. Annals of plastic surgery. Aug; 57()217-22,2006.

IIZUKA, M.; YAO, R.; WAINAPEL, S. Saphenous nerve injury following medial knee joint injection: a case report. Arch. Phys. Med. Rehabil., v. 86, p. 2062-2065, 2005.

JACOBS, J. M; LOVE, S. Qualitative and quantitative morphology of human sural nerve at different ages. Brain, v.108, p. 897-924, 1985.

JEFFERYS, J.G.R; PALMANO, K. P; SHARMA, A. K; THOMAS, P. K. Influence on dietary myoinositol on nerve conduction and inositol phospholipids in normal and diabetic rats. J. Neurol. Neurosurg. Pshychiatry, v. 41, p. 333-339, 1978.

JENQ, C. B.; COGGESHALL, R. E. Regeneration of axons in tributary nerves. Brain Res., v. 310, p. 107, 1984.

JERONIMO, A.; JERONIMO, C. A. D.; FILHO, O. A.; SANADA, L. S.; FAZAN, V. P. S. A morphometric study on the longitudinal and lateral symmetry of the sural nerve in mature and aging female rats. Brain Res., v. 1222, p. 51-60, 2008.

JERONIMO, A.; JERONIMO, C. A. D.; RODRIGUES FILHO, O. A.; SANADA, L. S.; FAZAN, V. P. S. Microscopic anatomy of the sural nerve in the postnatal developing rat: a longitudinal and lateral symmetry study. J. Anat., v. 206, n. 1, p. 93-99, 2005.

KANDA .K ; HASHIZUME .K; BURKER.E.. Effects of long-term physical exercise on agerelated changes of spinal motoneurons and peripheral nerves in rats. Neurosci Res. 1998 May;31(1):69-75.

KARAMUSEL, S.; CELEBIOGLU, S. Use of the medial side of the knee skin us a free flap: saphenous flap. Plast. Reconstr. Surg., v. 117, p. 1308-1314, 2006.

KARNES, J.; ROBB, R.; O’BRIEN, P. C.; LAMBERT, E. H.; DYCK, P. J. Computerized image recognition for morphometry of nerve atribute of shape of sampled transverse sections of myelinated fibers which best estimates their average diameter. J. Neurol. Sci., v. 34, p. 43$51,1977$.

KIM, D. H.; CONNOLLY, S. E.; KLINE, D. G.; VOORHIES, R. M.; SMITH, A.; POWELL, M.; YORES, T.; DANILOFF, J. K. Labeled Schwann cell transplants versus sural nerve grafts in nerve repair. J. Neurosurg., v. 80, p. 254-260, 1994.

KRINKE, G; FROEHLICH E, HEUMANN, M; SCHNIDER, K; DA SILVA, F; SUTER, J. Adjustment of the myelin sheath to axonal atrophy in the rat spinal root by the formation of infolded myelin loops. Acta Anatomica. v.131, p. 182-187, 1988.

KNOX, C. A; KOKMEN, E; DYCK, P. J. Morphometric alteration of rat myelinated fibers with aging. J. Neuropathol. Exp. Neurol., v. 48, p. 119-139, 1989. 
KOVACIC, U.; SKETELJ, J.; BAJROVIC, F. F. Sex-related difference in collateral sprouting of nociceptive axons after peripheral nerve injury in the rat. Exp. Neurol., v. 184, p. 479-488, 2003.

LAFRATA, C. W; CASTETRARI, R. E. A comparison of sensory and motor nerve conduction velocities as related to age. Arch. Phys. Med. Rehab., v. 49, p. 286-290, 1966.

LAMOTTE, C. C.; KAPADIA S. E. Deafferentation - induced terminal field expansion of myelinated saphenous afferents in the adult rat dorsal horn and the nucleus gracilis following pronase injection of the sciatic nerve. J. Comp. Neurol., v. 330, p. 83-94, 1993.

LAXMISHA, C.; THAPPA, D. M.; KUMAR, M. S.; JOSEPH, L. C.; JAYANTHI, S. Pure neural leprosy presenting with multiple nerve abscesses. Indian. J. Lepr., v. 76, p. 343-350, 2004.

LLOYD, D. P. C. Neuron patterns controlling transmission of ipsilateral hind limb reflex in cat. J. Neurophysiol., v. 6, p. 293-315, 1943.

MAJEED, S. K. Survey on spontaneous peripheral neuropathy in aging rats. ArzneimForsh/Drugs Res., v. 42, p. 986-990, 1992.

MENDONÇA A. C; BARBIERI, C. H; MAZZER, N. Directly applied low intensity direct electric current enhances peripheral nerve regeneration in rats. J Neurosci Methods. v. 129, p. 183-190, 2003

MOLANDER, C.; KINNMAN, E.; ALDSKOGIUS, H. Expansion of spinal Cord primary sensory afferent projections following combined sciatic nerve resection and saphenous nerve crush: a horseradish peroxidase study in the adult rat. J. Comp. Neurol., v. 276, p. 436-441, 1988.

MOORE, K. L.; DALLEY, A. F. Anatomia orientada para a clínica. 4. ed. Rio de Janeiro: Guanabara Koogan, 2001.

NAGAMATSU, M.; SUGIMURA, K.; AOKI, S.; TAKAHASHI, A. Morphometric analysis of the sural nerve in experimental dorsal rhizotomy in rats. J. Neurol. Sci., v. 116, p. 170$175,1993$.

NERI,L. O. ; AMORIM ,M. M.; CAMPOS,S.A.R; SANADA,L.S; FAZAN,V.P.S. Hind Limb Sensory Innervation in Rats: Comparison between Sural and Saphenous Nerve Morphometry. Int. J. Morphol., 33(2):743-750, 2015.

NIR-PAZ, R.; LUDER, A. S.; COZACOV, J. C.; SHAHIN R. Saphenous nerve entrapment in adolescende. Pediatrics, v. 103, p. 161-163, 1999.

OCHOA, J.; MAIR, W. P. G. The normal sural nerve in man- I. Ultrastructure and numbers of fibers and cells. Acta. Neuropathol., v. 13, p. 197-216, 1969a .

OCHOA, J.; MAIR, W. P. G. The normal sural nerve in man- II. Changes in the axons and Schwann cells due to ageing. Acta Neuropathol., v. 13, p. 217-239, 1969 b. 
OLIVEIRA, E. F; MAZER, N; BARBIERI, C. H; DELBEL, E.A. The end-to-side peripheral nerve repair. Funcional and morphometric study using the peroneal nerve of rats. J. Neurosci Methods. v. 136, p. 45-53, 2004.

ORGEL, M. G; TERZIS, J. K. Epineural vs perineaural repair. Plastic and reconstructive. v. 60, p. 80-91, 1977.

O'SUlLIVAN, D. J; SWALLOW, M. The fiber size and content of the radial and sural nerves. J. Neurosurg. Psychiary., v. 31, p. 464-470, 1968.

POLA,R ; APRAHAMIAN, T.R ; BOSCH-MARCÉ,M; CURRY,C Age-dependent VEGF expression and intraneural neovascularization during regeneration of peripheral nerves. Neurobiology of Aging. Volume 25, Issue 10, November-December 2004, Pages 1361-1368

POMERANZ, B.; MULLEN, M.; MARKUS, H. Effect of applied electrical fields on sprouting of intact saphenous nerve in adult rat. Brain Res., v. 303, p. 331-336, 1984.

PYNE, D.; JAWAD, A. S. M.; PADHIAR, N. Saphenous nerve injury after fasciotomy for compartment syndrome. Br. J. Sport Med., v. 37, p. 541-542, 2003.

RASO, V. V; BARBIERI, C. H; MAZER, N; FAZAN, V. P. S. Can therapeutic ultrasound influence the regeneration of peripheral nerves ? J. Neurosci Methods. v. 142, p. 185-92, 2005.

REXED, B. Contribution to the knowledge of the postnatal development of the peripheral nervous system in man. Acta Psychiat. Neurol., v. 206 p. 33-34, 1944.

RODRIGUES FILHO, O.A; FAZAN, V. P. S. Streptozotocin induced diabetes as a modelo of phrenic nerve neuropathy in rats. J Neurosci Methods. v. 151, p. 131-8, 2006.

RODRIGUES,F.F.; SKARTZ,I.; DOZZA,D.C.; MOSCOVICI,M.; SUCHMACHER,M. Traumatic lesions of internal saphenous nerve and branches. Arq Neuropsiquiatr 2009;67(3-B):897-899.

RUSHTON, W. A. H. A theory of the effects of fiber size in medullated nerve. J. Physiol., v. 115, p. 101-122, 1951.

SANADA, L. S.; ROCHA, K. A. L.; TAVARES, M. R.; NEURBEM, M. C.; SALGADO, H. C.; FAZAN, V. P. Sural nerve involvement in experimental hypertension: morphology and morphometry in male and female normotensive Wistar-Kyoto (WKY) and spontaneously hypertensive rats (SHR). BMC Neurosci., v. 13, p. 24, 2012.

SCHMELZER, J. D; LOW, P. A. Electrophysiological studies on the effect of age on caudal nerve of the rat. Exp. Neurol., v. 96, p. 612-629, 1987

SCHMITT, F. O.; BEAR, R. S. Optical properties of the axon sheaths of crustacean nerves. J. Cell. Comp. Physiol., v. 9, p. 275, 1937. 
SECKEL, B. R; RYAN, J. E; GAGNE, R. G; WATKINS, E. Vascularized vc nonvascularized nerve grafts: an experimental structural comparison. Plastic and Reconstructive Surgery. v. 78, p. 211-220, 1986

SHAKHNBEH, J.; KHLEIFAT, K. Failure of regeneration of sensory nerve fibers following neonatal denervation and crush lesion in rats. Turk. J. Biol., v. 27, p. 215-221, 2003.

SHAMALBRUCH, H. Fiber composition of the rat sciatic nerve. Anat. Rec., v. 215, n. 1, p. 71-81, 1986.

SHERRINGTON, C. S. On the anatomical constitution of nerves of skeletal muscles: with remarks on recurrent fibers in the ventral spinal root. J. Physiol., v. 17, p. 211-258, 1894.

SMITH, R. S.; KOLES, Z. J. Myelinated nerve fibers: computed effects of myelin thickness on conduction velocity. Am. J. Physiol., v. 219, p. 1256-1258, 1970.

SONG, A.; TRACEY, D. J.; ASHWELL, K. W. Development of the rat phrenic nerve and the terminal distribution of phrenic afferents in the cervical cord. Anat. Embryol., v. 200, n. 6, p. 625-643, 2000.

SUNDERLAND, S.; BRADLEY, K. C. The cross-sectional area of peripheral nerve trunks devoted to the nerve fibers. Brain., v. 72, p. 428-449, 1949.

SUNDERLAND, S.; LAVARACK, J. O.; RAY, L. J. The caliber of nerve fibers in human cutaneous nerves. J. Comp. Neurol., v. 91, p. 87-101, 1949.

SWALLOW, M. Fiber size and content of anterior tibial nerve of the foot. J. Neurol. Neurosurg. Psychiatry., v. 29, p. 205-213, 1966.

SWETT, J.E.; WOOLF,C.J. The somatotopic organization of primary afferent terminals in the superficial laminae of the dorsal horn of the rat spinal cord. J. Comp. Neurol., v. 231, p. 66$77,1985$.

TAYLOR, P. K. Nonlineal effects of age on nerve condution in adults. J. Neurol. Sci., v. 66, p. 223-234, 1984.

TEIXEIRA, A.R.; NUNES, M.G.P.; FREITAS, C.L.R. et al. Análise da qualidade de vida em idosos com sintoma de zumbido. Arq. Int. Otorrinolaringologia, v.14, n.1, p.54-59, 2010.

TIAGO,R.S.L.; PONTES,A.L.P.; BRASIL,O.O.C. Análise quantitativa das fibras mielínicas dos nervos laríngeos em humanos de acordo com a idade. Rev Bras Otorrinolaringo.2008;74(1):45-52.

TORCH, S; STOEBNER, P; USSON, Y; D AUBIGNY, G. D; SAXOD, R. There is no simple adequate sampling scheme for estimating the myelinated fiber size distribution in human peripheral nerve: a statistical ultrastructural study. Journal of Neuroscience Methods. v. 27, p. 149-164, 1989.

THOMAS, P. K. The connective tissue of peripheral nerve: an electron microscope study. J. Anat. London., v. 97, p. 35-44, 1963. 
THOMAS, P. K. The quantification of nerve biopsy findings. J. Neurol. Sci., v. 11, p. 285$295,1970$.

THOMAS, P. K.; KING, R. H. M.; SHARMA, A. K. Changes with age in the peripheral nerves of the rat. Acta Neuropathol., v. 52, p. 1-6, 1980.

TROJABORG, W. Motor and sensory conduction in the musculocutaneous nerve. J. Neurol. Psychiat., v. 39, p. 890-899, 1976.

VAN STENIS, G; KROES, R. Changes in the nervous system and musculature of old rats. Vet. Pathol., v. 8, p. 320-332, 1971.

VEJSADA, R.; PALECEK, J.; HNÍK, P. Permanent alterations of spinal cord reflexes following nerve lesion in newborn rats. Physiol., v. 48, p. 483-489, 1999.

VERDÚ, E; CEBALlOS, D; VILCHES, J. J; NAVARRO, X. Influence of aging on peripheral nerve function and regeneration. J. peripheral nervous system, v. 5, p. 191-208, 2000.

WALCAZAK, J. S.; PICHETTE, V.; LEBLOND, F.; DESBIENS, K.; BEAULIEU, P. Behavioral, pharmacological and molecular characterization of the saphenous nerve partial ligation: a new model of neuropathic pain. Neuroscience., v. 132, p. 1093-1102, 2005.

WIESENFELD-HALLIN, Z.; KINNMAN, E.; ALDSKOGIUS, H. Studies of normal and expansive cutaneous innervation territories of intact and regenerating $\mathrm{C}$-fibres in the hindlimb of the rat. Agents and Actions. V. 25. n 3-4, p. 260-262, 1988.

YASUDA, T.; MIKI, S.; YOSHINAGA, N.; SENBA, E. Effects of amitriptyline and gabapentin on bilateral hyperalgesia observed in an animal model of unilateral anatomy. Pain., v. 115, n. 1/2, p. 161-170, 2005. 
ANEXOS 


\begin{tabular}{ccccc} 
& \multicolumn{2}{c}{ Lado Direito } & \multicolumn{2}{c}{ Lado Esquerdo } \\
\cline { 2 - 5 } ANIMAL & Proximal & Distal & Proximal & Distal \\
\hline $\mathbf{1}$ & 56180,87 & 44397,67 & 45854,15 & 35078,49 \\
$\mathbf{2}$ & 45841,11 & 41610,16 & 30373,79 & 59541,74 \\
$\mathbf{4}$ & 47194,12 & 25157,89 & 52886,73 & 44218,17 \\
$\mathbf{5}$ & 45358,25 & 13590,06 & 53836,50 & 106853,50 \\
$\mathbf{6}$ & 57584,89 & 28744,53 & 57250,04 & 29662,06 \\
& 51424,63 & 35715,58 & 14262,23 & 40995,79 \\
Média & & & & \\
DPM & $\mathbf{5 0 5 9 7 , 3 1}$ & $\mathbf{3 1 5 3 5 , 9 8}$ & $\mathbf{4 2 4 1 0 , 5 7}$ & $\mathbf{5 2 7 2 4 , 9 6}$ \\
EPM & $\mathbf{5 3 3 5 , 5 0}$ & $\mathbf{1 1 4 4 4 , 7 3}$ & $\mathbf{1 6 7 9 0 , 3 7}$ & $\mathbf{2 8 3 8 8 , 7 4}$ \\
& $\mathbf{2 1 7 8 , 2 1}$ & $\mathbf{4 6 7 2 , 2 9}$ & $\mathbf{6 8 5 4 , 6 4}$ & $\mathbf{1 1 5 8 9 , 6 5}$ \\
\hline
\end{tabular}

Tabela I: Área fascicular (expressa em $\mu \mathrm{m}^{2}$ ) dos nervos safenos dos animais do grupo I (180 dias). DPM = desvio padrão da média. EPM = erro padrão da média.

\section{Lado Direito}

Lado Esquerdo

\begin{tabular}{ccccc}
\hline ANIMAL & Proximal & Distal & Proximal & Distal \\
\hline $\mathbf{1}$ & 32126,80 & 58303,34 & 53152,85 & 39229,99 \\
$\mathbf{2}$ & 75936,89 & 46856,03 & 74915,44 & 69105,24 \\
$\mathbf{3}$ & 51360,4 & 62558,47 & 60986,29 & 57083,05 \\
$\mathbf{4}$ & 74555,70 & 38178,31 & 58443,73 & 6243,37 \\
$\mathbf{5}$ & 60560,63 & 32362,84 & 65881,62 & 30197,09 \\
$\mathbf{6}$ & 62566,96 & 21439,51 & 60783,73 & 28907,87 \\
Média & $\mathbf{5 9 5 1 7 , 9 0}$ & $\mathbf{4 3 2 8 3 , 0 8}$ & $\mathbf{6 2 3 6 0 , 6 1}$ & $\mathbf{3 8 4 6 1 , 1 0}$ \\
DPM & $\mathbf{1 6 2 6 6 , 0 4}$ & $\mathbf{1 5 6 9 9 , 4 7}$ & $\mathbf{7 4 0 9 , 7 4}$ & $\mathbf{2 2 2 8 8 , 8 8}$ \\
EPM & $\mathbf{6 6 4 0 , 5 8}$ & $\mathbf{6 4 0 9 , 2 8}$ & $\mathbf{3 0 2 5 , 0 2}$ & $\mathbf{9 0 9 9 , 4 0}$ \\
\hline
\end{tabular}

Tabela II: Área fascicular (expressa em $\mu \mathrm{m}^{2}$ ) dos nervos safenos dos animais do grupo II (360 dias). DPM = desvio padrão da média. EPM = erro padrão da média. 


\section{Lado Direito Lado Esquerdo}

\begin{tabular}{ccccc}
\hline ANIMAL & Proximal & Distal & Proximal & Distal \\
\hline $\mathbf{1}$ & 38874,01 & 16004,96 & 52381,17 & 114387,10 \\
$\mathbf{2}$ & 47759,56 & 72532,21 & 38483,53 & 59920,86 \\
$\mathbf{3}$ & 64274,30 & 25901,24 & 62604,99 & 49663,97 \\
$\mathbf{4}$ & 46801,32 & 69856,28 & 47618,43 & 62153,11 \\
$\mathbf{5}$ & 51822,39 & 49308,33 & 80650,28 & 44823,93 \\
$\mathbf{6}$ & 20622,18 & 31622,07 & 62391,47 & 40327,73 \\
Média & $\mathbf{4 5 0 2 5 , 6 3}$ & $\mathbf{4 4 2 0 4 , 1 8}$ & $\mathbf{6 9 2 2 2 , 5 7}$ & $\mathbf{6 1 8 7 9 , 4 5}$ \\
DPM & $\mathbf{1 4 5 6 5 , 0 6}$ & $\mathbf{2 3 5 5 8 , 7 0}$ & $\mathbf{9 7 0 3 , 3 8}$ & $\mathbf{2 7 0 7 6 , 0 0}$ \\
EPM & $\mathbf{5 9 4 6 , 1 6}$ & $\mathbf{9 6 1 7 , 8 0}$ & $\mathbf{4 8 5 1 , 6 9}$ & $\mathbf{1 1 0 5 3 , 7 3}$ \\
\hline
\end{tabular}

Tabela III: Área fascicular (expressa em $\mu \mathrm{m}^{2}$ ) dos nervos safenos dos animais do grupo III (720 dias). DPM = desvio padrão da média. EPM = erro padrão da média.

\section{Lado Direito Lado Esquerdo}

\begin{tabular}{ccccc}
\hline ANIMAL & Proximal & Distal & Proximal & Distal \\
\hline $\mathbf{1}$ & 260,99 & 197,79 & 219,73 & 119,05 \\
$\mathbf{2}$ & 230,21 & 129,32 & 103,32 & 243,98 \\
$\mathbf{3}$ & 217,43 & 90,382 & 228,44 & 205,30 \\
$\mathbf{4}$ & 117,95 & 92,63 & 174,28 & 359,46 \\
$\mathbf{5}$ & 252,96 & 102,66 & 258,08 & 188,13 \\
$\mathbf{6}$ & 236,54 & 99,57 & 77,23 & 197,32 \\
Média & $\mathbf{2 1 9 , 3 5}$ & $\mathbf{1 1 8 , 7 3}$ & $\mathbf{1 7 6 , 8 5}$ & $\mathbf{2 1 8 , 8 7}$ \\
DPM & $\mathbf{5 2 , 0 8}$ & $\mathbf{4 1 , 1 7}$ & $\mathbf{7 2 , 7 1}$ & $\mathbf{7 9 , 9 4}$ \\
EPM & $\mathbf{2 1 , 2 6}$ & $\mathbf{1 6 , 8 1}$ & $\mathbf{2 9 , 6 8}$ & $\mathbf{3 2 , 6 4}$ \\
\hline
\end{tabular}

Tabela IV: Diâmetro mínimo fascicular (expresso em $\mu \mathrm{m}$ ) dos nervos safenos dos animais do grupo I (180 dias). DPM = desvio padrão da média. EPM = erro padrão da média. 


\section{Lado Direito Lado Esquerdo}

\begin{tabular}{ccccc}
\hline ANIMAL & Proximal & Distal & Proximal & Distal \\
\hline $\mathbf{1}$ & 118,29 & 250,65 & 237,88 & 131,97 \\
$\mathbf{2}$ & 269,21 & 191,38 & 247,70 & 181,64 \\
$\mathbf{3}$ & 239,05 & 91,08 & 229,22 & 139,71 \\
$\mathbf{4}$ & 289,65 & 136,95 & 253,56 & 83,87 \\
$\mathbf{5}$ & 217,95 & 118,48 & 252,76 & 133,39 \\
$\mathbf{6}$ & 276,26 & 142,11 & 262,44 & 169,82 \\
Média & $\mathbf{2 3 5 , 0 7}$ & $\mathbf{1 9 0 , 6 9}$ & $\mathbf{2 4 7 , 2 6}$ & $\mathbf{1 4 0 , 0 7}$ \\
DPM & $\mathbf{6 2 , 9 1}$ & $\mathbf{1 2 0 , 7 6}$ & $\mathbf{1 1 , 9 5}$ & $\mathbf{3 4 , 3 0}$ \\
EPM & $\mathbf{2 5 , 6 8}$ & $\mathbf{6 0 , 3 8}$ & $\mathbf{4 , 8 8}$ & $\mathbf{1 4 , 0 0}$ \\
\hline
\end{tabular}

Tabela V: Diâmetro mínimo fascicular (expresso em $\mu \mathrm{m}$ ) dos nervos safenos dos animais do grupo II (360 dias). $\mathrm{DPM}=$ desvio padrão da média. $\mathrm{EPM}=$ erro padrão da média.

\section{Lado Direito Lado Esquerdo}

\begin{tabular}{ccccc}
\hline ANIMAL & Proximal & Distal & Proximal & Distal \\
\hline $\mathbf{1}$ & 190,88 & 81,60 & 158,32 & 204,97 \\
$\mathbf{2}$ & 212,14 & 172,74 & 142,63 & 142,06 \\
$\mathbf{3}$ & 177,53 & 166,10 & 160,29 & 143,62 \\
$\mathbf{4}$ & 116,81 & 262,80 & 123,37 & 266,75 \\
$\mathbf{5}$ & 119,88 & 114,20 & 205,27 & 158,84 \\
$\mathbf{6}$ & 94,34 & 190,78 & 267,61 & 143,73 \\
\hline Média & $\mathbf{1 5 1 , 9 3}$ & $\mathbf{2 1 0 , 4 8}$ & $\mathbf{1 7 6 , 2 5}$ & $\mathbf{1 7 6 , 6 6}$ \\
DPM & $\mathbf{4 7 , 7 0}$ & $\mathbf{1 0 7 , 7 9}$ & $\mathbf{5 2 , 3 3}$ & $\mathbf{5 0 , 2 2}$ \\
EPM & $\mathbf{1 9 , 4 7}$ & $\mathbf{5 3 , 9 0}$ & $\mathbf{2 1 , 3 6}$ & $\mathbf{2 0 , 5 0}$ \\
\hline
\end{tabular}

Tabela VI: Diâmetro mínimo fascicular (expresso em $\mu \mathrm{m}$ ) dos nervos safenos dos ratos do grupo III (720 dias). $\mathrm{DPM}=$ desvio padrão da média. $\mathrm{EPM}=$ erro padrão da média. 


\begin{tabular}{ccccc} 
& \multicolumn{2}{c}{ Lado Direito } & \multicolumn{2}{c}{ Lado Esquerdo } \\
\cline { 2 - 5 } ANIMAL & Proximal & Distal & Proximal & Distal \\
\hline $\mathbf{1}$ & 1059 & 595 & 920 & 622 \\
$\mathbf{2}$ & 918 & 627 & 603 & 963 \\
$\mathbf{3}$ & 1005 & 525 & 969 & 944 \\
$\mathbf{4}$ & 907 & 313 & 956 & 1800 \\
$\mathbf{5}$ & 803 & 584 & 696 & 530 \\
$\mathbf{6}$ & 966 & 851 & 325 & 786 \\
\hline Média & $\mathbf{9 4 3}$ & $\mathbf{5 8 2 , 5 0}$ & $\mathbf{7 4 4 , 8 3}$ & $\mathbf{9 4 0}$ \\
DPM & $\mathbf{8 8 , 7 1}$ & $\mathbf{1 7 3 , 3 0}$ & $\mathbf{2 5 4 , 6 7}$ & $\mathbf{4 5 4 , 5 5}$ \\
EPM & $\mathbf{3 6 , 2 2}$ & $\mathbf{7 0 , 7 5}$ & $\mathbf{1 0 3 , 9 7}$ & $\mathbf{1 8 5 , 5 7}$
\end{tabular}

Tabela VII: Número de fibras dos nervos safenos dos animais do grupo I (180 dias). DPM = desvio padrão da média. EPM = erro padrão da média.

\begin{tabular}{ccccc} 
& \multicolumn{2}{c}{ Lado Direito } & \multicolumn{2}{c}{ Lado Esquerdo } \\
\cline { 2 - 5 } ANIMAL & Proximal & Distal & Proximal & Distal \\
\hline $\mathbf{1}$ & 517 & 820 & 970 & 658 \\
$\mathbf{2}$ & 1353 & 892 & 1163 & 1111 \\
$\mathbf{3}$ & 734 & 1021 & 889 & 862 \\
$\mathbf{4}$ & 1011 & 848 & 934 & 124 \\
$\mathbf{5}$ & 866 & 754 & 1251 & 615 \\
$\mathbf{6}$ & 996 & 377 & 1024 & 602 \\
\hline Média & $\mathbf{9 1 2 , 8 3}$ & $\mathbf{7 8 5 , 3 3}$ & $\mathbf{1 0 3 8 , 5 0}$ & $\mathbf{6 6 2}$ \\
DPM & $\mathbf{2 8 3 , 2 5}$ & $\mathbf{2 1 8 , 9 8}$ & $\mathbf{1 4 0 , 5 9}$ & $\mathbf{3 2 7 , 6 8}$ \\
EPM & $\mathbf{1 1 5 , 6 4}$ & $\mathbf{8 9 , 4 0}$ & $\mathbf{5 7 , 4 0}$ & $\mathbf{1 3 3 , 7 7}$
\end{tabular}

Tabela VIII: Número de fibras dos nervos safenos dos animais do grupo II (360 dias). DPM = desvio padrão da média. EPM = erro padrão da média. 


\section{Lado Direito Lado Esquerdo}

\begin{tabular}{ccccc}
\hline ANIMAL & Proximal & Distal & Proximal & Distal \\
\hline $\mathbf{1}$ & 508 & 227 & 371 & 690 \\
$\mathbf{2}$ & 397 & 567 & 1135 & 633 \\
$\mathbf{3}$ & 690 & 160 & 815 & 353 \\
$\mathbf{4}$ & 884 & 916 & 687 & 1087 \\
$\mathbf{5}$ & 962 & 801 & 882 & 785 \\
$\mathbf{6}$ & 177 & 273 & 590 & 656 \\
Média & $\mathbf{6 0 3}$ & $\mathbf{4 9 0 , 6 7}$ & $\mathbf{7 4 6 , 6 7}$ & $\mathbf{7 0 0}$ \\
DPM & $\mathbf{2 9 9 , 4 5}$ & $\mathbf{3 1 9 , 1 5}$ & $\mathbf{2 6 1 , 9 2}$ & $\mathbf{2 3 8 , 3 0}$ \\
EPM & $\mathbf{1 2 2 , 2 5}$ & $\mathbf{1 3 0 , 2 9}$ & $\mathbf{1 0 6 , 9 3}$ & $\mathbf{9 7 , 2 8}$ \\
\hline
\end{tabular}

Tabela IX: Número de fibras dos nervos safenos dos animais do grupo III (720 dias). DPM = desvio padrão da média. EPM = erro padrão da média.

\section{Lado Direito Lado Esquerdo}

\begin{tabular}{ccccc}
\hline ANIMAL & Proximal & Distal & Proximal & Distal \\
\hline $\mathbf{1}$ & 18849,83 & 13401,60 & 20063,61 & 17731,66 \\
$\mathbf{2}$ & 20025,69 & 15068,43 & 19852,64 & 16173,53 \\
$\mathbf{3}$ & 21295,02 & 20868,20 & 18322,18 & 21348,69 \\
$\mathbf{4}$ & 19996,36 & 23031,54 & 17757,47 & 16845,49 \\
$\mathbf{5}$ & 13944,62 & 20316,90 & 12157,20 & 17867,94 \\
$\mathbf{6}$ & 18784,77 & 23827,13 & 22787,46 & 19172,70 \\
Média & $\mathbf{1 8 8 1 6 , 0 5}$ & $\mathbf{1 9 4 1 8 , 9 7}$ & $\mathbf{1 8 4 9 0 , 0 9}$ & $\mathbf{1 8 1 9 0}$ \\
DPM & $\mathbf{2 5 5 8 , 6 9}$ & $\mathbf{4 2 5 5}$ & $\mathbf{3 5 6 2 , 8 8}$ & $\mathbf{1 8 5 0 , 9 8}$ \\
EPM & $\mathbf{1 0 4 4 , 5 8}$ & $\mathbf{1 7 3 7 , 1 0}$ & $\mathbf{1 4 5 4 , 5 4}$ & $\mathbf{7 5 5 , 6 6}$
\end{tabular}

Tabela X: Densidade de fibras (expressa em $\mathrm{n}^{\mathrm{o}}$ de fibras $/ \mathrm{mm}^{2}$ da área fascicular) dos nervos safenos dos animais do grupo I (180 dias). DPM = desvio padrão da média. EPM = erro padrão da média. 


\section{Lado Direito Lado Esquerdo}

\begin{tabular}{ccccc}
\hline ANIMAL & Proximal & Distal & Proximal & Distal \\
\hline $\mathbf{1}$ & 16092,48 & 14064,37 & 18249,26 & 16772,88 \\
$\mathbf{2}$ & 17817,42 & 19037,03 & 15524,17 & 16076,93 \\
$\mathbf{3}$ & 14291,16 & 16320,73 & 14577,05 & 15100,80 \\
$\mathbf{4}$ & 13560,33 & 22211,56 & 15981,19 & 19861,06 \\
$\mathbf{5}$ & 14299,72 & 23298,32 & 18988,6 & 20366,20 \\
$\mathbf{6}$ & 15918,94 & 17584,35 & 16846,61 & 20824,78 \\
\hline Média & $\mathbf{1 5 3 3 0 , 0 1}$ & $\mathbf{1 8 7 5 2 , 7 3}$ & $\mathbf{1 6 6 9 4 , 4 8}$ & $\mathbf{1 8 1 6 7 , 1 1}$ \\
DPM & $\mathbf{1 5 7 4 , 0 3}$ & $\mathbf{3 5 2 0 , 4 3}$ & $\mathbf{1 6 7 7 , 2 2}$ & $\mathbf{2 4 6 9 , 1 5}$ \\
$\mathbf{E P M}$ & $\mathbf{6 4 2 , 6 0}$ & $\mathbf{1 4 3 7 , 2 1}$ & $\mathbf{6 8 4 , 7 2}$ & $\mathbf{1 0 0 8 , 0 3}$ \\
\hline
\end{tabular}

Tabela XI: Densidade de fibras (expressa em $\mathrm{n}^{\mathrm{o}}$ de fibras $/ \mathrm{mm}^{2}$ da área fascicular) dos nervos safenos dos ratos do grupo II (360 dias). DPM = desvio padrão da média. EPM = erro padrão da média.

\section{Lado Direito Lado Esquerdo}

\begin{tabular}{ccccc}
\hline ANIMAL & Proximal & Distal & Proximal & Distal \\
\hline $\mathbf{1}$ & 13067,86 & 14183,10 & 7082,69 & 6032,14 \\
$\mathbf{2}$ & 8312,47 & 7817,22 & 29493,14 & 10563,93 \\
$\mathbf{3}$ & 10735,24 & 6177,31 & 13018,13 & 7107,76 \\
$\mathbf{4}$ & 18888,36 & 13112,64 & 14427,19 & 17489,07 \\
$\mathbf{5}$ & 18563,40 & 16244,72 & 10936,11 & 17512,97 \\
$\mathbf{6}$ & 8582,99 & 8633,21 & 9456,42 & 16266,72 \\
Média & $\mathbf{1 3 0 2 5 , 0 5}$ & $\mathbf{1 1 0 2 8 , 0 3}$ & $\mathbf{1 4 0 6 8 , 9 5}$ & $\mathbf{1 2 4 9 5 , 4 4}$ \\
DPM & $\mathbf{4 7 3 7 , 8 7}$ & $\mathbf{4 0 2 7 , 1 1}$ & $\mathbf{7 9 8 7 , 9 4}$ & $\mathbf{5 2 7 0 , 0 3}$ \\
EPM & $\mathbf{1 9 3 4 , 2 3}$ & $\mathbf{1 6 4 4 , 0 6}$ & $\mathbf{3 2 6 1 , 0 6}$ & $\mathbf{2 1 5 1 , 4 8}$
\end{tabular}

Tabela XII: Densidade de fibras (expressa em $\mathrm{n}^{\mathrm{o}}$ de fibras $/ \mathrm{mm}^{2}$ da área fascicular) dos nervos safenos dos animais do grupo III (720 dias). DPM = desvio padrão da média. EPM = erro padrão da média. 


\section{Lado Direito Lado Esquerdo}

\begin{tabular}{ccccc}
\hline ANIMAL & Proximal & Distal & Proximal & Distal \\
\hline $\mathbf{1}$ & 46,80 & 36,75 & 36,47 & 21,05 \\
$\mathbf{2}$ & 46,09 & 39,83 & 36,51 & 29,48 \\
$\mathbf{3}$ & 37,03 & 35,57 & 13,27 & 29,89 \\
$\mathbf{4}$ & 41,90 & 39,19 & 40,29 & 35,30 \\
$\mathbf{5}$ & 34,76 & 55,34 & 25,96 & 36,13 \\
$\mathbf{6}$ & 40,37 & 45,61 & 2,48 & 40,48 \\
\hline Média & $\mathbf{4 1 , 1 6}$ & $\mathbf{4 2 , 0 5}$ & $\mathbf{2 5 , 8 3}$ & $\mathbf{3 2 , 0 5}$ \\
DPM & $\mathbf{4 , 8 0}$ & $\mathbf{7 , 3 8}$ & $\mathbf{1 5 , 1 0}$ & $\mathbf{6 , 7 9}$ \\
EPM & $\mathbf{1 , 9 6}$ & $\mathbf{3 , 0 1}$ & $\mathbf{6 , 1 6}$ & $\mathbf{2 , 7 7}$ \\
\hline
\end{tabular}

Tabela XIII: Porcentagem da área fascicular ocupada pelas fibras mielínicas dos nervos safenos dos animais do grupo I (180 dias). DPM = desvio padrão da média. EPM = erro padrão da média.

\section{Lado Direito Lado Esquerdo}

\begin{tabular}{ccccc}
\hline ANIMAL & Proximal & Distal & Proximal & Distal \\
\hline $\mathbf{1}$ & 40,73 & 50,56 & 49,70 & 43,16 \\
$\mathbf{2}$ & 45,13 & 46,73 & 42,37 & 19,31 \\
$\mathbf{3}$ & 45,97 & 59,75 & 37,43 & 41,99 \\
$\mathbf{4}$ & 51,18 & 49,48 & 60,98 & 47,91 \\
$\mathbf{5}$ & 51,05 & 160,65 & 63,56 & 65,25 \\
$\mathbf{6}$ & 49,89 & 43,18 & 55,73 & 57,22 \\
Média & $\mathbf{4 7 , 3 3}$ & $\mathbf{6 8 , 4 0}$ & $\mathbf{5 1 , 6 3}$ & $\mathbf{4 5 , 8 1}$ \\
DPM & $\mathbf{4 , 1 3}$ & $\mathbf{4 5 , 5 3}$ & $\mathbf{1 0 , 3 7}$ & $\mathbf{1 5 , 7 2}$ \\
EPM & $\mathbf{1 , 6 9}$ & $\mathbf{1 8 , 5 9}$ & $\mathbf{4 , 2 3}$ & $\mathbf{6 , 4 2}$ \\
\hline
\end{tabular}

Tabela XIV: Porcentagem da área fascicular ocupada pelas fibras mielínicas dos nervos safenos dos animais do grupo II (360 dias). DPM = desvio padrão da média. EPM = erro padrão da média. 


\section{Lado Direito Lado Esquerdo}

\begin{tabular}{ccccc}
\hline ANIMAL & Proximal & Distal & Proximal & Distal \\
\hline $\mathbf{1}$ & 41 & 38,01 & 28,02 & 24,24 \\
$\mathbf{2}$ & 33 & 32,25 & 48,72 & 37,53 \\
$\mathbf{3}$ & 37 & 22,53 & 45,15 & 22,04 \\
$\mathbf{4}$ & 17 & 17,95 & 12,47 & 19,26 \\
$\mathbf{5}$ & 16 & 17,07 & 11,92 & 8,77 \\
$\mathbf{6}$ & 33 & 33,56 & 38,88 & 39,03 \\
\hline Média & $\mathbf{2 9 , 6 0}$ & $\mathbf{2 6 , 9 0}$ & $\mathbf{3 0 , 8 7}$ & $\mathbf{2 5 , 1 5}$ \\
DPM & $\mathbf{1 0 , 6 8}$ & $\mathbf{8 , 8 6}$ & $\mathbf{1 6 , 0 8}$ & $\mathbf{1 1 , 4 8}$ \\
EPM & $\mathbf{4 , 3 6}$ & $\mathbf{3 , 6 2}$ & $\mathbf{6 , 5 6}$ & $\mathbf{4 , 6 9}$ \\
\hline
\end{tabular}

Tabela XV: Porcentagem da área fascicular ocupada pelas fibras mielínicas dos nervos safenos dos ratos do grupo III (720 dias). DPM = desvio padrão da média. EPM = erro padrão da média.

\section{Lado Direito Lado Esquerdo}

\begin{tabular}{ccccc}
\hline ANIMAL & Proximal & Distal & Proximal & Distal \\
\hline $\mathbf{1}$ & 31,71 & 30,85 & 20,70 & 22,79 \\
$\mathbf{2}$ & 29,39 & 31,99 & 24,11 & 26,71 \\
$\mathbf{3}$ & 23,12 & 21,31 & 23,16 & 19,96 \\
$\mathbf{4}$ & 27,50 & 23,26 & 29,72 & 43,51 \\
$\mathbf{5}$ & 30,94 & 30,59 & 29,50 & 26,79 \\
$\mathbf{6}$ & 27,68 & 23,07 & 19,65 & 27,66 \\
\hline Média & $\mathbf{2 8 , 3 9}$ & $\mathbf{2 6 , 8 5}$ & $\mathbf{2 4 , 4 7}$ & $\mathbf{2 7 , 9 1}$ \\
DPM & $\mathbf{3 , 0 9}$ & $\mathbf{4 , 7 8}$ & $\mathbf{4 , 2 9}$ & $\mathbf{8 , 1 9}$ \\
EPM & $\mathbf{1 , 2 6}$ & $\mathbf{1 , 9 5}$ & $\mathbf{1 , 7 5}$ & $\mathbf{3 , 3 4}$ \\
\hline
\end{tabular}

Tabela XVI: Área média das fibras mielínicas dos nervos safenos dos animais do grupo I (180 dias). DPM = desvio padrão da média. EPM = erro padrão da média. 


\section{Lado Direito Lado Esquerdo}

\begin{tabular}{ccccc}
\hline ANIMAL & Proximal & Distal & Proximal & Distal \\
\hline $\mathbf{1}$ & 45,21 & 41,87 & 34,17 & 33,19 \\
$\mathbf{2}$ & 32,80 & 41,78 & 31,81 & 32,16 \\
$\mathbf{3}$ & 30,88 & 34,13 & 29,64 & 27,19 \\
$\mathbf{4}$ & 32,17 & 25,90 & 43,25 & 35,50 \\
$\mathbf{5}$ & 38,03 & 28,84 & 37,82 & 29,75 \\
$\mathbf{6}$ & 33,10 & 36,64 & 36,30 & 29,97 \\
Média & $\mathbf{3 5 , 3 7}$ & $\mathbf{3 4 , 8 7}$ & $\mathbf{3 5 , 5 1}$ & $\mathbf{3 1 , 3 0}$ \\
DPM & $\mathbf{5 , 4 1}$ & $\mathbf{6 , 5 9}$ & $\mathbf{4 , 8 1}$ & $\mathbf{2 , 9 3}$ \\
EPM & $\mathbf{2 , 2 1}$ & $\mathbf{2 , 6 9}$ & $\mathbf{1 , 9 7}$ & $\mathbf{1 , 2 0}$
\end{tabular}

Tabela XVII: Área média das fibras mielínicas dos nervos safenos dos animais do grupo II (360 dias). DPM = desvio padrão da média. EPM = erro padrão da média.

\section{Lado Direito Lado Esquerdo}

\begin{tabular}{ccccc}
\hline ANIMAL & Proximal & Distal & Proximal & Distal \\
\hline $\mathbf{1}$ & 31,45 & 26,80 & 39,57 & 35,53 \\
$\mathbf{2}$ & 39,91 & 41,26 & 16,53 & 18,33 \\
$\mathbf{3}$ & 38,70 & 38,88 & 15,71 & 12,21 \\
$\mathbf{4}$ & 34,82 & 19,47 & 41,11 & 31,29 \\
$\mathbf{5}$ & 13,89 & 16,34 & 34,68 & 31,01 \\
$\mathbf{6}$ & 12,64 & 36,47 & 18,48 & 40,19 \\
Média & $\mathbf{2 8 , 5 8}$ & $\mathbf{2 9 , 8 8}$ & $\mathbf{2 7 , 6 9}$ & $\mathbf{2 8 , 1 0}$ \\
DPM & $\mathbf{1 2 , 2 3}$ & $\mathbf{1 0 , 5 3}$ & $\mathbf{1 2 , 0 2}$ & $\mathbf{1 0 , 6 6}$ \\
EPM & $\mathbf{4 , 9 9}$ & $\mathbf{4 , 3 0}$ & $\mathbf{4 , 9 1}$ & $\mathbf{4 , 3 5}$
\end{tabular}

Tabela XVIII: Área média das fibras mielínicas dos nervos safenos dos ratos do grupo III (720 dias). DPM = desvio padrão da média. EPM = erro padrão da média. 


\section{Lado Direito Lado Esquerdo}

\begin{tabular}{ccccc}
\hline ANIMAL & Proximal & Distal & Proximal & Distal \\
\hline $\mathbf{1}$ & 5,18 & 5,22 & 4,59 & 4,72 \\
$\mathbf{2}$ & 5,22 & 5,28 & 4,86 & 5,00 \\
$\mathbf{3}$ & 4,50 & 4,52 & 4,68 & 4,36 \\
$\mathbf{4}$ & 4,82 & 4,53 & 5,13 & 6,51 \\
$\mathbf{5}$ & 5,42 & 5,68 & 5,20 & 5,04 \\
$\mathbf{6}$ & 5,13 & 4,80 & 4,39 & 5,04 \\
Média & $\mathbf{5 , 0 5}$ & $\mathbf{5 , 0 1}$ & $\mathbf{4 , 8 1}$ & $\mathbf{5 , 1 2}$ \\
DPM & $\mathbf{0 , 3 3}$ & $\mathbf{0 , 4 6}$ & $\mathbf{0 , 3 2}$ & $\mathbf{0 , 7 4}$ \\
EPM & $\mathbf{0 , 1 4}$ & $\mathbf{0 , 1 9}$ & $\mathbf{0 , 1 3}$ & $\mathbf{0 , 3 0}$
\end{tabular}

Tabela XIX: Diâmetro mínimo médio das fibras mielínicas dos nervos safenos dos ratos do grupo I (180 dias). $\mathrm{DPM}=$ desvio padrão da média. $\mathrm{EPM}$ = erro padrão da média.

\section{Lado Direito Lado Esquerdo}

\begin{tabular}{ccccc}
\hline ANIMAL & Proximal & Distal & Proximal & Distal \\
\hline $\mathbf{1}$ & 6,37 & 6,52 & 5,64 & 5,28 \\
$\mathbf{2}$ & 5,61 & 5,73 & 5,43 & 5,30 \\
$\mathbf{3}$ & 5,15 & 5,58 & 5,29 & 5,03 \\
$\mathbf{4}$ & 5,59 & 4,89 & 6,42 & 5,89 \\
$\mathbf{5}$ & 5,80 & 5,37 & 6,04 & 5,34 \\
$\mathbf{6}$ & 5,68 & 5,92 & 5,56 & 5,58 \\
Média & $\mathbf{5 , 7 0}$ & $\mathbf{5 , 6 7}$ & $\mathbf{5 , 7 3}$ & $\mathbf{5 , 4 1}$ \\
DPM & $\mathbf{0 , 3 9}$ & $\mathbf{0 , 5 4}$ & $\mathbf{0 , 4 2}$ & $\mathbf{0 , 3 0}$ \\
EPM & $\mathbf{0 , 1 6}$ & $\mathbf{0 , 2 2}$ & $\mathbf{0 , 1 7}$ & $\mathbf{0 , 1 2}$
\end{tabular}

Tabela XX: Diâmetro mínimo médio das fibras mielínicas dos nervos safenos dos ratos do grupo II (360 dias). $\mathrm{DPM}=$ desvio padrão da média. $\mathrm{EPM}=$ erro padrão da média. 


\section{Lado Direito Lado Esquerdo}

\begin{tabular}{ccccc}
\hline ANIMAL & Proximal & Distal & Proximal & Distal \\
\hline $\mathbf{1}$ & 5,52 & 4,79 & 5,91 & 5,85 \\
$\mathbf{2}$ & 5,94 & 5,96 & 3,87 & 4,31 \\
$\mathbf{3}$ & 5,83 & 5,77 & 4,12 & 3,38 \\
$\mathbf{4}$ & 5,62 & 4,24 & 6,03 & 5,49 \\
$\mathbf{5}$ & 3,59 & 4,03 & 5,59 & 5,24 \\
$\mathbf{6}$ & 3,49 & 5,85 & 4,15 & 6,10 \\
Média & $\mathbf{5 , 0 1}$ & $\mathbf{5 , 1 1}$ & $\mathbf{4 , 9 5}$ & $\mathbf{5 , 0 7}$ \\
DPM & $\mathbf{1 , 1 4}$ & $\mathbf{0 , 8 6}$ & $\mathbf{1 , 0 0}$ & $\mathbf{1 , 0 3}$ \\
EPM & $\mathbf{0 , 4 7}$ & $\mathbf{0 , 3 5}$ & $\mathbf{0 , 4 1}$ & $\mathbf{0 , 4 2}$
\end{tabular}

Tabela XXI: Diâmetro mínimo médio das fibras mielínicas dos nervos safenos dos ratos do grupo III (720 dias). $\mathrm{DPM}=$ desvio padrão da média. $\mathrm{EPM}=$ erro padrão da média

Lado Direito

Lado Esquerdo

\begin{tabular}{ccccc}
\hline ANIMAL & Proximal & Distal & Proximal & Distal \\
\hline $\mathbf{1}$ & 0,44 & 0,36 & 0,39 & 0,46 \\
$\mathbf{2}$ & 0,40 & 0,45 & 0,49 & 0,51 \\
$\mathbf{3}$ & 0,42 & 0,51 & 0,49 & 0,50 \\
$\mathbf{4}$ & 0,34 & 0,49 & 0,48 & 0,33 \\
$\mathbf{5}$ & 0,46 & 0,40 & 0,60 & 0,44 \\
$\mathbf{6}$ & 0,44 & 0,49 & 0,48 & 0,55 \\
Média & $\mathbf{0 , 4 2}$ & $\mathbf{0 , 4 6}$ & $\mathbf{0 , 4 9}$ & $\mathbf{0 , 4 7}$ \\
DPM & $\mathbf{0 , 0 4}$ & $\mathbf{0 , 0 6}$ & $\mathbf{0 , 0 7}$ & $\mathbf{0 , 0 8}$ \\
EPM & $\mathbf{0 , 0 2}$ & $\mathbf{0 , 0 2}$ & $\mathbf{0 , 0 3}$ & $\mathbf{0 , 0 3}$
\end{tabular}

Tabela XXII: Razão G média das fibras mielínicas dos nervos safenos dos ratos do grupo I (180 dias). DPM = desvio padrão da média. EPM = erro padrão da média 


\section{Lado Direito Lado Esquerdo}

\begin{tabular}{ccccc}
\hline ANIMAL & Proximal & Distal & Proximal & Distal \\
\hline $\mathbf{1}$ & 0,49 & 0,57 & 0,55 & 0,49 \\
$\mathbf{2}$ & 0,54 & 0,46 & 0,51 & 0,49 \\
$\mathbf{3}$ & 0,49 & 0,43 & 0,47 & 0,52 \\
$\mathbf{4}$ & 0,49 & 0,51 & 0,40 & 0,45 \\
$\mathbf{5}$ & 0,45 & 0,61 & 0,46 & 0,43 \\
$\mathbf{6}$ & 0,44 & 0,40 & 0,44 & 0,57 \\
Média & $\mathbf{0 , 4 9}$ & $\mathbf{0 , 5 0}$ & $\mathbf{0 , 4 8}$ & $\mathbf{0 , 5 0}$ \\
DPM & $\mathbf{0 , 0 3}$ & $\mathbf{0 , 0 8}$ & $\mathbf{0 , 0 5}$ & $\mathbf{0 , 0 5}$ \\
EPM & $\mathbf{0 , 0 1}$ & $\mathbf{0 , 0 3}$ & $\mathbf{0 , 0 2}$ & $\mathbf{0 , 0 2}$
\end{tabular}

Tabela XXIII: Razão G média das fibras mielínicas dos nervos safenos dos ratos do grupo II (360 dias). DPM = desvio padrão da média. $\mathrm{EPM}=$ erro padrão da média

\section{Lado Direito Lado Esquerdo}

\begin{tabular}{ccccc}
\hline ANIMAL & Proximal & Distal & Proximal & Distal \\
\hline $\mathbf{1}$ & 0,45 & 0,49 & 0,43 & 0,49 \\
$\mathbf{2}$ & 0,48 & 0,50 & 0,47 & 0,32 \\
$\mathbf{3}$ & 0,47 & 0,48 & 0,42 & 0,38 \\
$\mathbf{4}$ & 0,50 & 0,41 & 0,50 & 0,43 \\
$\mathbf{5}$ & 0,43 & 0,39 & 0,42 & 0,42 \\
$\mathbf{6}$ & 0,39 & 0,40 & 0,41 & 0,49 \\
Média & $\mathbf{0 , 4 6}$ & $\mathbf{0 , 4 5}$ & $\mathbf{0 , 4 5}$ & $\mathbf{0 , 4 3}$ \\
DPM & $\mathbf{0 , 0 4}$ & $\mathbf{0 , 0 5}$ & $\mathbf{0 , 0 4}$ & $\mathbf{0 , 0 7}$ \\
EPM & $\mathbf{0 , 0 2}$ & $\mathbf{0 , 0 2}$ & $\mathbf{0 , 0 2}$ & $\mathbf{0 , 0 3}$ \\
\hline
\end{tabular}

Tabela XXIV: Razão G média das fibras mielínicas dos nervos safenos dos ratos do grupo III (720 dias). $\mathrm{DPM}=$ desvio padrão da média. EPM = erro padrão da média 


\section{Lado Direito Lado Esquerdo}

\begin{tabular}{ccccc}
\hline ANIMAL & Proximal & Distal & Proximal & Distal \\
\hline $\mathbf{1}$ & 23,99 & 25,09 & 16,87 & 17,14 \\
$\mathbf{2}$ & 23,58 & 24,03 & 17,23 & 17,69 \\
$\mathbf{3}$ & 18,37 & 14,79 & 16,19 & 13,75 \\
$\mathbf{4}$ & 23,54 & 16,39 & 21,92 & 36,94 \\
$\mathbf{5}$ & 24,10 & 25,01 & 17,13 & 20,75 \\
$\mathbf{6}$ & 21,85 & 16,84 & 14,17 & 17,35 \\
Média & $\mathbf{2 2 , 5 7}$ & $\mathbf{2 0 , 3 6}$ & $\mathbf{1 7 , 2 5}$ & $\mathbf{2 0 , 6 1}$ \\
DPM & $\mathbf{2 , 2 1}$ & $\mathbf{4 , 8 3}$ & $\mathbf{2 , 5 5}$ & $\mathbf{8 , 3 1}$ \\
EPM & $\mathbf{0 , 9 0}$ & $\mathbf{1 , 9 7}$ & $\mathbf{1 , 0 4}$ & $\mathbf{3 , 3 9}$
\end{tabular}

Tabela XXV: Área média da bainha de mielina das fibras dos nervos safenos dos ratos do grupo I (180 dias). $\mathrm{DPM}=$ desvio padrão da média. $\mathrm{EPM}=$ erro padrão da média

\section{Lado Direito Lado Esquerdo}

\begin{tabular}{ccccc}
\hline ANIMAL & Proximal & Distal & Proximal & Distal \\
\hline $\mathbf{1}$ & 33,30 & 26,61 & 22,15 & 24,58 \\
$\mathbf{2}$ & 21,89 & 31,11 & 21,83 & 23,24 \\
$\mathbf{3}$ & 22,13 & 26,41 & 22,74 & 18,73 \\
$\mathbf{4}$ & 23,34 & 19,03 & 34,88 & 26,92 \\
$\mathbf{5}$ & 28,67 & 16,52 & 28,43 & 22,63 \\
$\mathbf{6}$ & 24,93 & 29,21 & 28,08 & 19,09 \\
Média & $\mathbf{2 5 , 7 1}$ & $\mathbf{2 4 , 8 2}$ & $\mathbf{2 6 , 3 6}$ & $\mathbf{2 2 , 5 4}$ \\
DPM & $\mathbf{4 , 4 7}$ & $\mathbf{5 , 7 8}$ & $\mathbf{5 , 1 2}$ & $\mathbf{3 , 1 7}$ \\
EPM & $\mathbf{1 , 8 2}$ & $\mathbf{2 , 3 5}$ & $\mathbf{2 , 0 9}$ & $\mathbf{1 , 2 9}$
\end{tabular}

Tabela XXVI: Área média da bainha de mielina das fibras dos nervos safenos dos ratos do grupo II (360 dias). DPM = desvio padrão da média. $\mathrm{EPM}=$ erro padrão da média 


\section{Lado Direito Lado Esquerdo}

\begin{tabular}{ccccc}
\hline ANIMAL & Proximal & Distal & Proximal & Distal \\
\hline $\mathbf{1}$ & 24,05 & 19,29 & 30,98 & 26,08 \\
$\mathbf{2}$ & 30,09 & 30,50 & 12,69 & 16,15 \\
$\mathbf{3}$ & 29,29 & 30,01 & 12,24 & 10,06 \\
$\mathbf{4}$ & 25,23 & 15,42 & 29,92 & 24,41 \\
$\mathbf{5}$ & 10,74 & 13,05 & 27,72 & 24,84 \\
$\mathbf{6}$ & 10,48 & 29,33 & 14,39 & 29,15 \\
Média & $\mathbf{2 1 , 6 5}$ & $\mathbf{2 2 , 9 4}$ & $\mathbf{2 1 , 3 3}$ & $\mathbf{2 1 , 7 9}$ \\
DPM & $\mathbf{8 , 8 5}$ & $\mathbf{7 , 9 5}$ & $\mathbf{9 , 0 9}$ & $\mathbf{7 , 1 9}$ \\
EPM & $\mathbf{3 , 6 1}$ & $\mathbf{3 , 2 4}$ & $\mathbf{3 , 7 1}$ & $\mathbf{2 , 9 3}$
\end{tabular}

Tabela XXVII: Área média da bainha de mielina das fibras dos nervos safenos dos ratos do grupo III (720 dias). $\mathrm{DPM}=$ desvio padrão da média. $\mathrm{EPM}=$ erro padrão da média

\section{Lado Direito}

\section{Lado Esquerdo}

\begin{tabular}{ccccc}
\hline ANIMAL & Proximal & Distal & Proximal & Distal \\
\hline $\mathbf{1}$ & 7,69 & 5,75 & 3,83 & 5,65 \\
$\mathbf{2}$ & 5,82 & 7,96 & 6,89 & 9,02 \\
$\mathbf{3}$ & 4,77 & 6,55 & 6,97 & 6,19 \\
$\mathbf{4}$ & 3,98 & 6,85 & 7,80 & 6,51 \\
$\mathbf{5}$ & 6,82 & 5,57 & 12,38 & 6,02 \\
$\mathbf{6}$ & 5,84 & 6,23 & 5,48 & 10,27 \\
Média & $\mathbf{5 , 8 2}$ & $\mathbf{6 , 4 9}$ & $\mathbf{7 , 2 3}$ & $\mathbf{7 , 2 8}$ \\
DPM & $\mathbf{1 , 3 4}$ & $\mathbf{0 , 8 9}$ & $\mathbf{2 , 8 9}$ & $\mathbf{1 , 9 0}$ \\
EPM & $\mathbf{0 , 5 5}$ & $\mathbf{0 , 3 5}$ & $\mathbf{1 , 1 8}$ & $\mathbf{0 , 7 8}$ \\
\hline
\end{tabular}

Tabela XXVIII: Área média dos axônios mielinizados dos nervos safenos dos ratos do grupo I (180 dias). $\mathrm{DPM}=$ desvio padrão da média. $\mathrm{EPM}=$ erro padrão da média 


\section{Lado Direito Lado Esquerdo}

\begin{tabular}{ccccc}
\hline ANIMAL & Proximal & Distal & Proximal & Distal \\
\hline $\mathbf{1}$ & 11,93 & 15,29 & 12,02 & 8,63 \\
$\mathbf{2}$ & 10,90 & 10,64 & 9,95 & 8,98 \\
$\mathbf{3}$ & 8,72 & 7,72 & 6,90 & 8,45 \\
$\mathbf{4}$ & 8,81 & 6,78 & 8,37 & 8,50 \\
$\mathbf{5}$ & 9,24 & 12,32 & 9,36 & 7,11 \\
$\mathbf{6}$ & 8,13 & 7,40 & 8,16 & 10,88 \\
\hline Média & $\mathbf{9 , 6 3}$ & $\mathbf{1 0 , 0 3}$ & $\mathbf{7 , 2 3}$ & $\mathbf{8 , 7 6}$ \\
DPM & $\mathbf{1 , 4 7}$ & $\mathbf{3 , 3 4}$ & $\mathbf{2 , 8 9}$ & $\mathbf{1 , 2 2}$ \\
EPM & $\mathbf{0 , 6 0}$ & $\mathbf{1 , 3 6}$ & $\mathbf{1 , 1 8}$ & $\mathbf{0 , 5 0}$ \\
\hline
\end{tabular}

Tabela XXIX: Área média dos axônios mielinizados dos nervos safenos dos ratos do grupo II (360 dias). $\mathrm{DPM}=$ desvio padrão da média. $\mathrm{EPM}=$ erro padrão da média

Lado Direito

Lado Esquerdo

\begin{tabular}{ccccc}
\hline ANIMAL & Proximal & Distal & Proximal & Distal \\
\hline $\mathbf{1}$ & 7,39 & 7,51 & 8,59 & 9,44 \\
$\mathbf{2}$ & 9,82 & 10,75 & 3,84 & 2,18 \\
$\mathbf{3}$ & 9,41 & 8,86 & 3,47 & 2,15 \\
$\mathbf{4}$ & 9,59 & 4,05 & 11,18 & 6,91 \\
$\mathbf{5}$ & 3,16 & 3,29 & 6,96 & 6,17 \\
$\mathbf{6}$ & 2,16 & 7,14 & 4,07 & 11,03 \\
Média & $\mathbf{6 , 9 3}$ & $\mathbf{6 , 9 4}$ & $\mathbf{6 , 3 6}$ & $\mathbf{6 , 3 2}$ \\
DPM & $\mathbf{3 , 4 3}$ & $\mathbf{2 , 8 4}$ & $\mathbf{3 , 1 2}$ & $\mathbf{3 , 6 6}$ \\
EPM & $\mathbf{1 , 4 0}$ & $\mathbf{1 , 1 6}$ & $\mathbf{1 , 2 7}$ & $\mathbf{1 , 4 9}$ \\
\hline
\end{tabular}

Tabela XXX: Área média dos axônios mielinizados dos nervos safenos dos ratos do grupo III (720 dias). $\mathrm{DPM}=$ desvio padrão da média. $\mathrm{EPM}=$ erro padrão da média 


\section{COMPOSIÇÃO DA RAÇÃO}

\section{Ração: NUVILAB CR1 NUVITAL ${ }^{\circledR}$}

Composição básica do produto: Carbonato de cálcio; farelo de milho; farelo de soja; farelo de trigo; fosfato de bicálcio; cloreto de sódio; premix mineral vitamínico; aminoácido.

\section{NÍVEIS DE GARANTIA}

\begin{tabular}{|c|c|c|c|}
\hline Umidade & (máx.) & ….......................... & $12,50 \%$ \\
\hline Proteína Bruta & (min.) & & $22,00 \%$ \\
\hline Extrato Etérico & (min.) & & $4,00 \%$ \\
\hline Material Mineral & (máx.) & & $10,00 \%$ \\
\hline Matéria Fibrosa & (máx.) & & $8,00 \%$ \\
\hline Cálcio & (máx.) & $\ldots .$. & $1,40 \%$ \\
\hline Fósforo & (min.) & (2) & $0,80 \%$ \\
\hline
\end{tabular}

Suplemento por quilo não menos que:

Vitaminas: Vitamina - A 12000 UI; Vitamina - D 1800 UI ; Vitamina - E 30,00 mg; vitamina - $\mathrm{B}_{2} 6,00 \mathrm{mg}$; Vitamina $-\mathrm{K}_{3} 3,00 \mathrm{mg}$; Vitamina $\mathrm{B}_{1} 5,00 \mathrm{mg}$; Vitamina - $\mathrm{B}_{6}$ 7,00 mg Vitamina $-B_{12} 20,00 \mathrm{mcg}$; Niacina - 60,00 mg; Ácido pontotênico 20,00 mg; Ácido fólico 1,00 mg; Biotina - 0,05 mg; Colina 600,00 mg.

Microelementos Minerais: Ferro - 50,00 mg; Zinco - 60,00 mg; Cobre - 10,00 mg; Iodo 2,00 mg; Manganês - 60,00 mg; Selenio - 0,05 mg; Cobalto - 1,50 mg.

Aminoácidos: DL - Metianina 300,00 mg; Lisina - 100,00 mg.

Aditivos: Antioxidante $-100,0 \mathrm{mg}$. 